WSRC-TR-2004-00053

Revision 0

\title{
Neutralization of Plutonium and Enriched Uranium Solutions Containing Gadolinium as a Neutron Poison
}

Michael G. Bronikowski and Tracy S. Rudisill

February 2004

Westinghouse Savannah River Company Aiken, SC 29808

Prepared for the U. S. Department of Energy under Contract DE-AC09-96SR18500 (mod. 100) 
This document was prepared in conjunction with work accomplished under Contract No. DE-AC09-96SR18500 with the U. S. Department of Energy.

\section{DISCLAIMER}

This report was prepared as an account of work sponsored by an agency of the United States Government. Neither the United States Government nor any agency thereof, nor any of their employees, makes any warranty, express or implied, or assumes any legal liability or responsibility for the accuracy, completeness, or usefulness of any information, apparatus, product or process disclosed, or represents that its use would not infringe privately owned rights. Reference herein to any specific commercial product, process or service by trade name, trademark, manufacturer, or otherwise does not necessarily constitute or imply its endorsement, recommendation, or favoring by the United States Government or any agency thereof. The views and opinions of authors expressed herein do not necessarily state or reflect those of the United States Government or any agency thereof.

This report has been reproduced directly from the best available copy.

Available for sale to the public, in paper, from: U.S. Department of Commerce, National Technical Information Service, 5285 Port Royal Road, Springfield, VA 22161, phone: (800) 553-6847, fax: (703) 605-6900

email: orders@ntis.fedworld.gov

online ordering: http://www.ntis.gov/help/index.asp

Available electronically at http://www.osti.gov/bridge

Available for a processing fee to U.S. Department of Energy and its contractors, in paper, from: U.S. Department of Energy, Office of Scientific and Technical Information, P.O. Box 62, Oak Ridge, TN 37831-0062,

phone: (865)576-8401,

fax: (865)576-5728

email: $\underline{\text { reports@ adonis.osti.gov }}$ 
Neutralization of Plutonium and Enriched Uranium Solutions Containing Gadolinium as a Neutron Poison

By

Michael G. Bronikowski and Tracy S. Rudisill

Issued: February 2004 


\section{This page was intentionally left blank.}




\section{Table of Contents}

\section{Section}

Summary $\ldots \ldots \ldots \ldots \ldots \ldots \ldots \ldots \ldots \ldots \ldots \ldots \ldots \ldots \ldots \ldots \ldots \ldots \ldots \ldots \ldots \ldots$

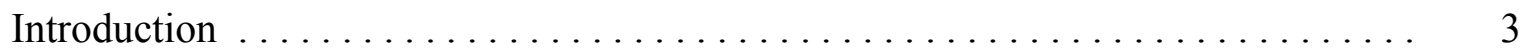

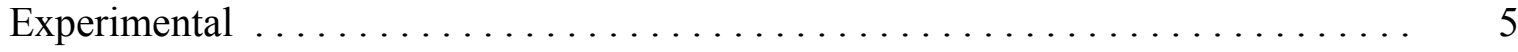

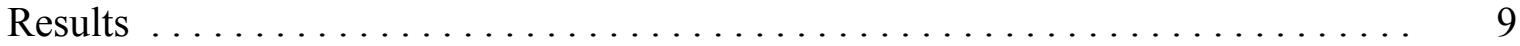

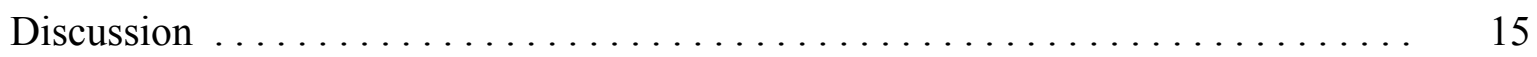

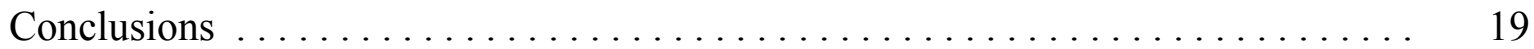

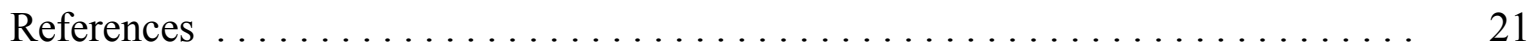

\section{List of Tables}

Table 1 Composition of H-Canyon Test Solutions Poisoned with Gd . . . . 5

Table 2 Volume of $\mathrm{NaOH}$ Added to Surrogate Solutions $\ldots \ldots \ldots \ldots \ldots$

Table $3 \quad \mathrm{U} / \mathrm{Gd}, \mathrm{Pu} / \mathrm{Gd}$, and Fissile/Gd Mass Ratios in the $\ldots \ldots \ldots \ldots$ Neutralized Solutions

Table 4 Percent of Each Element Precipitated from Solution Upon . . . . . 10 Neutralization

Table $5 \quad$ Neutralized Solution Densities from Beaker and . . . . . . . . . 12 Cylinder Experiments

Table $6 \quad \mathrm{H}: \mathrm{Pu}, \mathrm{H}: \mathrm{U}$, and H:Fissile Ratios in Centrifuged Solids $\ldots \ldots \ldots \ldots$

Table $7 \quad \mathrm{H}: \mathrm{Pu}, \mathrm{H}: \mathrm{U}$, and H:Fissile Ratios in One-Day Settled Solids $\ldots \ldots \ldots 14$ 


\section{List of Figures}

Page

Figure $1 \quad$ Neutralized $\mathrm{U} / \mathrm{Pu} / \mathrm{Gd}$ and $\mathrm{U} / \mathrm{Gd}$ Solutions $\ldots \ldots \ldots \ldots \ldots \ldots \ldots$

Figure 2 SEM Micrographs of Solids from Fully Neutralized . . . . . . . . 25 U/Gd Solution

Figure $3 \quad$ SEM Micrographs of Solids from Fully Neutralized . . . . . . . . . 27 $\mathrm{U} / \mathrm{Pu} / \mathrm{Gd}$ Solution

Figure $4 \quad$ SEM Micrographs of Solids from Partially Neutralized . . . . . . . 29 U/Gd Solution

Figure $5 \quad$ SEM Micrographs of Solids from Partially Neutralized . . . . . . . 29 $\mathrm{U} / \mathrm{Pu} / \mathrm{Gd}$ Solution

Figure $6 \quad$ Representative EDS for Solids from Fully Neutralized . . . . . . . 31 $\mathrm{U} / \mathrm{Pu} / \mathrm{Gd}$ Solution

Figure $7 \quad$ Representative EDS for Solids from Fully Neutralized . . . . . . . 37 U/Gd Solution

Figure $8 \quad$ Representative EDS for Solids from Partially Neutralized $\ldots \ldots$. . . 43 $\mathrm{U} / \mathrm{Pu} / \mathrm{Gd}$ Solution

Figure $9 \quad$ Representative EDS for Solids from Partially Neutralized $\ldots \ldots$. . . 47 U/Gd Solution

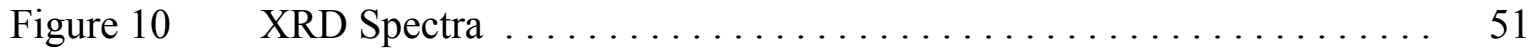

Figure $11 \quad$ Settling Rate of Neutralized Solutions $\ldots \ldots \ldots \ldots \ldots \ldots$

Figure $12 \quad$ Particle Size Distribution of Precipitated Solids $\ldots \ldots \ldots \ldots \ldots \ldots$

Figure $13 \quad$ Percent of Precipitated Solids of Increasing Size $\ldots \ldots \ldots \ldots$

Figure 14 Thermogravimetric Analyses of Precipitate Solids $\ldots \ldots \ldots \ldots$. . . 61

Figure $15 \quad$ Effect of $\mathrm{H}$ on the Safe $\mathrm{Gd}: \mathrm{Pu}$ Ratio $\ldots \ldots \ldots \ldots \ldots$ 


\section{List of Appendices}

\section{Page}

Appendix A Procedure to Measure Water Content of Settled Solids . . . . . . . 65

Appendix B Sample Calculations for Gd Ratios and Extent of Precipitation . . . . . 67

Appendix C Sample Calculations for $\mathrm{H}: \mathrm{Pu}, \mathrm{H}: \mathrm{U}$, and $\mathrm{H}$ :Fissile Ratios $\ldots \ldots \ldots 71$ Using Data from Thermogravimetric Analyses

Appendix D Sample Calculations for $\mathrm{H}: \mathrm{Pu}, \mathrm{H}: \mathrm{U}$, and $\mathrm{H}:$ Fissile Ratios $\ldots \ldots \ldots 75$

Using Data from Graduated Cylinder Experiments 
WSRC-TR-2004-00053

Revision 0

\section{This page was intentionally left blank.}




\title{
Neutralization of Plutonium and Enriched Uranium Solutions Containing Gadolinium as a Neutron Poison
}

\author{
Michael G. Bronikowski and Tracy S. Rudisill \\ Westinghouse Savannah River Company \\ Aiken, SC 29808
}

\section{Summary}

Materials currently being dissolved in the HB-Line Phase I Facility will result in an accumulated solution containing an estimated uranium:plutonium (U:Pu) ratio of $4.3: 1$ and an ${ }^{235} \mathrm{U}$ enrichment estimated at $30 \%$. The U:Pu ratio and the enrichment are outside the evaluated concentration range for disposition to high level waste (HLW) using gadolinium (Gd) as a neutron poison. To confirm that the solution generated during the current HB-Line dissolving campaign can be poisoned with Gd, neutralized and discarded to the Savannah River Site (SRS) high level waste (HLW) system without undue nuclear safety concerns the caustic precipitation of surrogate solutions was examined.

Experiments were performed with a U/Pu/Gd solution representative of the HB-Line estimated concentration ratio and also a U/Gd solution. Depleted U was used in the experiments as the enrichment of the $U$ will not affect the chemical behavior during neutralization, but will affect the amount of $\mathrm{Gd}$ added to the solution. The amount of $\mathrm{Gd}\left(\right.$ as $\left.\mathrm{Gd}\left(\mathrm{NO}_{3}\right)_{3}\right)$ added to these solutions was at a 1:1 Gd:Fissile mass ratio which assumed ${ }^{235} \mathrm{U}$ and ${ }^{239} \mathrm{Pu}$ have a one to one equivalence and the ${ }^{235} \mathrm{U}$ enrichment was $30 \%$. The $\mathrm{U} / \mathrm{Pu} / \mathrm{Gd}$ solution was $3 \mathrm{~g} / \mathrm{L} \mathrm{U}, 0.7 \mathrm{~g} / \mathrm{L} \mathrm{Pu}$, and $1.7 \mathrm{~g} / \mathrm{L}$ Gd. The U/Gd solution was $5 \mathrm{~g} / \mathrm{L} \mathrm{U}$, and $5.7 \mathrm{~g} / \mathrm{L} \mathrm{Gd}$. Both solutions were in $6 \mathrm{M}$ nitric acid $\left(\mathrm{HNO}_{3}\right)$ and contained $0.1 \mathrm{~g} / \mathrm{L}$ aluminum $(\mathrm{Al})$ as expected from past dissolutions.

The $\mathrm{U} / \mathrm{Pu} / \mathrm{Gd}$ and $\mathrm{U} / \mathrm{Pu}$ solutions were neutralized partially to $\mathrm{pH} 4.5$ and fully to $1.2 \mathrm{M} \mathrm{OH}^{-}$ using $50 \mathrm{wt} \%$ sodium hydroxide $(\mathrm{NaOH})$. Settling behavior of the neutralized solutions was found to be comparable to previous studies. The neutralized solutions mixed easily and had expected densities of typical neutralized waste. The neutralized solids were found to be homogeneous and less than 20 microns in size. Partially neutralized solids were more amorphous than the fully neutralized solids.

The solids in this work at higher $U$ concentrations show two important differences from previous work. First, in the U/Gd case, fully neutralized solids are homogenous down to 3 microns where a few, predominantly Gd, crystals were found. Second, the partially neutralized solids had less Gd precipitate than previous studies. Only $4.4 \%$ and $3.0 \%$ of the Gd precipitates at $\mathrm{pH} 4.5$ for the $\mathrm{U} / \mathrm{Pu} / \mathrm{Gd}$ and $\mathrm{U} / \mathrm{Gd}$ solutions tested, respectively.

The hydrogen to $\mathrm{X}(\mathrm{H}: \mathrm{X})$ ratios for two accident scenarios were determined. The first was for transient neutralization and agitator failure. Experimentally this scenario was determined by measuring the $\mathrm{H}: \mathrm{X}$ ratio of the settled solids. The minimum $\mathrm{H}: \mathrm{U}$ and $\mathrm{H}: \mathrm{Pu}$ ratios for solids from 
fully neutralized $\mathrm{U} / \mathrm{Gd}$ and $\mathrm{U} / \mathrm{Pu} / \mathrm{Gd}$ solutions were 1700:1 and 7400:1, respectively. If a conservative ${ }^{235} \mathrm{U}$ enrichment of $33 \%$ is assumed, the minimum $\mathrm{H}$ :Fissile ratios are still in the thousands and safe with respect to nuclear safety. For the solids produced from the partial neutralization of the $\mathrm{U} / \mathrm{Pu} / \mathrm{Gd}$ solution, the $\mathrm{H}: \mathrm{Pu}$ and $\mathrm{H}: \mathrm{U}$ ratios are even larger (12500:1 and 2800:1, respectively). The second accident scenario is for a pump box agitator failure with the solids drying out. Experimentally, this scenario was determined by measuring the $\mathrm{H}$ : $\mathrm{X}$ ratio in centrifuged solids. The previous safe ratio for a 1:1 Gd:Pu mass ratio was 30:1 H:Pu atom ratio. The minimum $\mathrm{H}: \mathrm{Pu}: \mathrm{U}$ and $\mathrm{H}:$ Fissile atom ratios for centrifuged $\mathrm{U} / \mathrm{Pu} / \mathrm{Gd}$ precipitated solid material are 219:1:4.7 and 85:1. The minimum H:U and H:Fissile atom ratios for centrifuged U/Gd precipitated solid material are 31:1 and 94:1. Thus $U$ was found to have a possible concentration limit where Gd may not be a viable poison for $U$ solutions at a 1:1 mass ratio.

Based on the results of these experiments, Gd was found to be a viable poison for neutralizing a $\mathrm{U} / \mathrm{Pu} / \mathrm{Gd}$ solution with a $\mathrm{U}: \mathrm{Pu}$ mass ratio of 4.3:1 thus extending the U:Pu mass ratio from the previously investigated $0-3: 1$ to $4.3: 1$. However, further work is needed to allow higher $\mathrm{U}$ concentrations or $\mathrm{U}: \mathrm{Pu}$ ratios greater than investigated in this work. 


\section{Introduction}

The HB-Line Phase I Facility is currently dissolving materials containing quantities of $\mathrm{Pu}$ and enriched U which are excess to the Department of Energy needs. The isotopic concentrations of the $\mathrm{Pu}$ in those materials do not meet mixed oxide (MOx) fuel specifications, thus precluding the disposition of the $\mathrm{Pu}$ as MOx fuel. Following recent dissolution campaigns, similar solutions were poisoned with Gd, neutralized, and discarded to the SRS HLW system.[1,2] A neutron poison is required to allow the neutralization of solution batches containing greater than a fissile mass of $\mathrm{Pu}$. Gadolinium is very effective in capturing thermal neutrons; therefore, the amount of Gd added to a solution is much less compared to other poisons. Minimizing the mass of poison results in a smaller volume of HLW glass and is important in facilitating the transfer of the precipitate slurry. The formation of large quantities of metal hydroxides upon neutralization can result in sludges which are difficult to suspend and transfer. Although Gd is highly effective in capturing thermal neutrons, it is less effective in capturing fast neutrons; therefore, it is important that the fissile material is always associated with enough $\mathrm{H}$, as water, to thermalize the neutrons.

In previous studies, the feasibility of adding $\mathrm{Gd}$ as a neutron poison and neutralization to $1.2 \mathrm{M}$ excess hydroxide $\left(\mathrm{OH}^{-}\right)$was demonstrated with solutions containing only $\mathrm{Pu}$ and with solutions containing a 3:1 mixture of slightly enriched U (0.8\%) and Pu.[1,2] Sufficient Gd precipitated with the $\mathrm{Pu}$ and $\mathrm{U} / \mathrm{Pu}$ mixture and enough water was associated with the solids during transfer accident scenarios such that no nuclear criticality event could occur in those cases. However, the materials currently being dissolved in the HB-Line Phase I Facility will result in an accumulated solution containing an estimated $\mathrm{U}: \mathrm{Pu}$ ratio of 4.3:1 which is outside the evaluated concentration range. The $U$ enrichment is estimated at $30 \%$ which is also outside the scope of the previous tests. The enrichment of the $\mathrm{U}$ will not affect the chemical behavior during neutralization, but it will affect the amount of $\mathrm{Gd}$ added to the solution. A 1:1 Gd to fissile ratio has been proposed for poisoning the solution based on a 1:1 equivalence factor for ${ }^{239} \mathrm{Pu}$ and ${ }^{235} \mathrm{U}$.

To confirm that the U/Pu solution generated during the current HB-Line dissolving campaign can be poisoned with Gd, neutralized and discarded to the SRS HLW system without nuclear criticality safety concerns, the Actinide Technology Section (ATS) examined the caustic precipitation of a surrogate $\mathrm{U} / \mathrm{Pu} / \mathrm{Gd}$ solution representative of the estimated concentration ratio. Experiments were also performed using a U/Gd solution to evaluate the neutralization of solutions containing higher concentrations of $\mathrm{U}$. The study measured the ratio of $\mathrm{Pu}$ and/or $\mathrm{U}$ to Gd in the first solids precipitated during neutralization and in the solids following neutralization to $1.2 \mathrm{M}$ excess $\mathrm{OH}^{-}$. The ratios of $\mathrm{H}$ to $\mathrm{Pu}$ and $\mathrm{U}$ were estimated from the amount of water associated with the initial solids produced during neutralization (after settling) and centrifuged solids from the fully neutralized solutions. The particle size distribution of the precipitated solids from each neutralization was also measured. 


\section{This page was intentionally left blank.}




\section{Experimental}

\section{$\underline{\text { Solution Preparation }}$}

Since the dissolution campaign in the HB-Line Phase I Facility was still in progress, a sample of the final accumulated dissolving solution was not available for use in the neutralization studies. Therefore, a simulated solution was prepared based on the HB-Line feedstock characterization data provided by facility technical support personnel. A U solution poisoned with Gd was also prepared to evaluate the neutralization of solutions containing higher concentrations of $U$. The solutions were prepared by dissolving reagent grade aluminum nitrate nonahydrate $\left(\mathrm{Al}\left(\mathrm{NO}_{3}\right)_{3} \bullet 9 \mathrm{H}_{2} \mathrm{O}\right)$, gadolinium nitrate hexahydrate $\left(\mathrm{Gd}\left(\mathrm{NO}_{3}\right)_{3} \bullet 6 \mathrm{H}_{2} \mathrm{O}\right)$, and depleted uranyl nitrate hexahydrate $\left(\mathrm{UO}_{2}\left(\mathrm{NO}_{3}\right)_{2} \bullet 6 \mathrm{H}_{2} \mathrm{O}\right)$ in nominally $6.8 \mathrm{M} \mathrm{HNO}$. For the simulated dissolving solution, the $\mathrm{Pu}$ was added by transferring a measured aliquot of a $40 \mathrm{~g} / \mathrm{L} \mathrm{Pu}$ solution previously purified by anion exchange. The target and measured concentrations of the solutions are given in Table 1.

Table 1 Composition of H-Canyon Test Solutions Poisoned with Gd

\begin{tabular}{|c|c|c|c|c|c|c|c|c|c|c|}
\hline \multirow[t]{2}{*}{ Sol. } & \multicolumn{2}{|c|}{$\mathrm{HNO}_{3}$} & \multicolumn{2}{|r|}{$\overline{\mathrm{U}}$} & \multicolumn{2}{|c|}{$\overline{\mathrm{Pu}}$} & \multicolumn{2}{|c|}{$\overline{\mathrm{Gd}}$} & \multicolumn{2}{|c|}{$\overline{\mathrm{Al}}$} \\
\hline & $\begin{array}{l}\text { Target } \\
\text { (M) }\end{array}$ & $\begin{array}{l}\text { Measured } \\
\text { (M) }\end{array}$ & $\begin{array}{l}\text { Target } \\
(\mathrm{g} / \mathrm{L})\end{array}$ & $\begin{array}{c}\text { Measured } \\
(\mathrm{g} / \mathrm{L})\end{array}$ & $\begin{array}{l}\text { Target } \\
(\mathrm{g} / \mathrm{L})\end{array}$ & $\begin{array}{c}\text { Measured } \\
(\mathrm{g} / \mathrm{L})\end{array}$ & $\begin{array}{l}\text { Target } \\
(\mathrm{g} / \mathrm{L})\end{array}$ & $\begin{array}{c}\text { Measured } \\
(\mathrm{g} / \mathrm{L})\end{array}$ & $\begin{array}{l}\text { Target } \\
(\mathrm{g} / \mathrm{L})\end{array}$ & $\begin{array}{c}\text { Measured } \\
(\mathrm{g} / \mathrm{L})\end{array}$ \\
\hline$\overline{\mathrm{U} / \mathrm{Pu}}$ & 6.8 & $6.04^{\mathrm{a}}$ & 3.5 & 3.06 & 0.7 & 0.71 & 1.8 & 1.73 & 0.1 & $0.068^{b}$ \\
\hline $\mathrm{U}$ & 6.8 & $6.19^{a}$ & 6 & 5.16 & NA & NA & 6 & 5.71 & 0.1 & NR \\
\hline
\end{tabular}

(a) $\pm 10 \%$ uncertainty

(b) Corrected for Gd interference

NR - Not resolvable due to Gd interference

NA - Not Applicable

The two solutions target $\mathrm{U}: \mathrm{Pu}: \mathrm{Gd}$ and $\mathrm{U}: \mathrm{Gd}$ ratios of 5:1:2.6 and 1:1, respectively. The $\mathrm{HNO}_{3}$ concentration of the solutions is based on the HB-Line dissolving flowsheet and estimated dilution factors. The concentration of $\mathrm{Al}$ is based on a measured value for the previous H-Canyon solution discarded to the HLW system.[2] The HB-Line flowsheet uses a small amount of fluoride to catalyze the dissolution of plutonium oxide which is subsequently complexed with Al to prevent excessive corrosion. No other elements were added to the synthetic solutions since the characterization data indicated no individual concentration exceeded $1 / 10$ of the $\mathrm{Pu}$ concentration.

\section{$\underline{\text { Precipitation and Sampling }}$}

Precipitation tests were performed using two $50 \mathrm{~mL}$ aliquots from each solution. One aliquot was used for the partially neutralized test and the other aliquot for the fully neutralized test. The $50 \mathrm{~mL}$ aliquots were measured using a graduated cylinder and transferred to $100 \mathrm{~mL}$ beakers. The aliquots were stirred at $500 \mathrm{rpm}$ with a magnetic stir bar and neutralized to the desired endpoint by the drop-wise addition of a $50 \mathrm{wt} \% \mathrm{NaOH}$ solution ensuring that the temperature of the solutions did not exceed $50^{\circ} \mathrm{C}$. The volume of the $\mathrm{NaOH}$ solution was determined by mass and density (Table 2). 
WSRC-TR-2004-00053

Revision 0

Table 2 Volume of $\mathrm{NaOH}$ Added to Surrogate Solutions

\begin{tabular}{|c|c|c|c|}
\hline Solution & $\begin{array}{c}\text { Volume of } \\
\text { Solution } \\
\text { Neutralized } \\
(\mathrm{mL})\end{array}$ & $\begin{array}{c}\text { Neutralization } \\
\text { End Point }\end{array}$ & $\begin{array}{c}\text { Volume of } \\
50 \mathrm{wt}^{\mathrm{o}} \mathrm{NaOH} \\
\text { Added }^{\mathrm{a}} \\
(\mathrm{mL})\end{array}$ \\
\hline $\mathrm{U} / \mathrm{Pu} / \mathrm{Gd}$ & 50 & $\mathrm{pH} 4.5$ & 18.14 \\
\hline $\mathrm{U} / \mathrm{Pu} / \mathrm{Gd}$ & 50 & 1.2M Excess $\mathrm{OH}^{-}$ & 23.65 \\
\hline $\mathrm{U} / \mathrm{Gd}$ & 50 & $\mathrm{pH} 4.0-4.5$ & 17.94 \\
\hline $\mathrm{U} / \mathrm{Gd}$ & 50 & 1.2M Excess $\mathrm{OH}^{-}$ & 23.01 \\
\hline
\end{tabular}

(a) Volume based on a density of $1.52 \mathrm{~g} / \mathrm{cm}^{3}$

Once the formation of solids was observed in the partially neutralized solutions and after $1.2 \mathrm{M}$ excess $\mathrm{OH}^{-}$was obtained in the fully neutralized solutions, the beakers were covered with Parafilm $\mathrm{M}^{\mathrm{TM}}$ and the solutions were stirred for 2-3 hours prior to sampling. The $\mathrm{pH}$ of both partially neutralized solutions was nominally 4.5 as measured by $\mathrm{pH}$ paper with $\pm 0.5 \mathrm{pH}$ unit resolution. This value is consistent with the $\mathrm{pH}$ measured during the partial neutralization of the 3:1 U:Pu solution tested during previous studies.[2]

While stirring, four $1.5 \mathrm{~mL}$ aliquots of the precipitate slurry were removed from each beaker and transferred into four $1.5 \mathrm{~mL}$ conical centrifuge tubes; the 16 samples were then centrifuged at $5000 \mathrm{~g}$ for 5 minutes. A $1 \mathrm{~mL}$ aliquot of supernate was removed from each of two centrifuge tubes for $\mathrm{Pu}, \mathrm{U}, \mathrm{Gd}$, and $\mathrm{Al}$ analyses for each neutralization test. One aliquot was used for $\mathrm{Pu}$ analysis which was performed by thenolytrifluoroacetone (TTA) extraction and alpha pulse height analysis (APHA). Using the second aliquot, the $\mathrm{U}, \mathrm{Gd}$, and $\mathrm{Al}$ analyses were performed by inductively coupled plasma emission spectroscopy (ICP-ES). Each aliquot for the ICP-ES analyses was diluted (1:9) with deionized water in preparation for the analysis. The centrifuged solids were prepared for analysis by removing the remainder of the supernate and dissolving the solids in each tube using a $1 \mathrm{~mL}$ aliquot of $8 \mathrm{M} \mathrm{HNO}_{3}$. Samples of the solution were analyzed for $\mathrm{Pu}$ by TTA extraction and APHA and for U, Gd, and Al by ICP-ES. These ICP-ES samples were also diluted (1:9) with deionized water. The aqueous phase was subsequently removed from the two remaining centrifuge tubes and a small amount of the precipitate was analyzed by $\mathrm{x}$-ray diffraction (XRD) and scanning electron microscopy (SEM).

\section{Density}

The densities of the supernate and precipitate slurry from each neutralization were determined gravimetrically. After settling for 24 hours, a $5 \mathrm{~mL}$ aliquot of the supernate was transferred to a beaker and the mass determined by difference. The supernate was transferred back to the original beaker. The contents of the beaker were then stirred and a $5 \mathrm{~mL}$ aliquot of the supernate and solids was removed. The supernate and solids were transferred to a beaker and the mass determined by difference. The density of the supernate and settled solids was also determined during the measurement of $\mathrm{H}$ ratios in settled solids (see section below). 


\section{$\underline{\text { Settling Experiments }}$}

The settling times for the solids precipitated during each neutralization were measured using a $25 \mathrm{~mL}$ graduated cylinder. Prior to the measurement, each neutralized solution was stirred until well mixed. A $25 \mathrm{~mL}$ aliquot was then transferred to the graduated cylinder. The solids were allowed to settle and the volume corresponding to the top of the solids in the graduated cylinder was recorded as a function of time.

\section{$\underline{\text { Particle Size Analysis }}$}

The particle size distribution of the solids produced during each neutralization was measured using a Leeds and Northrup Microtrac II particle size analyzer. Prior to analysis of the actual samples, $300 \mathrm{~mL}$ of diluent solution, prepared to closely match the ionic strength of the precipitation supernate, were analyzed to establish a baseline. The diluent was prepared by neutralizing a solution containing $6.8 \mathrm{M} \mathrm{HNO}_{3}$ plus enough additional $\mathrm{HNO}_{3}$ to account for the nitrate associated with the $\mathrm{Pu}, \mathrm{U}, \mathrm{Gd}$, and $\mathrm{Al}$ in each solution. The $\mathrm{HNO}_{3}$ solution was neutralized with $50 \mathrm{wt} \% \mathrm{NaOH}$ to the appropriate end point (i.e. $\mathrm{pH} 4.5$ or $1.2 \mathrm{M}$ excess $\mathrm{OH}^{-}$). The analysis was performed by adding the precipitate slurry to the diluent until the concentration of particles was sufficient to perform the measurement.

\section{$\underline{\mathrm{H}: \mathrm{Pu}, \mathrm{H}: \mathrm{U} \text {, and } \mathrm{H}: \text { Fissile Ratios }}$}

To calculate the $\mathrm{H}$ to $\mathrm{Pu}, \mathrm{U}$, and total fissile ratios in the precipitated solids, the amount of water associated with the solids produced during neutralization (after the particles settle) and with the centrifuged solids from the neutralizations was measured. The procedure used to measure the water content of the settled solids is given in Appendix A. Once the water content was known, the $\mathrm{H}$ ratios were calculated from the $\mathrm{U}$ and $\mathrm{Pu}$ analyses for the solids and the known stoichiometry. The water content of the partially neutralized U/Gd solution could not be measured due to the inadvertent loss of a portion of the precipitate slurry.

The amount of water present in the centrifuged solids from the neutralized solutions was determined by thermogravimetric analysis. A $25 \mathrm{mg}$ sample from each solution was prepared by transferring $1.5 \mathrm{~mL}$ of the well mixed precipitate slurry to a conical centrifuge tube. The samples were centrifuged at $5000 \mathrm{~g}$ for 5 minutes and the supernate removed. An additional $1.5 \mathrm{~mL}$ of the precipitate slurry was then added to the same tube; the tube was centrifuged at $5000 \mathrm{~g}$ for 5 minutes, and the supernate removed. The accumulated solids were transferred directly from the centrifuge tube to the thermogravimetric analyzer (TGA). A platinum sample pan was used. The samples were then heated at $10^{\circ} \mathrm{C} / \mathrm{min}$ up to $600^{\circ} \mathrm{C}$. Prior to the analysis, a calcium oxalate monohydrate $\left(\mathrm{CaC}_{2} \mathrm{O}_{4} \cdot \mathrm{H}_{2} \mathrm{O}\right)$ standard was heated in the TGA to confirm that waters of hydration were removed between $150-200^{\circ} \mathrm{C}$. A $30 \mathrm{mg}$ standard was also used to check the calibration of the TGA weighing pan. The water associated with the centrifuged solids was calculated using the difference in the initial mass and the mass of the sample at $250^{\circ} \mathrm{C}$. The $\mathrm{H}$ to $\mathrm{U}, \mathrm{Pu}$, and total fissile ratios were subsequently calculated using the water content of the solids, the $\mathrm{U}, \mathrm{Pu}$, and $\mathrm{Gd}$ analyses for the solids, and the stoichiometry assumed for the precipitated solids. 


\section{This page was intentionally left blank.}




\section{Results}

\section{$\underline{\text { Visual Observations }}$}

The $\mathrm{U} / \mathrm{Pu} / \mathrm{Gd}$ solution was yellow with a slight green tint to it. The yellow color, which is characteristic to uranyl nitrate solutions, was expected as the U:Pu ratio was higher in this solution than in the previous work.[2] The solution used in the previous work had a yellow/brown color due to a smaller $\mathrm{U}: \mathrm{Pu}$ ratio. Unlike the previous $\mathrm{U} / \mathrm{Pu} / \mathrm{Gd}$ solutions, no color change occurred prior to precipitation with the present solutions. The $\mathrm{U} / \mathrm{Pu} / \mathrm{Gd}$ precipitate was olive green at $\mathrm{pH} 4.5$, or slightly greener than the original solution. As more $\mathrm{NaOH}$ was added, up to full neutralization $\left(1.2 \mathrm{M}\right.$ excess $\left.\mathrm{OH}^{-}\right)$, the solids darkened to become a drab olive in color.

The initial U/Gd solution was yellow. The $\mathrm{U}$ began to precipitate when enough $\mathrm{NaOH}$ was added to reach $\mathrm{pH}$ 4.5. The precipitate was lemon yellow. Upon full neutralization the precipitate became yellow/orange in color which is expected for $\mathrm{U}$ in waste solutions due the presence of sodium diuranate $\left(\mathrm{Na}_{2} \mathrm{U}_{2} \mathrm{O}_{7}\right)$ solids.

The four neutralized solutions are shown on Figure 1 following one day of settling. All of the solids were easily resuspended as in previous studies.[1,2] The partially neutralized solids were easiest to mix and appeared more amorphous (i.e. less crystalline) than the fully neutralized solids. The fully neutralized U/Gd solids appeared the most crystalline and were easily resuspended as expected for $\mathrm{Na}_{2} \mathrm{U}_{2} \mathrm{O}_{7}$ solids. After a day of settling, the partially neutralized solids had a volume of $\sim 10 \mathrm{~mL}$ out of $\sim 60 \mathrm{~mL}$ total in the beakers. After one day of settling, the fully neutralized solids took up twice as much volume in the beakers or $\sim 20 \mathrm{~mL}$ out of $\sim 65 \mathrm{~mL}$ total.

The volume of solids is also different following centrifuging. The fully neutralized solutions had noticeably more solids associated with them than the partially neutralized solutions. However, for the fully neutralized cases, the solids only took up $\sim 10 \%$ of the total volume.

\section{$\underline{\text { Neutralization Tests }}$}

The U:Gd, Pu:Gd, and Fissile:Gd ratios obtained from the neutralization experiments are shown in Table 3. The ratios were calculated from the ICP-ES and Pu TTA extraction/APHA analyses. Sample calculations are shown in Appendix B. In the table, the fissile amount is calculated by assuming $33 \%$ of the $U$ is fissile $\left({ }^{235} \mathrm{U}\right)$ and $\mathrm{Pu}$ makes up the rest of the fissile material. The mass ratios reflect the fact that all of the $\mathrm{U}, \mathrm{Pu}$, and $\mathrm{Gd}$ is expected to precipitate at full neutralization. For example, the two solutions neutralized have $\mathrm{U}: \mathrm{Pu}: \mathrm{Gd}$ and $\mathrm{U}: \mathrm{Gd}$ ratios of 4.3:1:2.4 and 0.9:1. If all the $\mathrm{Pu}, \mathrm{U}$ and $\mathrm{Gd}$ precipitated at full neutralization, the $\mathrm{U} / \mathrm{Gd}$ solids mass ratios would be 1.79 and 0.90 , respectively for the $\mathrm{U} / \mathrm{Pu} / \mathrm{Gd}$ and $\mathrm{U} / \mathrm{Gd}$ solutions. Assuming (a conservative) 33\% enrichment gives 1.2:1:1 and 2.0:1:3.3, $\left({ }^{238} \mathrm{U}:\right.$ fissile:Gd) mass ratios, respectively, for the $\mathrm{Pu} / \mathrm{U} / \mathrm{Gd}$ and $\mathrm{U} / \mathrm{Gd}$ solutions. Fissile:Gd ratios in the solids with $100 \%$ precipitation at full neutralization would then be 1 and 0.3 , which is what was found experimentally if the $(1 \sigma) 5 \%$ measurement error is taken into account. 
WSRC-TR-2004-00053

Revision 0

Table $3 \mathrm{U} / \mathrm{Gd}, \mathrm{Pu} / \mathrm{Gd}$, and Fissile/Gd Mass Ratios in the Neutralized Solutions

\begin{tabular}{ccccccc}
\hline \hline $\begin{array}{c}\text { Solution } \\
\text { Neutralized }\end{array}$ & $\begin{array}{c}\text { Supernate } \\
\mathrm{U}: \mathrm{Gd}\end{array}$ & $\begin{array}{c}\text { Solids } \\
\mathrm{U}: \mathrm{Gd}\end{array}$ & $\begin{array}{c}\text { Supernate } \\
\text { Pu:Gd }\end{array}$ & $\begin{array}{c}\text { Solids } \\
\text { Pu:Gd }\end{array}$ & $\begin{array}{c}\text { Supernate } \\
\text { Fissile:Gd }\end{array}$ & $\begin{array}{c}\text { Solids } \\
\text { Fissile:Gd }\end{array}$ \\
\hline $\mathrm{U} / \mathrm{Pu} / \mathrm{Gd}, \mathrm{pH} 4.5$ & 0.127 & 32.5 & $3.34 \mathrm{E}-02$ & 6.90 & $7.53 \mathrm{E}-02$ & 17.6 \\
$\mathrm{U} / \mathrm{Pu} / \mathrm{Gd}, 1.2 \mathrm{M} \mathrm{OH}^{-}$ & 18.5 & 1.70 & 1.47 & 0.349 & 7.59 & 0.911 \\
$\mathrm{U} / \mathrm{Gd}, \mathrm{pH} 4.5$ & $9.86 \mathrm{E}-02$ & 26.5 & $\mathrm{NA}$ & NA & $3.25 \mathrm{E}-02$ & 8.74 \\
$\mathrm{U} / \mathrm{Gd}, 1.2 \mathrm{M} \mathrm{OH}^{-}$ & 4.32 & 0.951 & $\mathrm{NA}$ & NA & 1.43 & 0.314 \\
\hline NA - Not Applicable & & & & & &
\end{tabular}

The same data are presented in Table 4 as the percent precipitated when the initial solution is partially and fully neutralized. (Sample calculations are shown in Appendix B.) As expected, nearly $100 \%$ of the $\mathrm{Pu}, \mathrm{U}$, and $\mathrm{Gd}$ precipitate at full neutralization. Less precipitates at $\mathrm{pH} 4.5$. This same trend was seen in the previous work.[1,2]

Table 4 Percent of Each Element Precipitated from Solution Upon Neutralization

\begin{tabular}{lcccc}
\hline \hline $\begin{array}{c}\text { Solution } \\
\text { Neutralized }\end{array}$ & $\mathrm{Gd}$ & $\mathrm{U}$ & $\mathrm{Pu}$ & $\mathrm{Al}$ \\
& $(\%)$ & $(\%)$ & $(\%)$ & $(\%)$ \\
\hline $\mathrm{U} / \mathrm{Pu} / \mathrm{Gd}, \mathrm{pH} 4.5$ & 4.4 & 92.2 & 90.5 & 83.6 \\
$\mathrm{U} / \mathrm{Pu} / \mathrm{Gd}, 1.2 \mathrm{M} \mathrm{OH}^{-}$ & 99.9 & 98.9 & 99.6 & $0^{(\mathrm{NR})}$ \\
$\mathrm{U} / \mathrm{Gd}, \mathrm{pH} 4.5$ & 3.0 & 89.1 & $\mathrm{NA}$ & $100^{(\mathrm{NR})}$ \\
$\mathrm{U} / \mathrm{Gd}, 1.2 \mathrm{M} \mathrm{OH}^{-}$ & 99.8 & 99.3 & $\mathrm{NA}$ & $0^{(\mathrm{NR})}$ \\
\hline $\mathrm{NR}-$ Not resolvable due to Gd interference & & & \\
$\mathrm{NA}-$ Not Applicable & & & &
\end{tabular}

The amount of Al precipitated during the neutralization experiments could only be calculated for the $\mathrm{U} / \mathrm{Pu} / \mathrm{Gd}$ solution neutralized to $\mathrm{pH} 4.5$ due to the interference of $\mathrm{Gd}$ with the $\mathrm{Al}$ peak used for the ICP-Es analysis. The amount of Al precipitated in the other experiments could not be resolved. Therefore, the percent of the $\mathrm{Al}$ which precipitated in these experiments is based on the fact that $\mathrm{Al}$ is amphoteric. At partial neutralization, aluminum hydroxide $\left(\mathrm{Al}(\mathrm{OH})_{3}\right)$ precipitates, but at full neutralization, aluminate $\left(\mathrm{Al}(\mathrm{OH})_{4}{ }^{-}\right)$, a soluble anion, forms.

\section{$\underline{\text { SEM and XRD Analysis }}$}

Scanning electron micrographs were obtained for the solids from each neutralization with a LEO 440 electron microscope. Both secondary electron (SE) and quadropole back scattering electron (QBSE) spectra were taken. The SE pictures give an idea of the sample topography. The QBSE pictures indicate the relative atomic number, where the brighter the area or spot the higher the atomic number is of the material. Magnification was from 16X-2300X. Representative micrographs for the solids are shown on Figures 2-5.

All of the micrographs at low magnification $(\leq 300 \mathrm{X})$ had broad areas of light and dark solids. Energy dispersive spectra (EDS) (Figures 6-9) were obtained to identify the elements of both areas and spots seen on the micrographs. The darker areas contained a large amount of sodium 
(Na) from the sodium nitrate $\left(\mathrm{NaNO}_{3}\right)$ which precipitated upon neutralization (Figures $6 \mathrm{a}, 7 \mathrm{a}, 8 \mathrm{a}$, and 9a). Uranium and Gd were also present but usually at a lower amount. The light areas contained large amounts of $U$ for the partially neutralized solutions (Figure $8 b$ and $9 b$ ) or $U$ and Gd for fully neutralized solutions (Figures $6 \mathrm{~b}$ and $7 \mathrm{~b}$ ). Energy dispersive spectra of areas and spots did not show Gd as it was below instrument detection limits for the solids from the partial neutralizations (Figures 8 and 9). No Pu was found in any of the EDS due to its low concentration compared to $\mathrm{U}$ in the solids and to the resolution of the instrument.

Solids from both partial neutralization experiments were similar and appeared amorphous (Figures 4 and 5). The solids from the full neutralization of the U/Pu/Gd solution appeared amorphous up to 500X magnification (Figure 3). Even at 2000X, the material appeared to have some amorphous qualities (fluffy and white). However, at this magnification 1-3 micron needlelike crystals were uniformly mixed with the amorphous material. Energy dispersive spectra (Figure 6c) of both the needles and fluffy material were the same as that for the light areas (Figure 3d).

The solids from the full neutralization of the U/Gd solution (Figure 2) were more crystaline than the other solids. Even at 50X magnification, 10-20 micron crystals could be seen within each broad light or dark area. Most of the crystals and the lighter area contained mainly $U$ and $\mathrm{Gd}$. Unlike the U/Pu/Gd material where EDS of the lighter material were the same, two EDS for the $\mathrm{U} / \mathrm{Gd}$ material were found (Figure 7). The spectra for the majority of the material had U and Gd peaks of the same height or the Gd peaks slightly lower. The second spectrum was obtained from 3-5 micron square crystals that contained mainly Gd with a small amount of U. At 2300X, the Gd-containing crystals can be seen imbedded in needle-like crystals (Figure 2c). These U/Gd crystals are much like the crystals in the $\mathrm{U} / \mathrm{Pu} / \mathrm{Gd}$ solids but are longer and less amorphous material is associated with them.

X-ray diffraction results (Figure 10) were obtained for the solids precipitated during each of the neutralization tests. Solids generated from the partial neutralization of the U/Gd and U/Pu/Gd solutions have characteristic x-ray lines of $\mathrm{NaNO}_{3}$ and magnesium aluminum hydroxide $\mathrm{Mg}_{2} \mathrm{Al}(\mathrm{OH})_{7}$. More likely, these solids contain calcium aluminum hydroxide $\left(\mathrm{Ca}_{2} \mathrm{Al}(\mathrm{OH})_{7}\right)$ because it is isostructural with $\mathrm{Mg}_{2} \mathrm{Al}(\mathrm{OH})_{7}$. Calcium is present as an impurity in the $\mathrm{NaOH}$ used for the neutralizations. The spectra of the solids from the full neutralizations contain characteristic $x$-ray lines from $\mathrm{NaNO}_{3}$ and various sodium uranium oxides. Compounds identified in the solids from the U/Gd solutions include $\mathrm{Na}_{2} \mathrm{UO}_{4}, \mathrm{Na}_{3} \mathrm{UO}_{4}$, and $\mathrm{Na}_{2} \mathrm{U}_{2.5} \mathrm{O}_{8.5}$. Compounds identified in the $\mathrm{U} / \mathrm{Pu} / \mathrm{Gd}$ solids include $\mathrm{Na}_{3} \mathrm{UO}_{4}$ and Clarkeite $\left(\mathrm{Na}\left(\left(\mathrm{UO}_{2}\right) \mathrm{O}(\mathrm{OH})\right)\right)$. The presence of sodium carbonate $\left(\mathrm{Na}_{2} \mathrm{CO}_{3}\right)$ was also detected in the U/Pu/Gd solids. Its presence is due to the reaction of $\mathrm{NaOH}$ with carbon dioxide $\left(\mathrm{CO}_{2}\right)$ in the atmosphere (equation $1)$.

$$
2 \mathrm{NaOH}+\mathrm{CO}_{2} \rightarrow \mathrm{Na}_{2} \mathrm{CO}_{3}+\mathrm{H}_{2} \mathrm{O}
$$

Plutonium and Gd compounds in the XRD spectra were not detected in the solids from any of the neutralizations. One would not expect to see compounds of these elements since the solids were either amorphous or the crystal sizes were generally much less than 10 microns. 


\section{$\underline{\text { Density Measurements }}$}

Neutralized solution densities were measured after a day of settling in two experiments. Both results are within the range expected for neutralized canyon waste. The densities are close to previous work and within the range of 4 to $6 \mathrm{M} \mathrm{NaNO}_{3}(1.2256-1.3175 \mathrm{~g} / \mathrm{mL})$ diluted with $1.2 \mathrm{M} \mathrm{NaOH}(1.0538 \mathrm{~g} / \mathrm{mL})$ which makes up most of the solution. As noted in previous studies,[2] the difference in the supernate and settled solids densities is small. This result is consistent with the ease of mixing observed with the neutralized solutions.

The first density measurement was from the initial beaker in which the neutralizations were performed. After a day of settling $5.000 \mathrm{~mL}$ of the supernate were weighed. The supernate was returned to the beaker. The solution was mixed and $5.000 \mathrm{~mL}$ of slurry were weighed. These densities are listed under "Beaker Supernate" and "Beaker Slurry" in Table 5. Using the estimated volumes of the settled solids in the beaker a settled solids density was estimated.

Table 5 Neutralized Solution Densities from Beaker and Cylinder Experiments

\begin{tabular}{cccccc}
\hline \hline $\begin{array}{c}\text { Solution } \\
\text { Neutralized }\end{array}$ & $\begin{array}{c}\text { Beaker } \\
\text { Supernate }\end{array}$ & $\begin{array}{c}\text { Beaker } \\
\text { Slurry }\end{array}$ & $\begin{array}{c}\text { Estimated } \\
\text { Beaker Settled } \\
\text { Solids }( \pm 15 \%) \\
(\mathrm{g} / \mathrm{mL})\end{array}$ & $\begin{array}{c}\text { Cylinder } \\
\text { Supernate }\end{array}$ & $\begin{array}{c}\text { Cylinder } \\
\text { Settled Solids }\end{array}$ \\
\hline $\mathrm{U} / \mathrm{gu} / \mathrm{mL})$ & $(\mathrm{gd}, \mathrm{pH} 4.5$ \\
$\mathrm{U} / \mathrm{Pu} / \mathrm{Gd}, 1.2 \mathrm{M} \mathrm{OH}^{-}$ & 1.172 & 1.259 & 1.69 & 1.269 & 1.281 \\
$\mathrm{U} / \mathrm{Gd}, \mathrm{pH} 4.5$ & 1.158 & 1.281 & 1.56 & 1.298 & 1.348 \\
$\mathrm{U} / \mathrm{Gd}, 1.2 \mathrm{M} \mathrm{OH}^{-}$ & 1.192 & 1.220 & 1.36 & $\mathrm{NA}$ & $\mathrm{NA}$ \\
\hline
\end{tabular}

N/A - Not Available

The second density measurements were from the graduated cylinder experiment to determine $\mathrm{H}$ ratios in settled solids. In this experiment, $25 \mathrm{ml}$ of slurried solution was allowed to settle for a day. Most of the supernate (15.0-17.6 ml) was removed and weighed to determine the density. This density was used to subtract the weight of the remaining volume of supernate (2.2-3.2 $\mathrm{mL}$ ). The remaining weight was that of the settled solids, from which their density was determined.

\section{$\underline{\text { Settling Experiments }}$}

The settling curves for each precipitate slurry are shown on Figure 11. The solids settle from each of the neutralized solutions to reach a steady state of $20-30 \%$ of the original volume within one day. Two basic curves were seen. The first curve is for fully neutralized solutions. In this case, the solids begin settling immediately at a rapid rate, so that at 200 minutes they are essentially settled. The second curve is for the partially neutralized U/Gd and U/Pu/Gd solutions. In this second case, an induction period is seen where little to no settling occurs. At approximately 60-120 minutes, the settling rate increases and appears to be about the same as the fully neutralized solutions. 


\section{$\underline{\text { Particle Size Analysis }}$}

The particle size distribution of the precipitated solids was measured using a Leeds and Northrup Microtrac II particle size analyzer. Particle size distributions for the partially ( $\mathrm{pH} 4.5$ ) and fully neutralized (1.2M excess $\left.\mathrm{OH}^{-}\right) \mathrm{U} / \mathrm{Pu} / \mathrm{Gd}$ and for the fully neutralized $\mathrm{U} / \mathrm{Pu} / \mathrm{Gd}$ and $\mathrm{U} / \mathrm{Gd}$ solutions are compared on Figure 12. Unfortunately, there were not enough solids to perform an analysis for the partial neutralization of the U/Gd solution. Two reasons for the failure to measure the particle size in the U/Gd neutralization can be suggested. The first is that the particles in the solid were too small to measure. The second is that upon dilution the solids dissolved because the precipitated $U$ compounds have a large solubility at intermediate $\mathrm{pH}$ values. The solids generated by the partial neutralization of the $\mathrm{U} / \mathrm{Pu} / \mathrm{Gd}$ solution had a bimodal distribution. This behavior was seen previously following the neutralization of actual H-Canyon solutions containing Pu poisoned with Gd.[1] Unlike the previous work, where the bimodal distribution was attributed to agglomeration of the amorphous solids which broke up upon mixing, this distribution must be attributed to the particles themselves as the solids were mixed vigorously prior to analysis and were not allowed to stand for a week before being measured. The fraction of the solids as a function of increasing particle size for the same data are shown on Figure 13.

\section{$\underline{\mathrm{H}: \mathrm{Pu}, \mathrm{H}: \mathrm{U} \text {, and } \mathrm{H}: \text { Fissile Ratios }}$}

\section{TGA}

The thermogravimetric analyses for the solids from the fully neutralized $\mathrm{U} / \mathrm{Pu} / \mathrm{Gd}$ and $\mathrm{U} / \mathrm{Gd}$ solutions are shown on Figure 14 along with the $\mathrm{CaC}_{2} \mathrm{O}_{4} \cdot \mathrm{H}_{2} \mathrm{O}$ standard. The TGA standard shows a two step mass loss. The first step is for waters of hydration removal and the second is for oxalate destruction which forms $\mathrm{CO}_{2}$. All of the TGA spectra for the solids from the test solutions were similar, having a single mass loss step corresponding to the temperature expected for $\mathrm{H}_{2} \mathrm{O}$ removal. The mass loss at $250^{\circ} \mathrm{C}$, where a constant mass was attained, was used to determine the amount of water in the centrifuged solids. Sodium nitrate as well as metal hydroxide compounds decompose above this temperature.

The $\mathrm{H}: \mathrm{Pu}, \mathrm{H}: \mathrm{U}$, and $\mathrm{H}:$ Fissile ratios of the centrifuged solids from the TGA analysis are given in Table 6. The ratios were calculated assuming that the final compounds in the solids after water removal are $\mathrm{Na}_{2} \mathrm{U}_{2} \mathrm{O}_{7}, \mathrm{Pu}(\mathrm{OH})_{4}$, and $\mathrm{Gd}(\mathrm{OH})_{3}$. This assumption is conservative because the $\mathrm{NaNO}_{3}$ which may be present in the solids is not taken into account nor is the $\mathrm{H}$ from the hydroxides. For the H:Fissile ratio, $33 \%$ of the $\mathrm{U}$ is assumed to be ${ }^{235} \mathrm{U}$. Representative calculations of the $\mathrm{H}$ ratios for the centrifuged solids are given in Appendix $\mathrm{C}$. 
WSRC-TR-2004-00053

Revision 0

Table 6 H:Pu, H:U, and H:Fissile Ratios in Centrifuged Solids

\begin{tabular}{lccc}
\hline \hline Solution Neutralized & $\mathrm{H}: \mathrm{Pu}$ & $\mathrm{H}: \mathrm{U}$ & H:Fissile \\
\hline $\mathrm{U} / \mathrm{Pu} / \mathrm{Gd}, \mathrm{pH} 4.5$ & 219 & 46 & 85 \\
$\mathrm{U} / \mathrm{Pu} / \mathrm{Gd}, 1.2 \mathrm{M} \mathrm{OH}^{-}$ & 370 & 76 & 141 \\
$\mathrm{U} / \mathrm{Gd}, \mathrm{pH} 4.5$ & $\mathrm{~N} / \mathrm{A}$ & 31 & 94 \\
$\mathrm{U} / \mathrm{Gd}, 1.2 \mathrm{M} \mathrm{OH}^{-}$ & $\mathrm{N} / \mathrm{A}$ & 126 & 382 \\
\hline $\mathrm{N} / \mathrm{A}-$ Not Applicable & & &
\end{tabular}

\section{Graduated Cylinder Tests}

Water content was based on the evaporated mass from both the solids settled after $\sim 24$ hours and from the supernate. This mass was used to calculate the $\mathrm{H}: \mathrm{Pu}$ ratio for the solids generated by the partial $(\mathrm{pH} 4.5)$ and full neutralization $\left(1.2 \mathrm{M} \mathrm{OH}^{-}\right)$of the $\mathrm{U} / \mathrm{Pu} / \mathrm{Gd}$ solution. At the conclusion of the available time, the fully neutralized U/Gd supernate had not completely dried; the beaker still contained approximately $4 \mathrm{~mL}$ of solution to evaporate. If this volume is considered as all water and the corresponding mass is subtracted from the wet solids mass, a conservative estimate of the dry $\mathrm{H}: \mathrm{U}$ ratio is obtained. Assuming a ${ }^{235} \mathrm{U}$ enrichment of $33 \%$ allows the calculation of the H:Fissile ratio for the solids generated during each neutralization. The $\mathrm{H}$ ratios are summarized in Table 7. Sample calculations for these values are presented in Appendix D.

Table $7 \mathrm{H}: \mathrm{Pu}, \mathrm{H}: \mathrm{U}$, and H:Fissile Ratios in One-Day Settled Solids

\begin{tabular}{lcccc}
\hline \hline \multicolumn{1}{c}{$\begin{array}{c}\text { Neutralized } \\
\text { Solution }\end{array}$} & $\mathrm{H}: \mathrm{Pu}$ & $\mathrm{H}: \mathrm{U}$ & $\mathrm{H}: \mathrm{U}$ & $\mathrm{H}:$ Fissile \\
Wet & & & \\
\hline $\mathrm{U} / \mathrm{Pu} / \mathrm{Gd}, \mathrm{pH} 4.5$ & $12500: 1$ & $\mathrm{NR}$ & 2800 & $5100: 1$ \\
$\mathrm{U} / \mathrm{Pu} / \mathrm{Gd}, 1.2 \mathrm{M} \mathrm{OH}^{-}$ & $7400: 1$ & $\mathrm{NR}$ & 1700 & $3000: 1$ \\
$\mathrm{U} / \mathrm{Gd}, \mathrm{pH} 4.5$ & $\mathrm{NA}$ & $\mathrm{NM}$ & $\mathrm{NM}$ & $\mathrm{NM}$ \\
$\mathrm{U} / \mathrm{Gd}, 1.2 \mathrm{M} \mathrm{OH}^{-}$ & $\mathrm{NA}$ & $1900: 1$ & $1700: 1^{(1)}$ & $5800: 1$ \\
\hline $\mathrm{NA}-$ Not Applicable & & & & \\
$\mathrm{NR}-$ Not Required (Solution evaporated to dryness.) & & & \\
$\mathrm{NM}-$ Not Measured & & & & \\
(1)- Estimated Dry & & &
\end{tabular}




\section{Discussion}

This work was performed to support the use of Gd as a neutron poison for neutralization of $\mathrm{Pu}$-containing solutions and subsequent disposal of those solutions to the SRS HLW system when large amounts of $U$ are present. Specifically this work expands the U:Pu mass ratio from 3:1 to 4.3:1 for neutralizations poisoned with $\mathrm{Gd}$ at the same ratios as in the past.[1,2] The quantity of Gd to be used for this higher U:Pu material was based on the expected $\mathrm{U}$ enrichment and a 1 to 1 equivalence between ${ }^{239} \mathrm{Pu}$ and ${ }^{235} \mathrm{U}$. Finally, $\mathrm{U}$ experiments were performed in an attempt to demonstrate that pure U could be dispositioned to the HLW system using Gd as a neutron poison.

Gadolinium is an effective neutron poison as long as enough Gd is uniformly distributed within the fissile material, the particles are small, and the neutrons being absorbed are thermalized. For neutralized solids, this means uniform solids must be precipitated. The size of the precipitated solids needs to be less than 100 microns so Gd self-shielding is minimized. Finally, enough $\mathrm{H}$ in the form of water is required to thermalize the neutrons.

The H:X mass ratio needed for the safe neutralization of more than a fissile mass (of equivalent $\mathrm{Pu}$ ) depends both on the $\mathrm{Gd}: \mathrm{X}$ ratio and the $\mathrm{H}: \mathrm{X}$ ratio. Both ratios have been measured for three scenarios. The first is for partial and full neutralization where the neutralization tank is agitated throughout the neutralization process. In this case, plenty of water is present to thermalize the neutrons so only the Gd:X ratio is important. The second scenario, which corresponds to losing agitation in the tank during neutralization followed by a day of solids settling, requires both $\mathrm{H}$ : $\mathrm{X}$ and Gd:X ratios in the settled solids to attain a certain level. The final scenario, corresponds to a pump box agitator failure where the solids are allowed to dry. Once again $\mathrm{H}: \mathrm{X}$ and $\mathrm{Gd}: \mathrm{X}$ ratios in the packed solids are important. For the last two scenarios, sufficient Gd was used in the experiments so that if the solution was neutralized, only the thermalization of the neutrons or the $\mathrm{H}$ :X ratio was important. The limiting $\mathrm{H}: \mathrm{X}$ ratio must be determined by a nuclear criticality safety evaluation; however, previous $\mathrm{H}$ :X ratios will be used here for comparison as they are expected to be greater than those for ${ }^{235} \mathrm{U}$ due to its lower mass deficit than ${ }^{239} \mathrm{Pu}$ and less energetic neutron spectrum.

\section{$\underline{\text { Precipitations }}$}

The most important difference between these studies and previous work at lower $U$ concentrations is that the amount of $\mathrm{Gd}$ which precipitates is less than the $6 \%$ at $\mathrm{pH} 4.5$ found in the previous studies. Only 4.4 and $3.0 \%$ of the $\mathrm{Gd}$ precipitates at $\mathrm{pH} 4.5$ for the tested $\mathrm{U} / \mathrm{Pu} / \mathrm{Gd}$ and $\mathrm{U} / \mathrm{Gd}$ solutions, respectively. The amount of $\mathrm{U}$ that precipitates at $\mathrm{pH} 4.5$ is also substantially higher than in the previous studies. The most probable cause for the lower amount of precipitated $\mathrm{Gd}$ appears to be the greater amount of $\mathrm{U}$ or higher $\mathrm{U}: \mathrm{Pu}$ ratio in the latest tests. It should be noted that the previous $U / G d$ solutions had a $U: G d$ ratio of 1:1.5 with a substantial amount of boron (B) present as compared to the 0.9:1 U:Gd ratio with Al present in this study. The presence of B may have an effect on the amount of Gd which precipitates.

The settling studies show that the precipitates in general are consistent with previous studies. The precipitates settle to a steady state within about a day and are easily resuspended upon 
mixing. As such, no problems are expected for pumping or mixing the slurries in canyon tanks. Two points should be noted on the settling of the solids. The first point is that the partially neutralized solutions are more amorphous and take more time to settle. The second point is that additional elements in these solutions (e.g. Al and B) generally tend to slow down the settling as noted by Visser et al.[2] Both of these elements are amphoteric and could affect the final solids as well as their settling properties. Other species that may be present during future campaigns, such as iron $(\mathrm{Fe})$, manganese, zirconium, and sulfate $\left(\mathrm{SO}_{4}{ }^{2-}\right)$ could affect settling and the properties of the solids.

\section{$\underline{\text { Solids }}$}

Gadolinium was found to be uniformly distributed within the fissile solids in all but the U/Gd case where it was uniform down to a 3 micron particle size. Although EDS for the partially neutralized solutions do not show Gd as being present, ICP-ES results from the same solids show its presence. Much like $\mathrm{Pu}$, the $\mathrm{Gd}$ is at the limit of detection due to its minimal concentration, how well it is mixed within the solids, and its particle size. Similarly, Al was not detected in the EDS, although it was present in the XRD spectra as crystals and detected by the ICP-ES analyses. The EDS of the fully neutralized solutions show Gd and $U$ being present in all solids with the only difference being the amount of Na present in the solids. In the EDS of the $\mathrm{U} / \mathrm{Pu} / \mathrm{Gd}$ solids, the $\mathrm{U}$ and $\mathrm{Gd}$ peaks are in about the same ratio for all the solids examined. For the fully neutralized U/Gd solids, EDS show that the $U$ and Gd peaks were similar down to about a 3 micron particle size where a few crystals were predominantly Gd. These square Gd crystals were observed randomly situated in a mesh of needle-like U/Gd crystals with a few amorphous spots of the same U/Gd composition.

The particle sizes of all the precipitated solids are generally less than 20 microns. This particle size agrees with earlier assessment of $U$ particle sizes in the waste tanks by Karraker.[3] Similar sizes were measured for neutralized $\mathrm{Pu} / \mathrm{Gd}$ solutions after mixing.[1] The small size is less than the 100 micron size needed for Gd self-shielding to be minimal. The uniform makeup of the solids should also help negate self-shielding of Gd.

Although the particle sizes are small, each of the solutions produce solids that have a unique distribution which may be explained by crystal or particle growth. As shown in Figure 12, the partially neutralized $\mathrm{U} / \mathrm{Pu} / \mathrm{Gd}$ distribution is bimodal and changes to a single distribution upon full neutralization. From the XRD results, Al compounds redissolve as one goes from partial to full neutralization. However, the small amount of Al solids would not change the particle size distribution this drastically from partial to full neutralization. On examining the SEM results for approximate particle sizes, one can correlate the darker solids, or more Na-bearing U/Pu/Gd solids (probably due to $\mathrm{NaNO}_{3}$ ) with the peak at larger particle size in the bimodal distribution. The peak at the smaller particle size would then represent the smaller amorphous $\mathrm{U} / \mathrm{Pu} / \mathrm{Gd}$ particles containing less $\mathrm{Na}$. As more $\mathrm{NaOH}$ is added, the rest of the $\mathrm{Pu}, \mathrm{U}$, and Gd precipitates through growth at the nucleation sites (particles) already present or through agglomeration. The smaller particle size peak in the bimodal distribution thus grows into the larger particle size peak. The abundance of $\sim 3$ micron needle-like $\mathrm{U} / \mathrm{Pu} / \mathrm{Gd}$ crystals seen in micrographs for the full neutralization and not in the partial neutralization support this crystal growth or particle hypothesis (Figure 3d). 
The U/Gd particle size distribution for the solids from the fully neutralized solution can also be explained by crystal growth. In this distribution, the smaller particle size peak or shoulder correlates with solids which contain more $\mathrm{Na}$ (from SEM results). The peak for these solids is at about the same particle size as those for Na-rich solids in the partially neutralized U/Pu/Gd distribution. The largest solids in the fully neutralized U/Gd material are seen as 10-20 micron "boulders" (more crystalline material) in the micrographs and are composed of U and Gd (Figure 2). The $\mathrm{U}$ and $\mathrm{Gd}$ concentration in the $\mathrm{U} / \mathrm{Gd}$ solution must be large enough to allow for larger particles to form. In fact, even at the highest magnification of $2300 \mathrm{X}$, the U/Gd needle-like crystals appear larger than those of the fully neutralized $\mathrm{U} / \mathrm{Pu} / \mathrm{Gd}$ solution.

From the discussion above, an argument can be made that while a little $U$ is good to have for waste neutralizations as it reduces the formation of $\mathrm{Pu}$ polymers by chain termination, too much $U$ promotes crystallization and larger particle sizes. If the concentration of $U$ is too great, the particle size may grow to more than the 100 micron size where neutron shielding may become a problem for use of $\mathrm{Gd}$ as a poison. Thus a $\mathrm{U}$ concentration limit may exist for using $\mathrm{Gd}$ as a neutron poison for neutralizing greater than a fissile mass (of equivalent $\mathrm{Pu}$ ). On the practical side, the limit would be at greater than the 4.3:1 U:Pu ratio solution to be neutralized in the near future.

\section{$\underline{\text { H to X Ratio }}$}

The $\mathrm{H}$ to $\mathrm{X}(\mathrm{X}=\mathrm{Pu}, \mathrm{U}$, or Fissile $)$ atom ratios should allow safe use of $\mathrm{Gd}$ as a neutron poison for the $\mathrm{U} / \mathrm{Pu} / \mathrm{Gd}$ solution even if there is a failure of the agitator in the neutralization tank. The $\mathrm{H}: \mathrm{Pu}$ ratios of the present work are much larger than those of the initial $\mathrm{Pu} / \mathrm{Gd}$ neutralization studies.[1] The initial $\mathrm{H}: \mathrm{Pu}$ values determined for a $2 \mathrm{~g} / \mathrm{L} \mathrm{Pu}, 2.92 \mathrm{~g} / \mathrm{L}$ B solution which was partially neutralized were $>1900: 1$ and $>2500: 1$ for 1:1 and 1:1.5 Pu:Gd mass ratios, respectively. The present study found a 12,500:1 H:Pu ratio for a partially neutralized and 7400:1 ratio for a fully neutralized $\mathrm{U} / \mathrm{Pu} / \mathrm{Gd}$ solution. Even the $\mathrm{H}:$ Fissile ratios of 3000:1 for the partially and 5100:1 for the fully neutralized U/Pu/Gd solutions are larger. Using the relationship between the minimum safe $\mathrm{Gd}: \mathrm{Pu}$ and $\mathrm{H}: \mathrm{Pu}$ ratios presented in reference [1] and reproduced as Figure 15, the lower $\mathrm{Gd}: \mathrm{Pu}$ ratio (where $\mathrm{Gd}: \mathrm{Pu}=1 / 6.90$ ) at partial neutralization has a higher $\mathrm{H}: \mathrm{Pu}$ ratio and hence is still in the safe region. Assuming a 1 to 1 correspondence and equivalence for ${ }^{235} \mathrm{U}$ and ${ }^{239} \mathrm{Pu}$, the $\mathrm{H}$ :Fissile ratio for the same solution is also in the safe region.

The $\mathrm{H}: \mathrm{X}$ atom ratios determined for the $\mathrm{U} / \mathrm{Gd}$ solution suggest the use of Gd as a poison for neutralizing greater than a fissile mass may not have as large a safety margin as in the previous $\mathrm{Pu}$ or present $\mathrm{Pu} / \mathrm{U}$ neutralizations if an agitator fails in the neutralization tank. Once again the assumption of 1 to 1 equivalence of ${ }^{235} \mathrm{U}$ to ${ }^{239} \mathrm{Pu}$ is used with Figure 15 . The fully neutralized $\mathrm{H}: \mathrm{U}$ ratio of 1900:1 is as high as the $\mathrm{H}: \mathrm{Pu}$ ratio (>1900:1) measured during the initial studies.[1] The estimated dry value of 1700:1 moves the plotted value for the fully neutralized U/Gd solution closer to the line between the safe and unsafe regions. However, assuming $33 \%$ of the $\mathrm{U}$ is fissile increases the $\mathrm{H}: \mathrm{X}$ ratio and moves the plotted value back toward the safe region. A plotted value for the partial neutralization of the U/Gd solution would be closer to the unsafe region because less Gd precipitated than in the two previous studies (3\% verses 5 and 6\%). From Figure 15, higher H:X ratios are needed for lower Gd:X ratios. Thus the H:X ratios 
suggest that there may be a limit to the amount of $U$ which can be safely neutralized using Gd as a neutron poison.

Similar results are seen for the pump box agitator failure followed by the drying-out of the solids. In this scenario (for a 1:1 Gd:X mass ratio), a 30:1 $\mathrm{H}: \mathrm{Pu}$ atom ratio or $\mathrm{H}: \mathrm{U}$ ratio assuming equivalence is needed. From Table 6, it can be seen that all the ratios for the U/Pu/Gd solution neutralizations are much greater than the 30:1 needed. Therefore, the solution should be safe to dispose of with $\mathrm{Gd}$ as a poison. However, the U/Gd solution has lower $\mathrm{H}: \mathrm{U}$ values. In fact, the partial neutralization has only a 31:1 ratio suggesting Gd can not be used as a poison at this $U$ concentration. If only the fissile $U(33 \%)$ is taken into account, it appears Gd can be used since the $\mathrm{H}$ :Fissile ratio increases by a factor of three.

The lower H:X values found for the U/Gd system suggests a limit on the amount of $U$ which can be neutralized using $\mathrm{Gd}$ as a neutron poison. The lower $\mathrm{H}$ :X ratios may be due to the more crystalline nature of the $\mathrm{U} / \mathrm{Gd}$ solids. The $\mathrm{U} / \mathrm{Gd}$ solids settled in a day to a lower volume percent than the $\mathrm{U} / \mathrm{Pu} / \mathrm{Gd}$ solids, as one would expect for larger more crystalline solids. Centrifuging the more crystalline $\mathrm{U} / \mathrm{Gd}$ solids would tend to pack them more closely than the more amorphous $\mathrm{U} / \mathrm{Pu} / \mathrm{Gd}$ solids and thus force out more water and lower the $\mathrm{H}: \mathrm{X}$ ratio. 


\section{Conclusions}

Gadolinium was found to be a viable poison for neutralizing a U/Pu/Gd solution with a U:Pu mass ratio of 4.3:1 thus extending the U:Pu mass ratio from the previously investigated $0-3: 1$ to 4.3:1. The amount of $\mathrm{Gd}$ added to this solution was at a 1:1 Gd:Fissile mass ratio which assumed ${ }^{235} \mathrm{U}$ and ${ }^{239} \mathrm{Pu}$ has a one to one equivalence and the ${ }^{235} \mathrm{U}$ enrichment was $30 \%$. The neutralized solids were found to be homogeneous and less than 20 microns in size. Partially neutralized solids were more amorphous than the fully neutralized solids. The partially neutralized solids also had less of the total $\mathrm{Gd}(4.4 \%)$ precipitate than in previous studies.

The H:X ratios for two accident scenarios were determined. The first was for transient neutralization and agitator failure. Experimentally this scenario was determined by measuring the $\mathrm{H}$ :X ratio of the settled solids. The minimum $\mathrm{H}: \mathrm{U}$ and $\mathrm{H}: \mathrm{Pu}$ ratios for solids from fully neutralized $\mathrm{U} / \mathrm{Gd}$ and $\mathrm{U} / \mathrm{Pu} / \mathrm{Gd}$ solutions were 1700:1 and 7400:1, respectively. If a conservative ${ }^{235} \mathrm{U}$ enrichment of $33 \%$ is assumed, the minimum $\mathrm{H}:$ Fissile ratios are still in the thousands and safe with respect to nuclear safety. For the solids produced from the partial neutralization of the $\mathrm{U} / \mathrm{Pu} / \mathrm{Gd}$ solution, the $\mathrm{H}: \mathrm{Pu}$ and $\mathrm{H}: \mathrm{U}$ ratios are even larger (12500:1 and 2800:1, respectively). The second accident scenario is for a pump box agitator failure with the solids drying out. Experimentally, this scenario was determined by measuring the $\mathrm{H}$ : $\mathrm{X}$ ratio in centrifuged solids. The minimum $\mathrm{H}: \mathrm{Pu}: \mathrm{U}$ and $\mathrm{H}:$ Fissile atom ratios for centrifuged $\mathrm{U} / \mathrm{Pu} / \mathrm{Gd}$ precipitated solid material are 219:1:4.7 and 85:1. The minimum H:U and H:Fissile atom ratios for centrifuged U/Gd precipitated solid material are 31:1 and 94:1.

Enriched uranium was found to have a possible concentration limit where Gd may not be a viable poison for $\mathrm{U}$ solutions at a 1:1 mass ratio. Experimentally, a $5 \mathrm{~g} / \mathrm{L} \mathrm{U}$ solution with a 1:1 $\mathrm{U}$ :Gd mass ratio was neutralized. The neutralized solids were less than 20 microns in size. The partially neutralized solids were homogeneous and more amorphous than the fully neutralized solids. The fully neutralized solids are homogenous down to 3 microns where a few, predominantly $\mathrm{Gd}$, crystals were found. This size is small enough that Gd self-shielding is not important. The partially neutralized solids had even less of the total Gd (3.0\%) precipitate than the $\mathrm{U} / \mathrm{Pu} / \mathrm{Gd}$ solution.

Before solutions containing higher ratios of $\mathrm{U}$ to $\mathrm{Pu}$ than 4.3:1 are poisoned with Gd, neutralized, and dispositioned to the SRS HLW system, additional work is required. Three things need to be experimentally determined to allow such use. First, determine if there is an optimum Pu:U ratio that would keep the solids amorphous and homogeneous. Second, determine the U concentration limit for safely neutralizing with Gd as a neutron poison. Finally, determine the effect of impurities such as Al, B, and Fe on the neutralized solids and settling. 


\section{This page was intentionally left blank.}




\section{References}

1. M. G. Bronikowski, J. H. Gray, B. C. Hill, F. R. Graham, and D. G. Karraker, Caustic Precipitation of Plutonium using Gadolinium as the Neutron Poison for Disposition to High Level Waste, Report No. WSRC-TR-2002-00198, Westinghouse Savannah River Company, Aiken, SC (May 2002).

2. A. E. Visser, T. S. Rudisill, and M. G. Bronikowski, Investigation of Plutonium and Uranium Precipitation Behavior with Gadolinium as a Neutron Poison, Report No.

WSRC-TR-2003-00193, Westinghouse Savannah River Company, Aiken, SC (May 2003).

3. D. G. Karraker, Uranium Settling Rates in SRS Waste Supernate, Report No.

WSRC-TR-94-00058, Westinghouse Savannah River Company, Aiken, SC (January 1994). 


\section{This page was intentionally left blank.}


Figure 1 Neutralized U/Pu/Gd and U/Gd Solutions

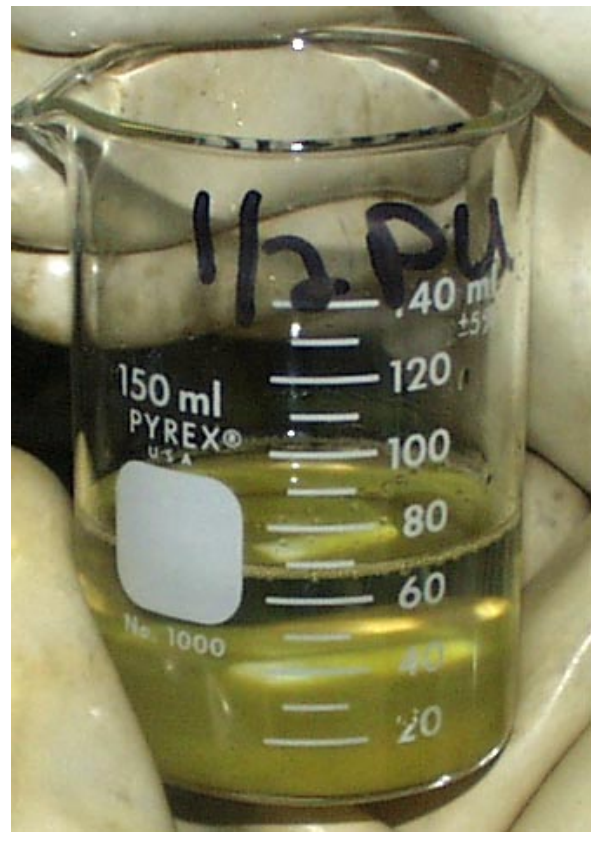

$\mathrm{U} / \mathrm{Pu} / \mathrm{Gd}$ Surrogate $-\mathrm{pH} 4.5$

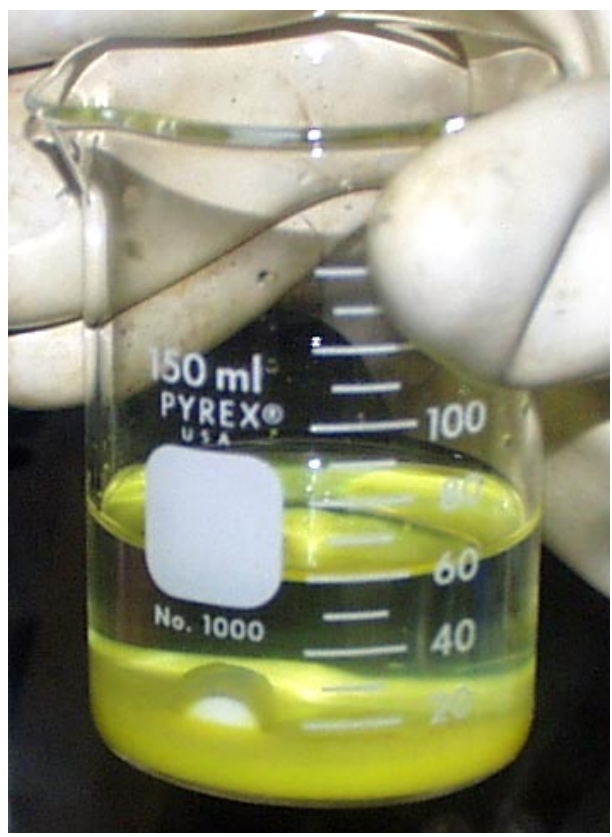

U/Gd Surrogate - $\mathrm{pH} 4.5$

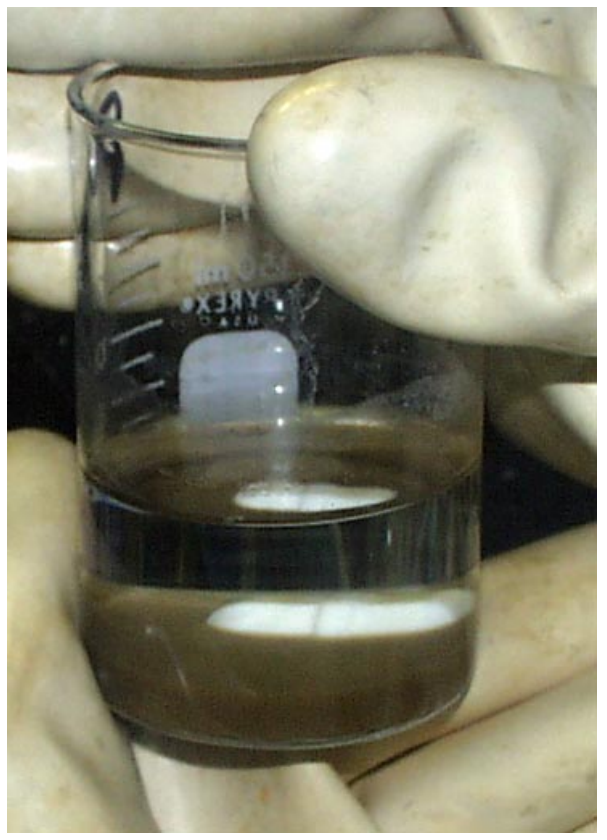

$\mathrm{U} / \mathrm{Pu} / \mathrm{Gd}$ Surrogate $-1.2 \mathrm{M}$ Excess $\mathrm{OH}^{-}$

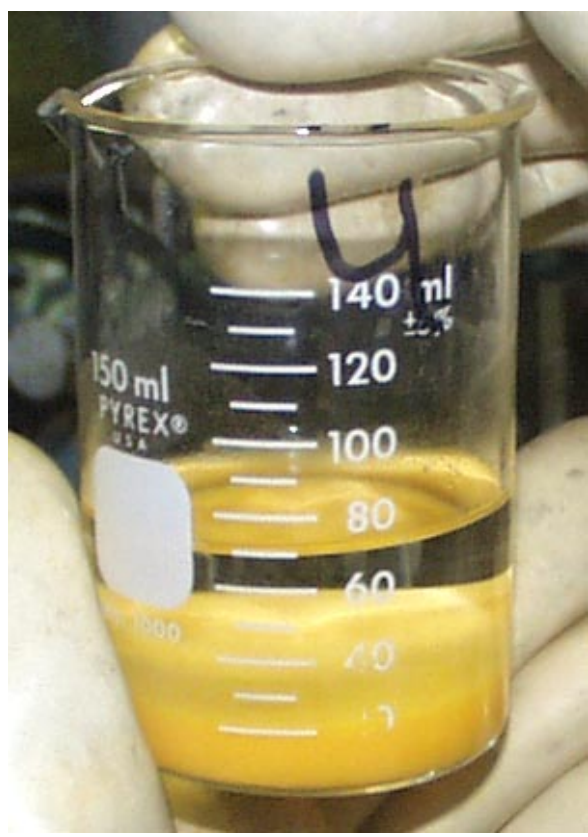

$\mathrm{U} / \mathrm{Gd}$ Surrogate $-1.2 \mathrm{M}$ Excess $\mathrm{OH}^{-}$ 


\section{This page was intentionally left blank.}


WSRC-TR-2004-00053

Revision 0

Figure 2 SEM Micrographs of Solids from Fully Neutralized U/Gd Solution

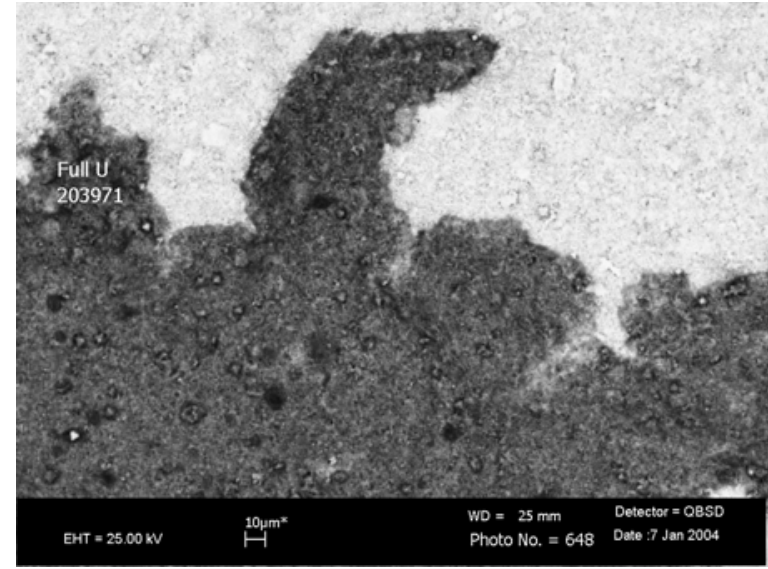

(a) $300 \mathrm{X}$ QBSD

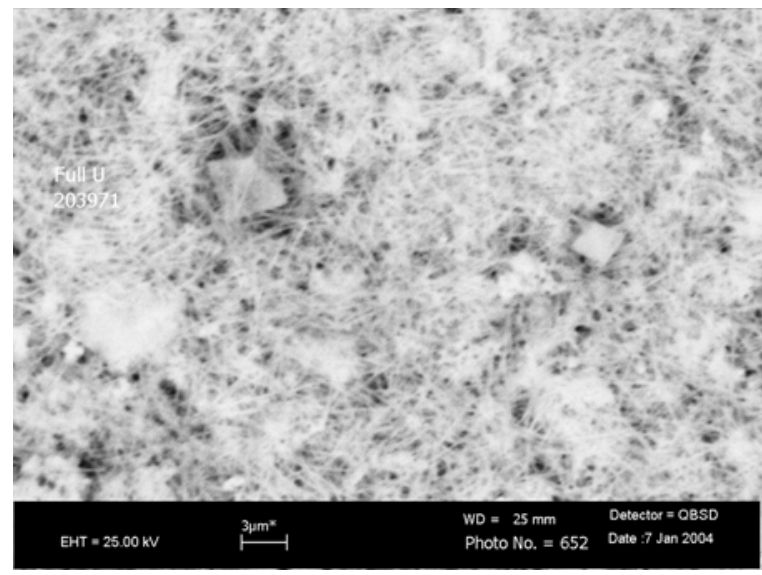

(c) 2300X QBSD

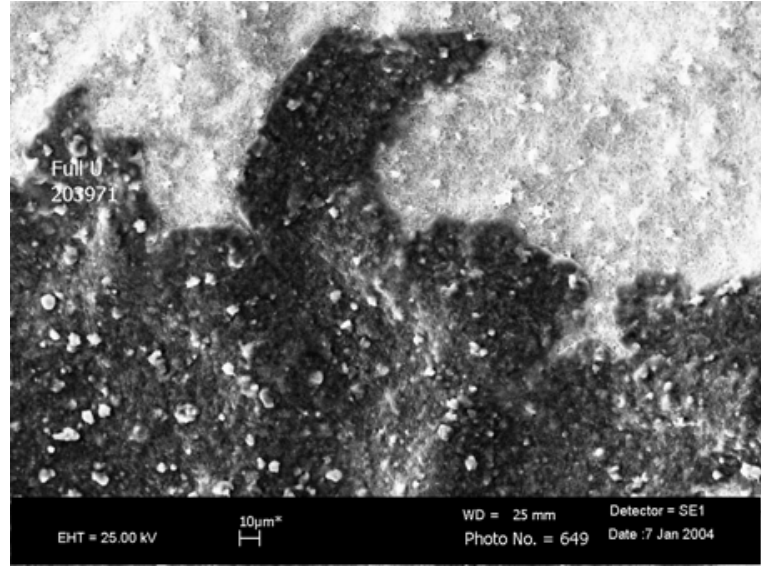

(b) $50 \mathrm{X} \mathrm{SE}$

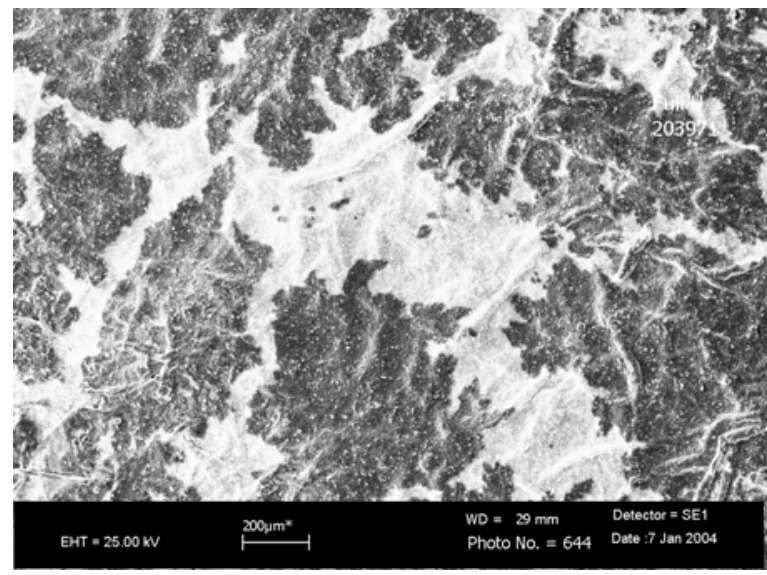

(d) $50 \mathrm{X} \mathrm{SE}$ 


\section{This page was intentionally left blank.}


Figure 3 SEM Micrographs of Solids from Fully Neutralized U/Pu/Gd Solution

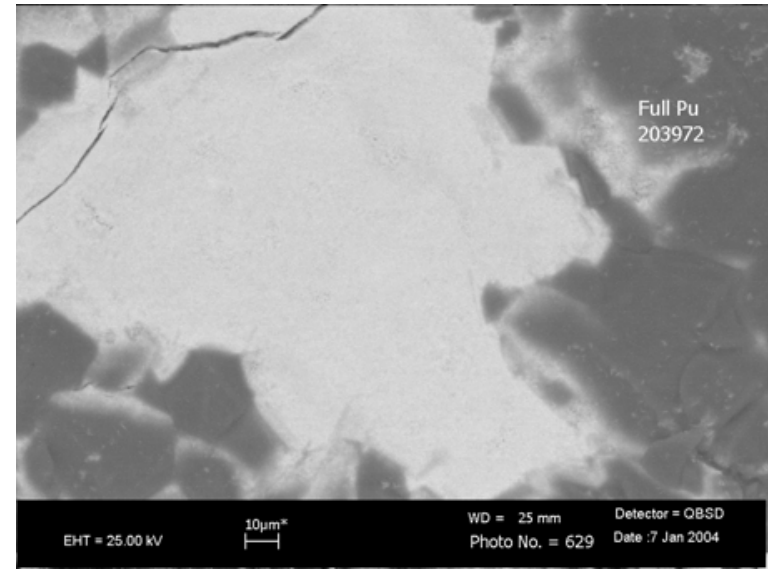

(a) $500 \mathrm{X}$ QBSD

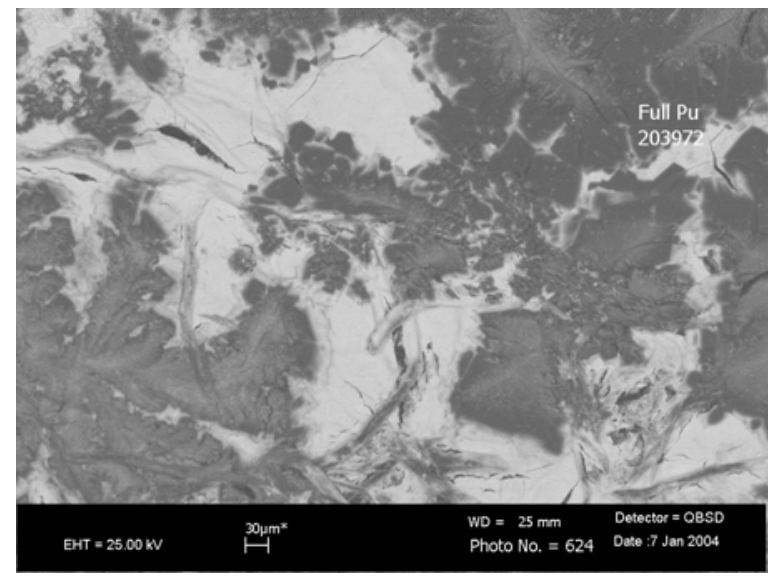

(c) 16X QBSD

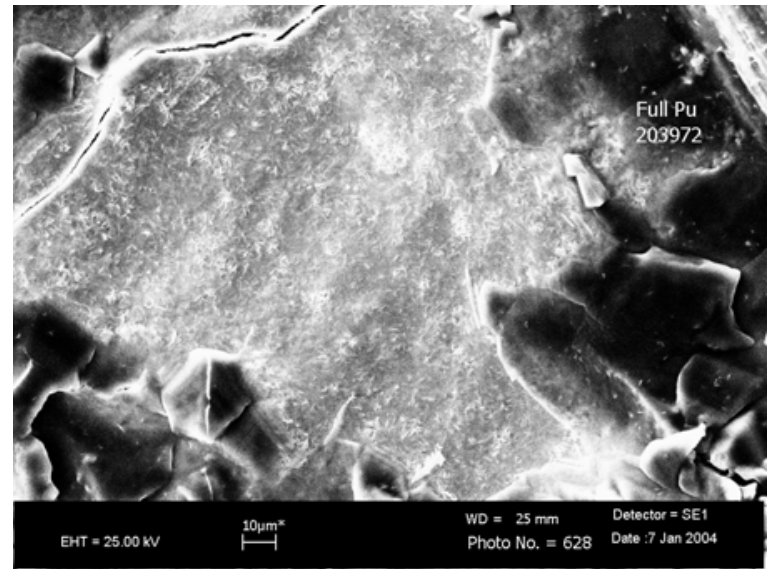

(b) $500 \mathrm{X} \mathrm{SE}$

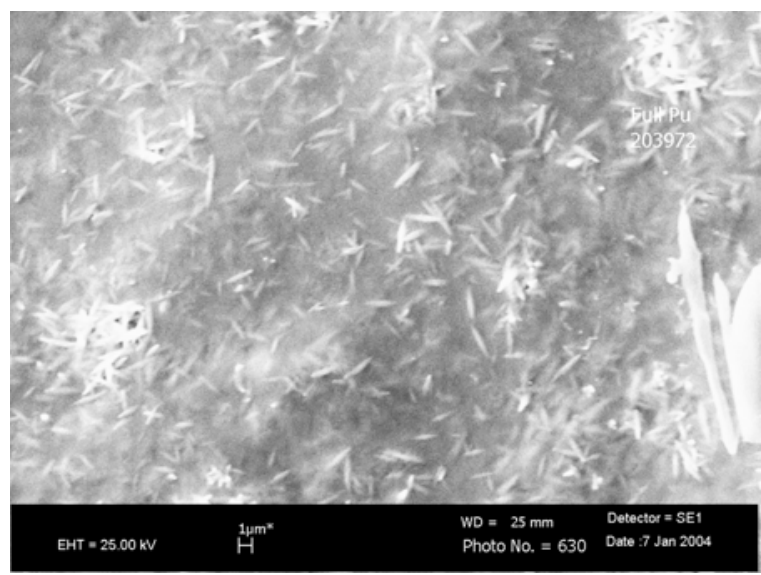

(d) 2000X SE 


\section{This page was intentionally left blank.}


Figure 4 SEM Micrographs of Solids from Partially Neutralized U/Gd Solution

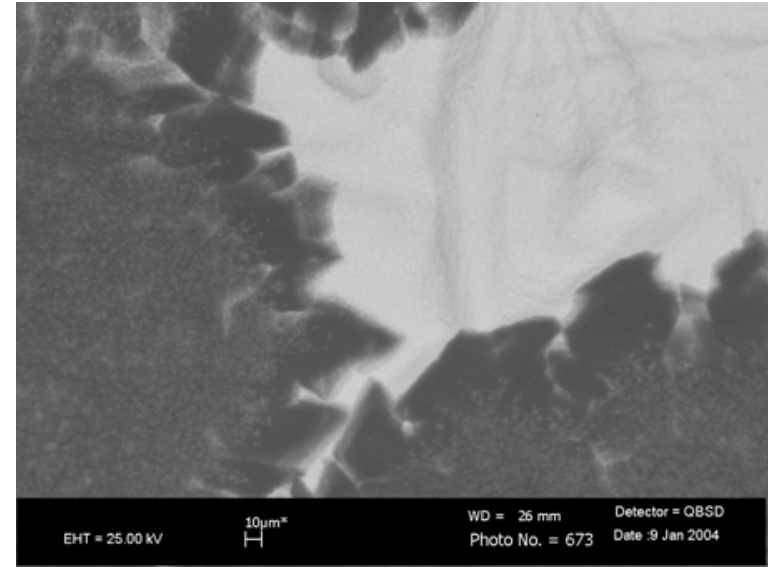

(a) 250X QBSD

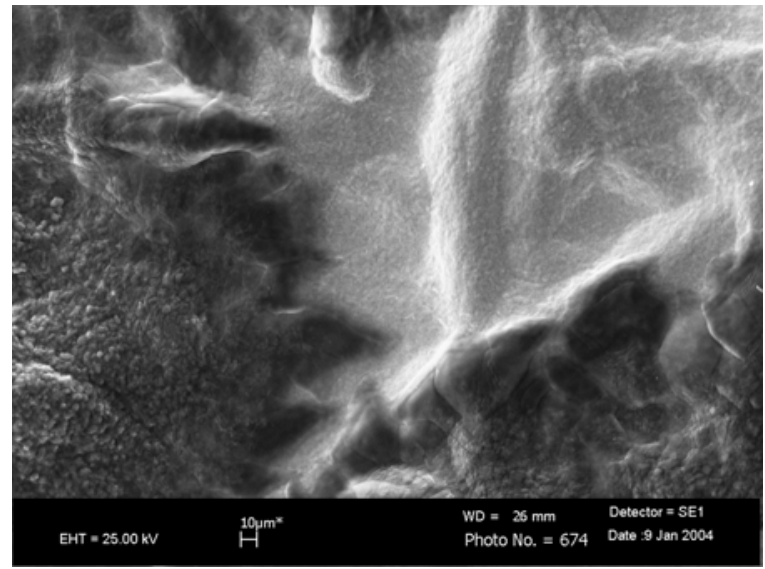

(b) 250X SE

Figure 5 SEM Micrographs of Solids from Partially Neutralized U/Pu/Gd Solution

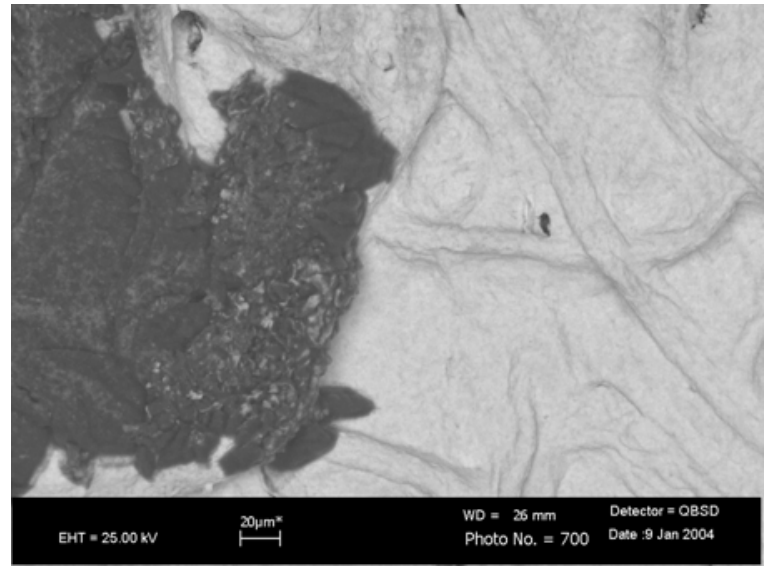

(a) 300X QBSD

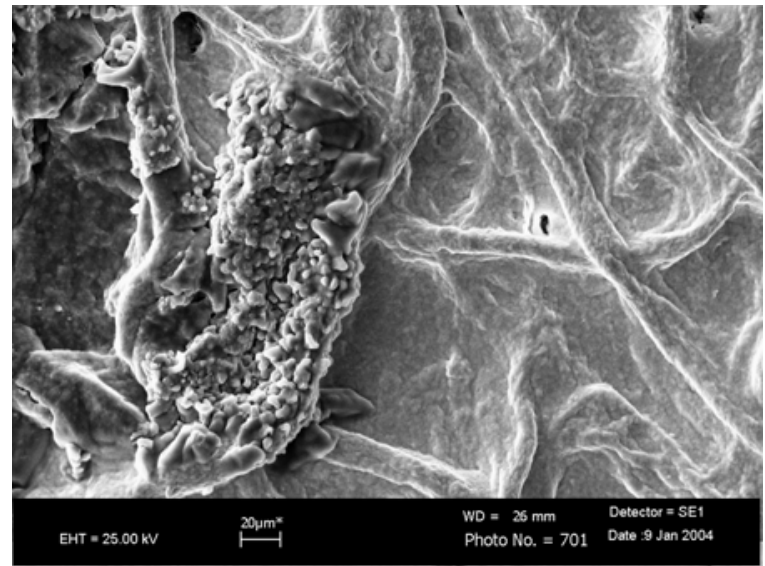

(b) $300 \mathrm{X} \mathrm{SE}$ 


\section{This page was intentionally left blank.}


Figure 6 Representative EDS for Solids from Fully Neutralized U/Pu/Gd Solution
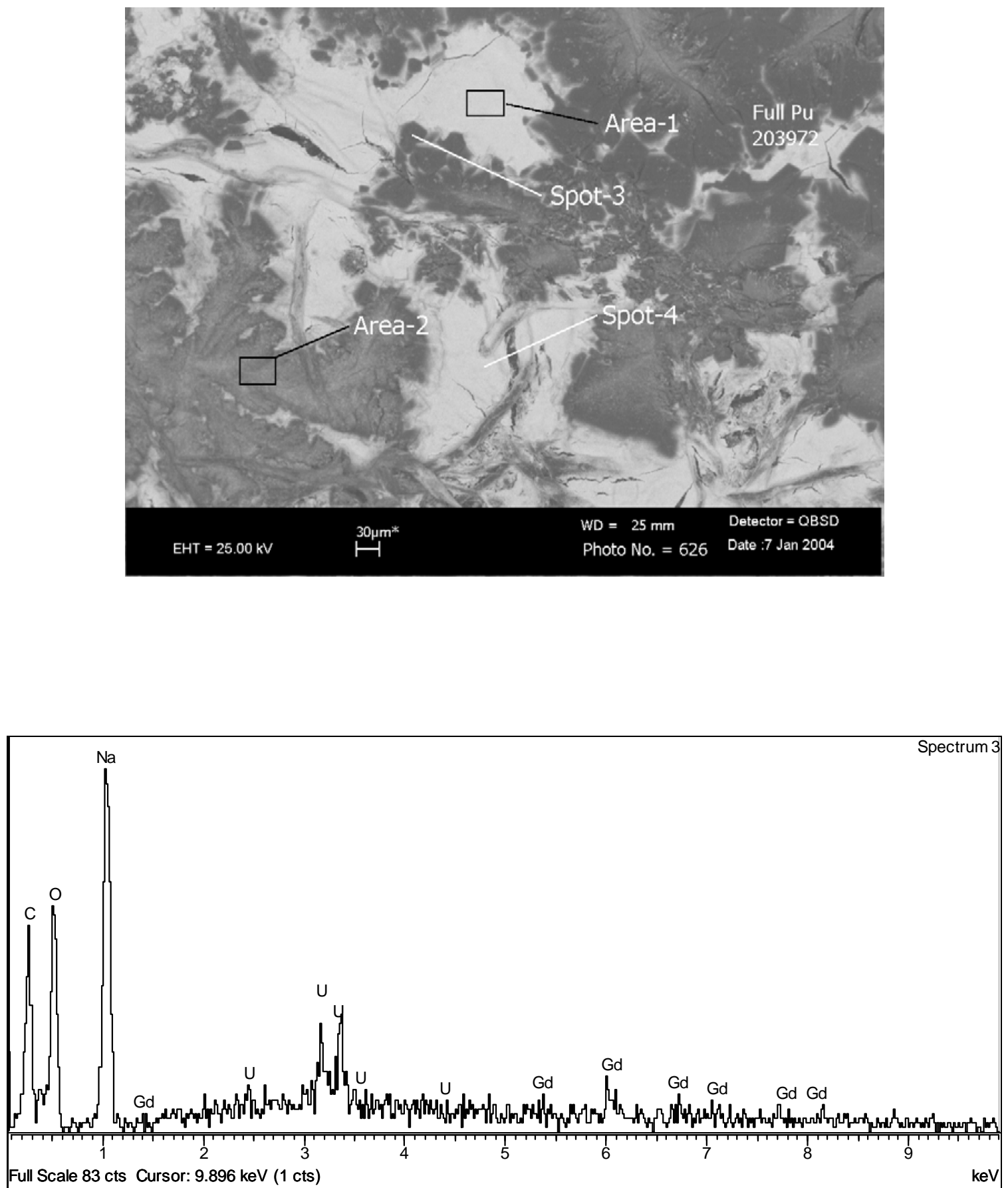

(a) U/Pu/Gd Dark Solids (Spot 3, Photo No. 626) 


\section{This page was intentionally left blank.}


Figure 6 Continued

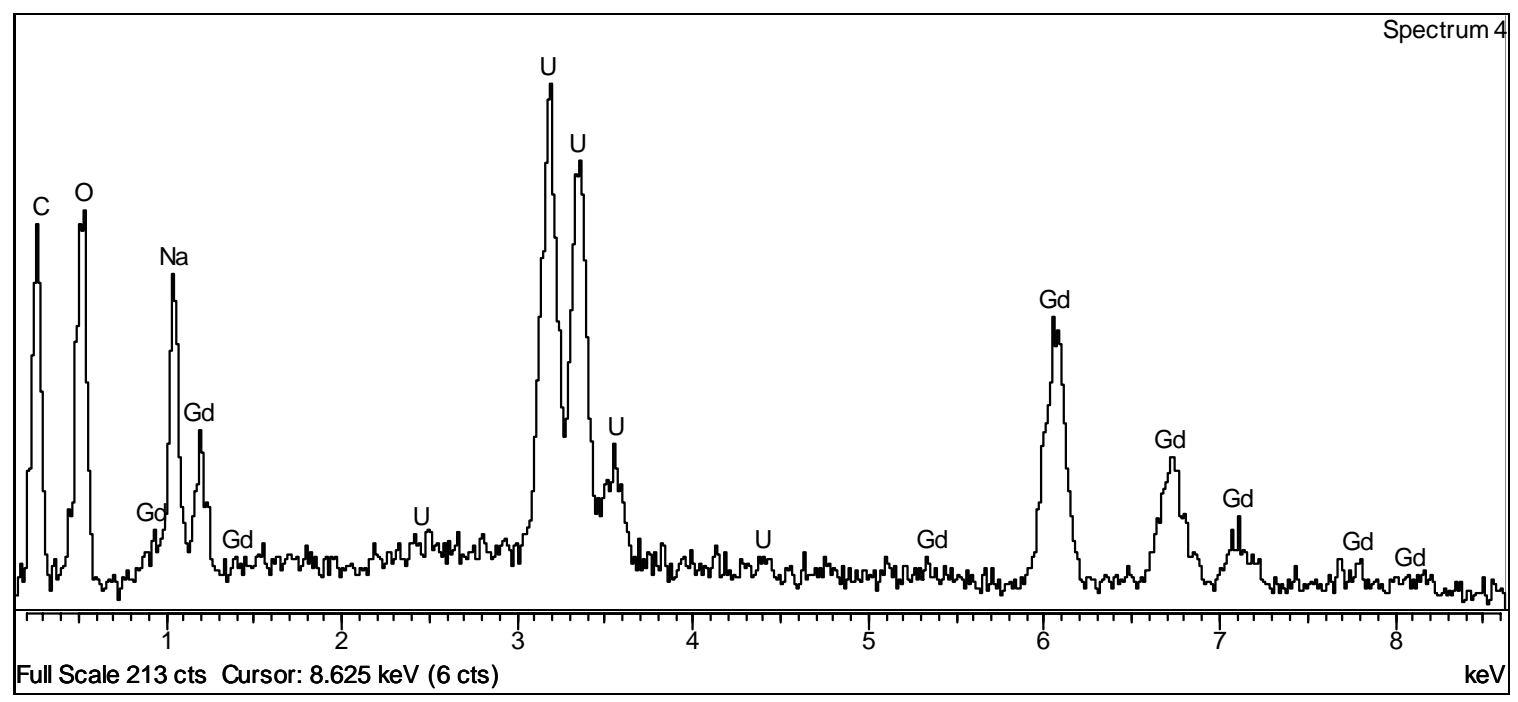

(b) U/Pu/Gd Light Solids (Spot 4, Photo No. 626) 


\section{This page was intentionally left blank.}


Figure 6 Continued
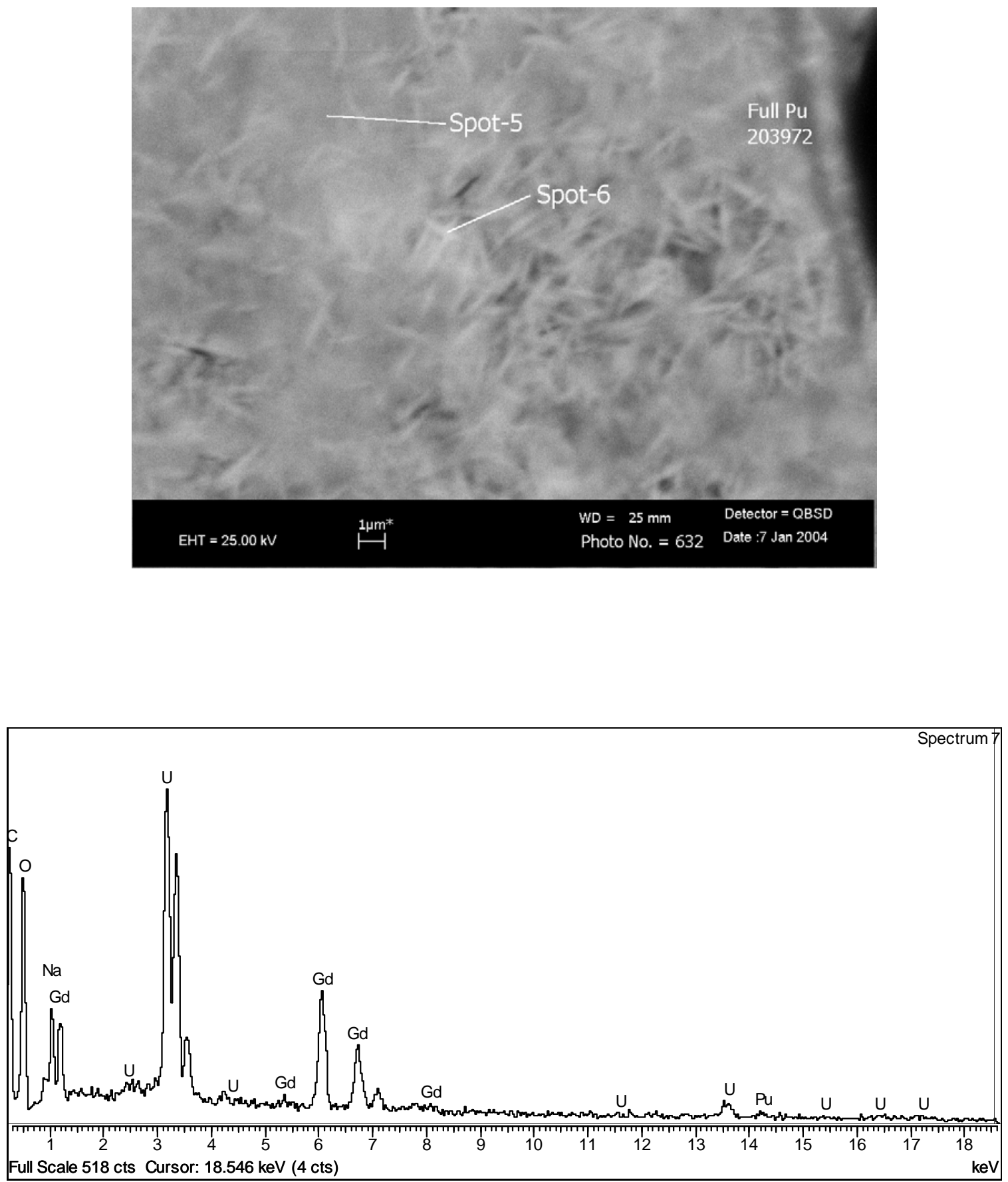

(c) U/Pu/Gd 3 micron Needle-like Crystals (Spot 6, Photo No. 632) 


\section{This page was intentionally left blank.}


Figure 7 Representative EDS for Solids from Fully Neutralized U/Gd Solution
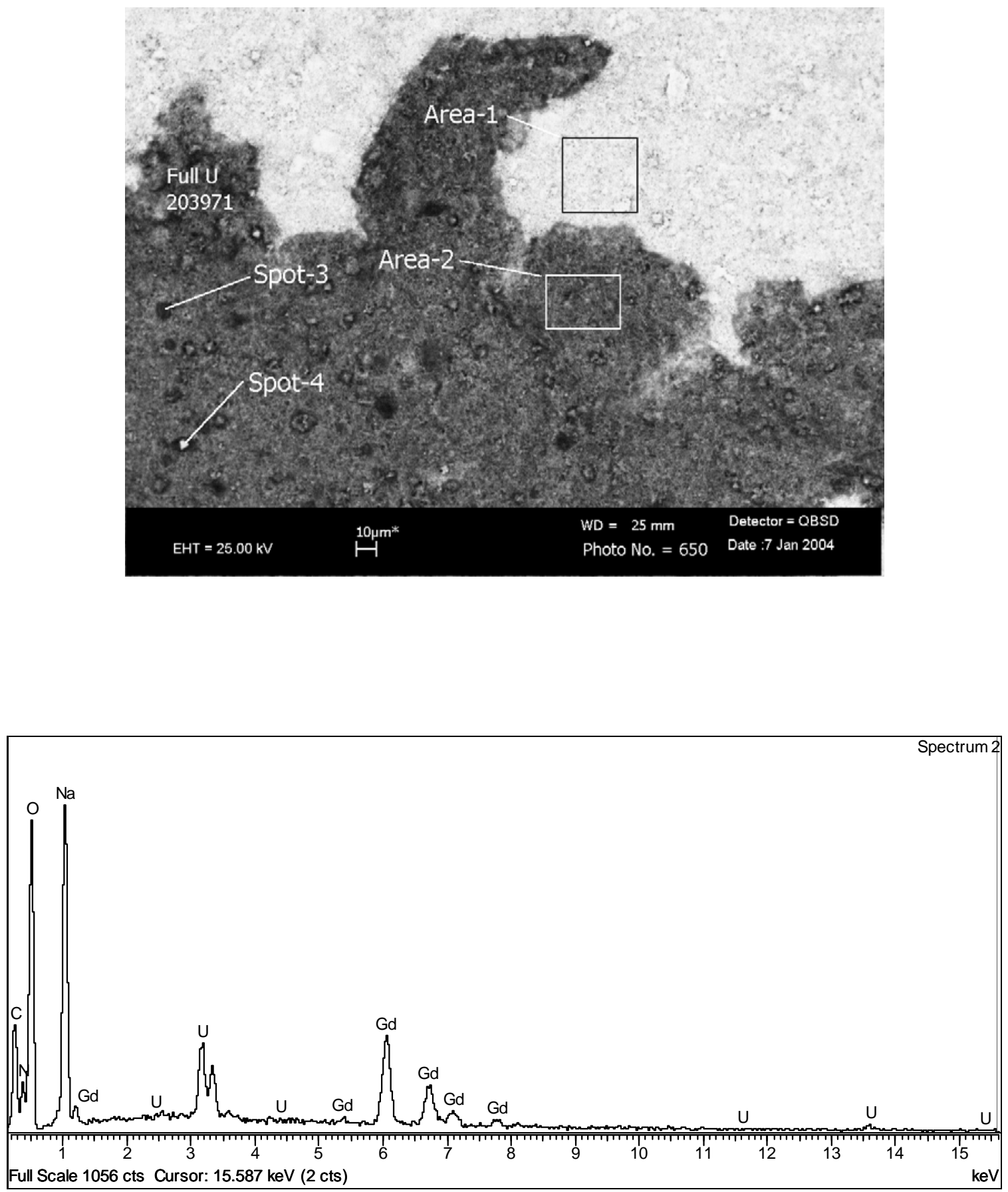

(a) U/Gd Dark Solids (Area 2, Photo No. 650) 


\section{This page was intentionally left blank.}


Figure 7 Continued

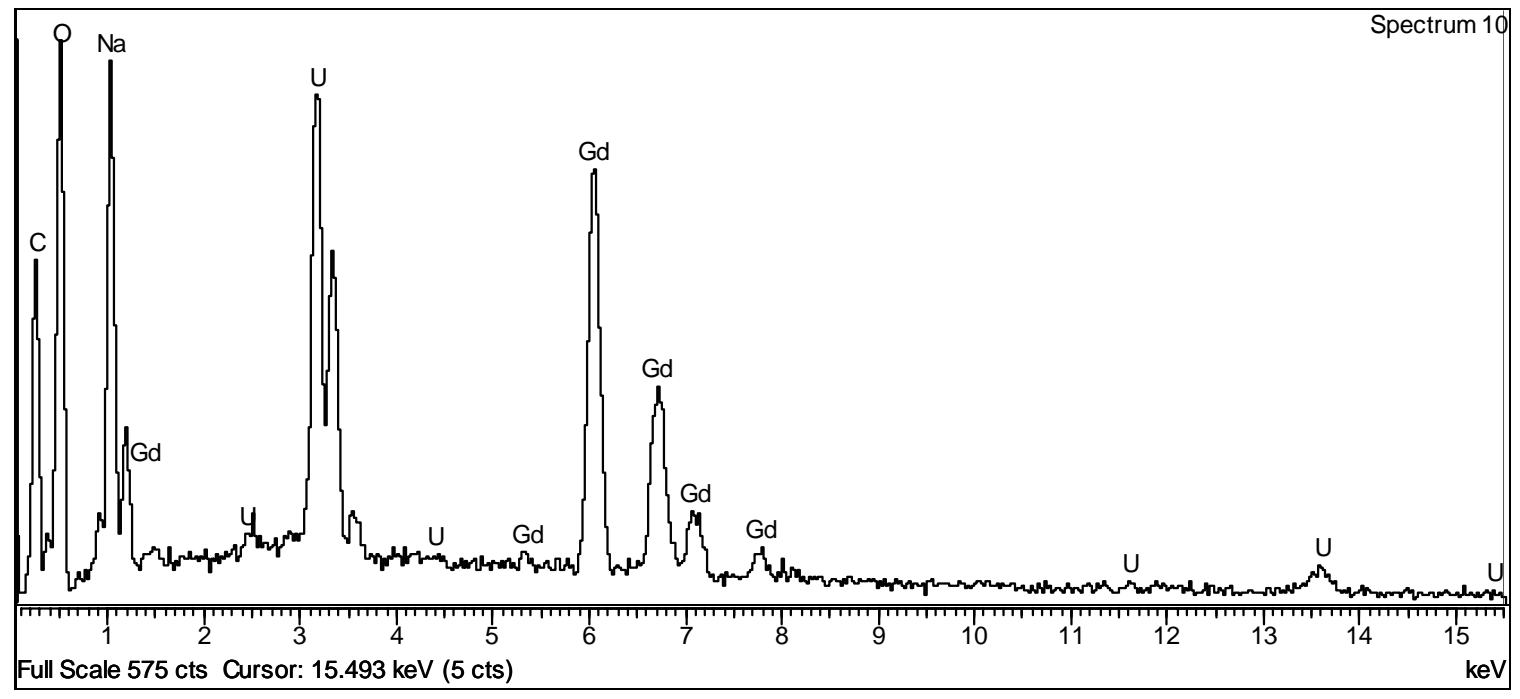

(b) U/Gd Light Solids (Area 1, Photo No. 650) 


\section{This page was intentionally left blank.}


Figure 7 Continued
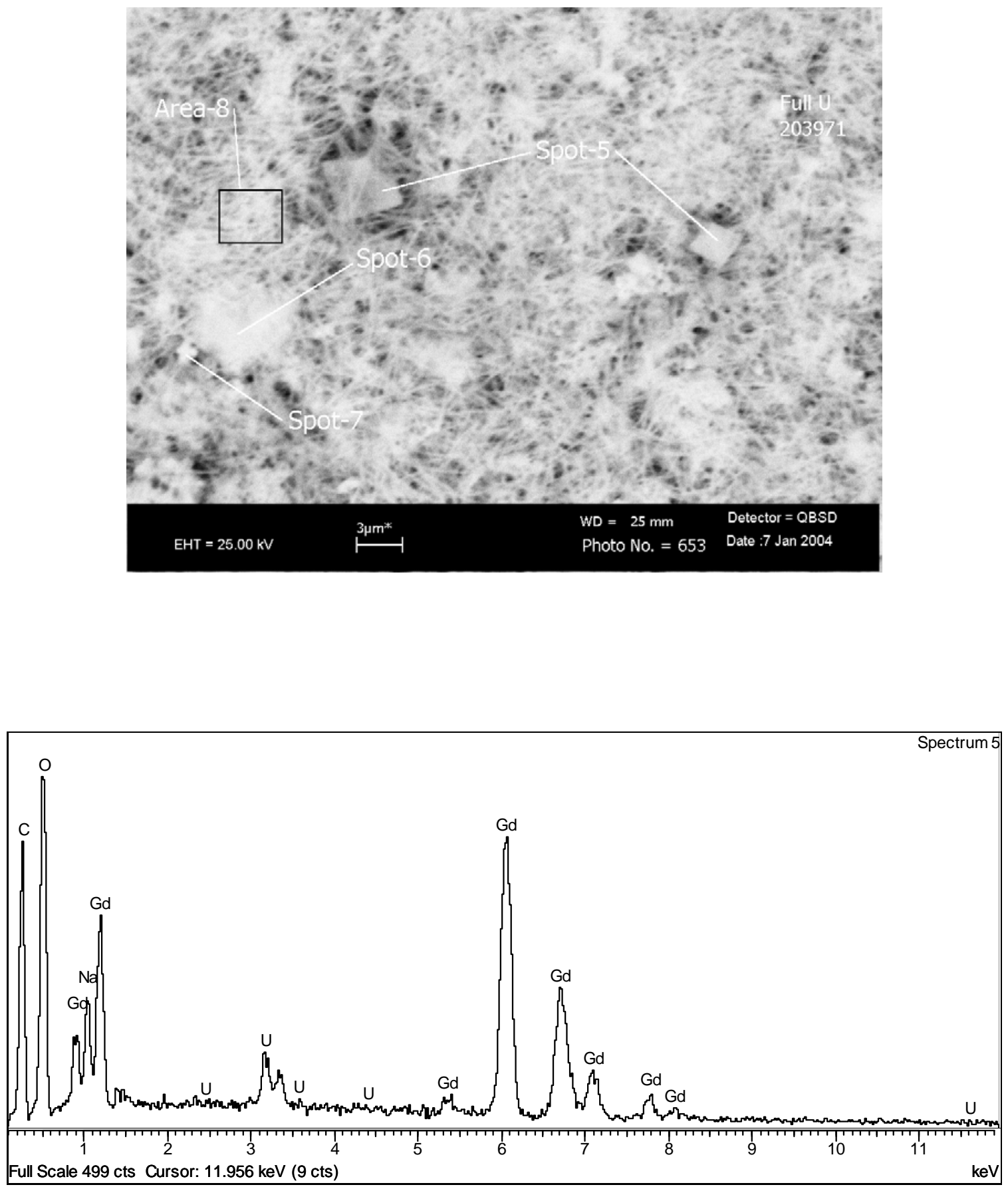

(c) U/Gd 3 micron Square Crystals (Spot 5, Photo No. 653) 


\section{This page was intentionally left blank.}


Figure 8 Representative EDS for Solids from Partially Neutralized U/Pu/Gd Solution
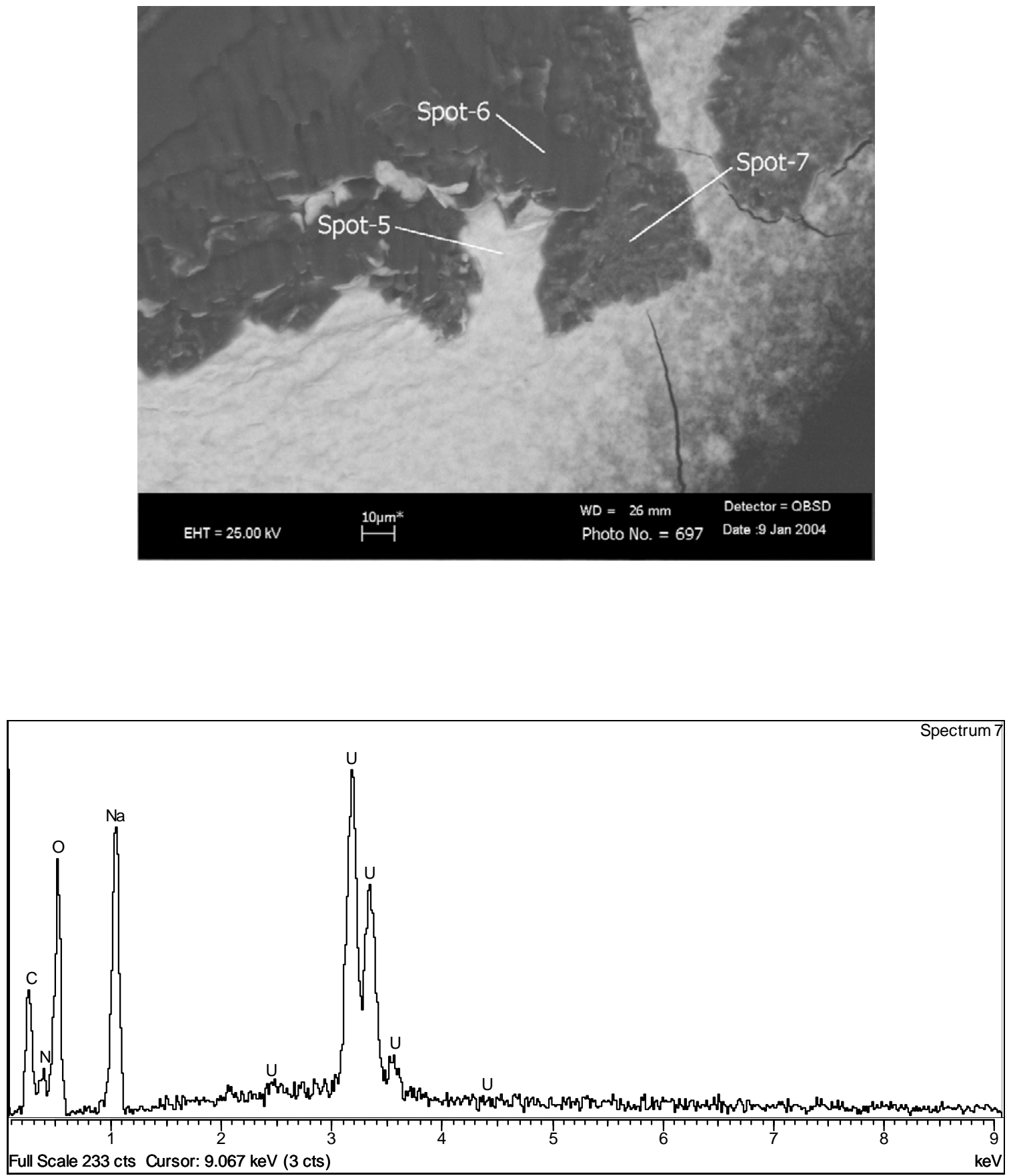

(a) $\mathrm{U} / \mathrm{Pu} / \mathrm{Gd}$ Dark Solids (Spot 7, Photo 697) 


\section{This page was intentionally left blank.}


Figure 8 Continued

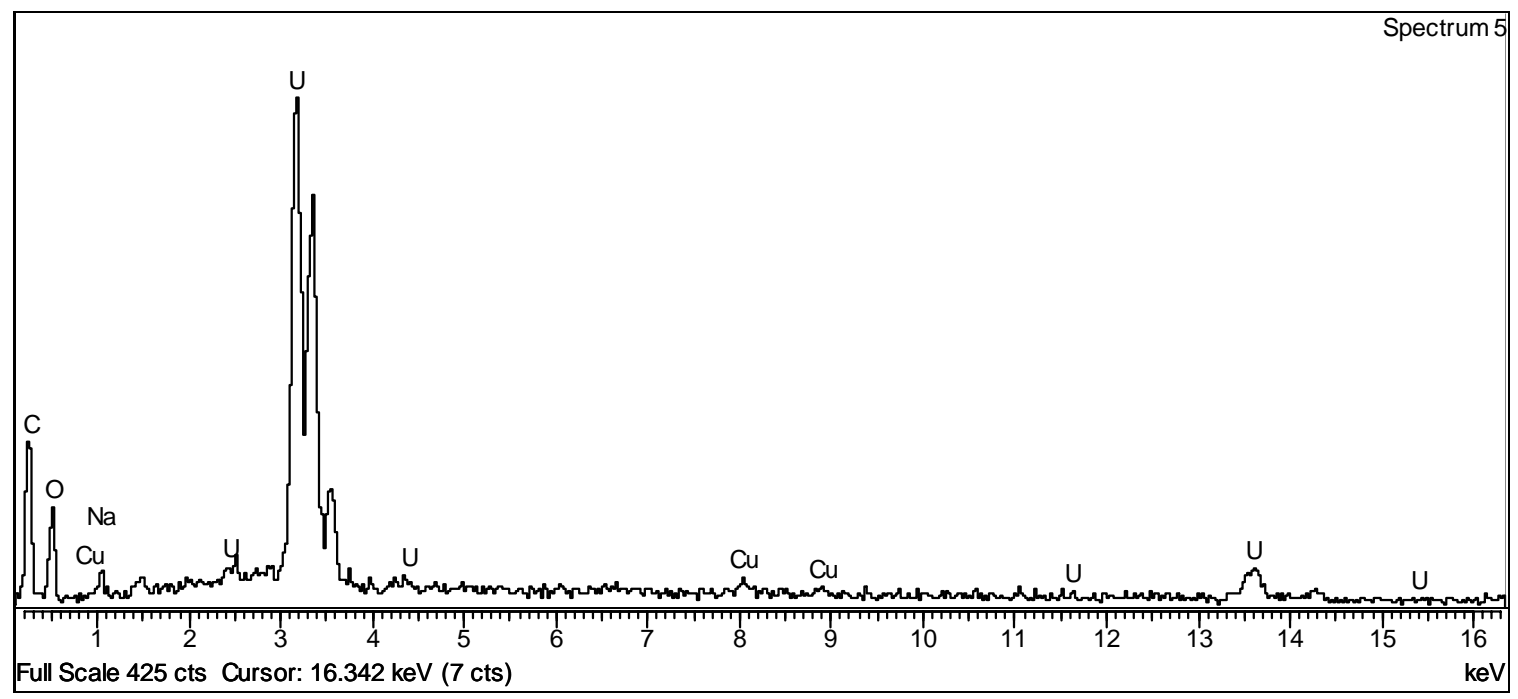

(b) U/Pu/Gd Light Solids (Spot 5, Photo No. 697)

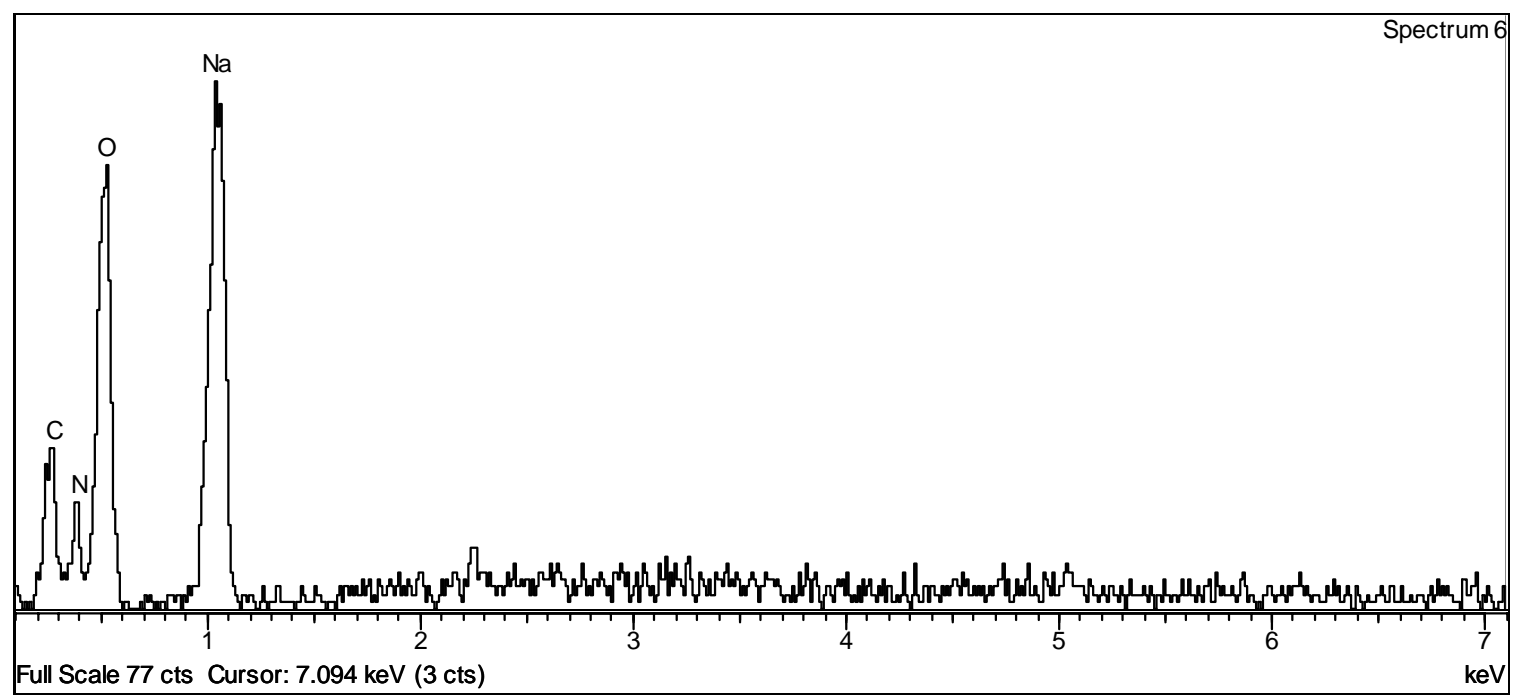

(c) U/Pu/Gd 3 micron Square Crystals (Spot 6, Photo 697) 


\section{This page was intentionally left blank.}


Figure 9 Representative EDS for Solids from Partially Neutralized U/Gd Solution
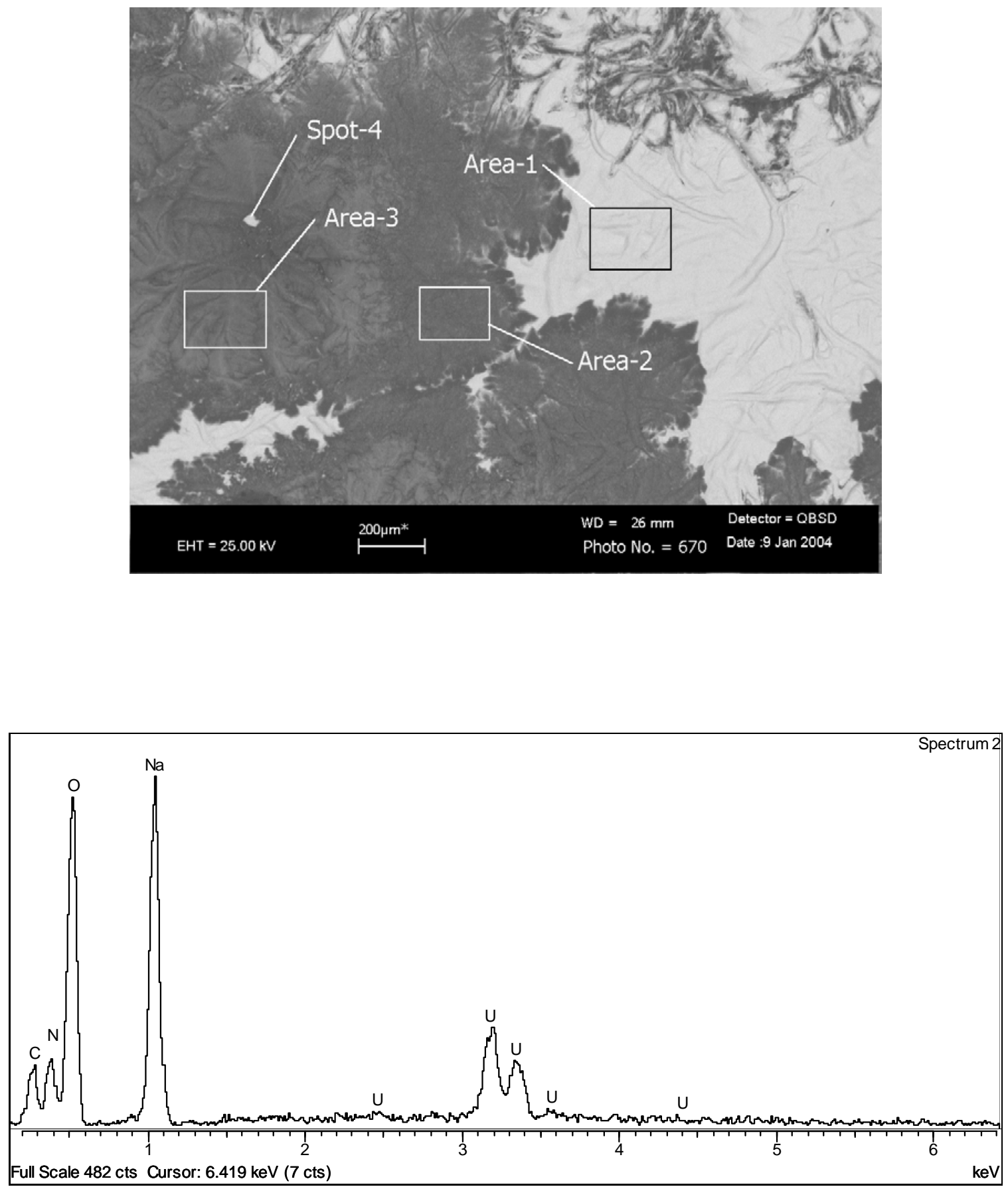

(a) U/Gd Dark Solids (Area 2, Photo No. 670) 


\section{This page was intentionally left blank.}


WSRC-TR-2004-00053

Revision 0

Figure 9 Continued

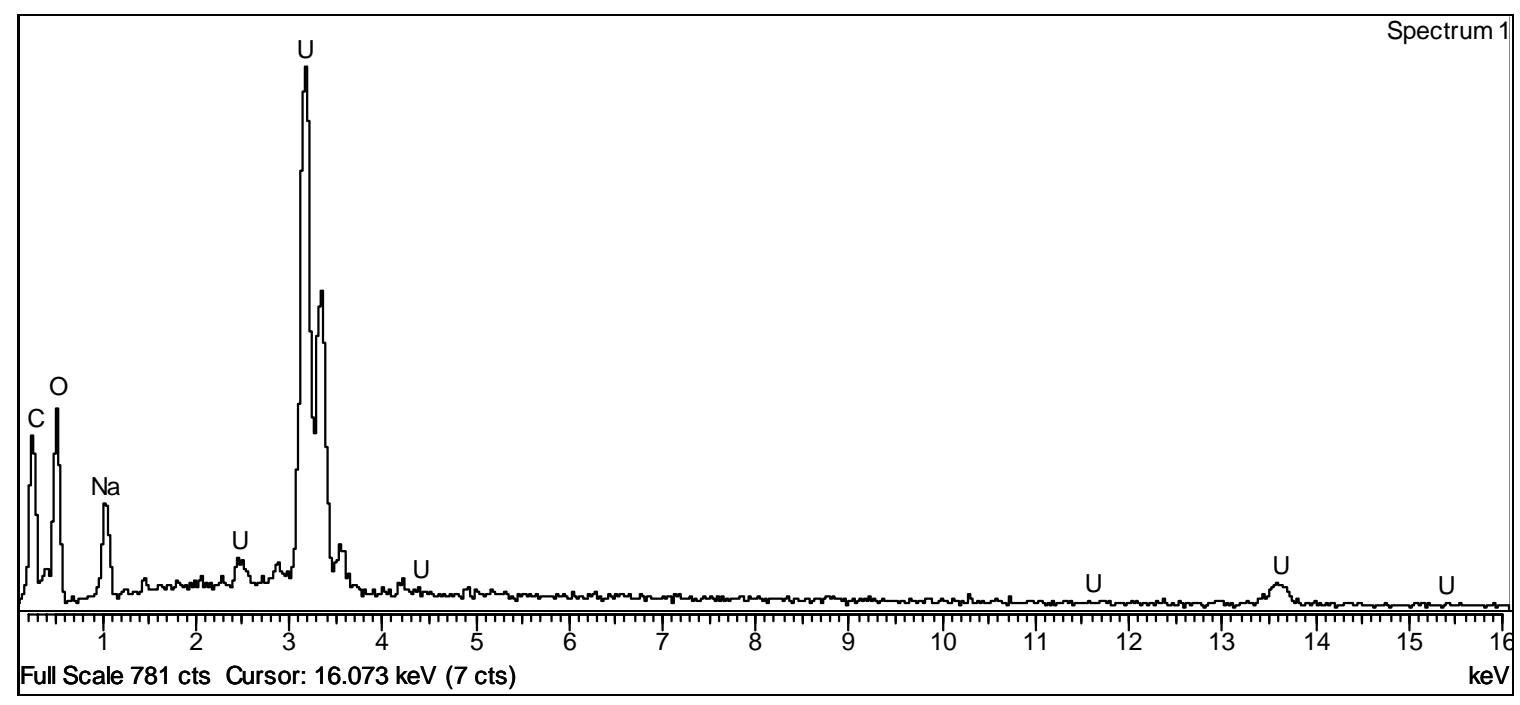

(b) U/Gd Light Solids (Area 1, Photo 670) 


\section{This page was intentionally left blank.}


Figure 10 XRD Spectra

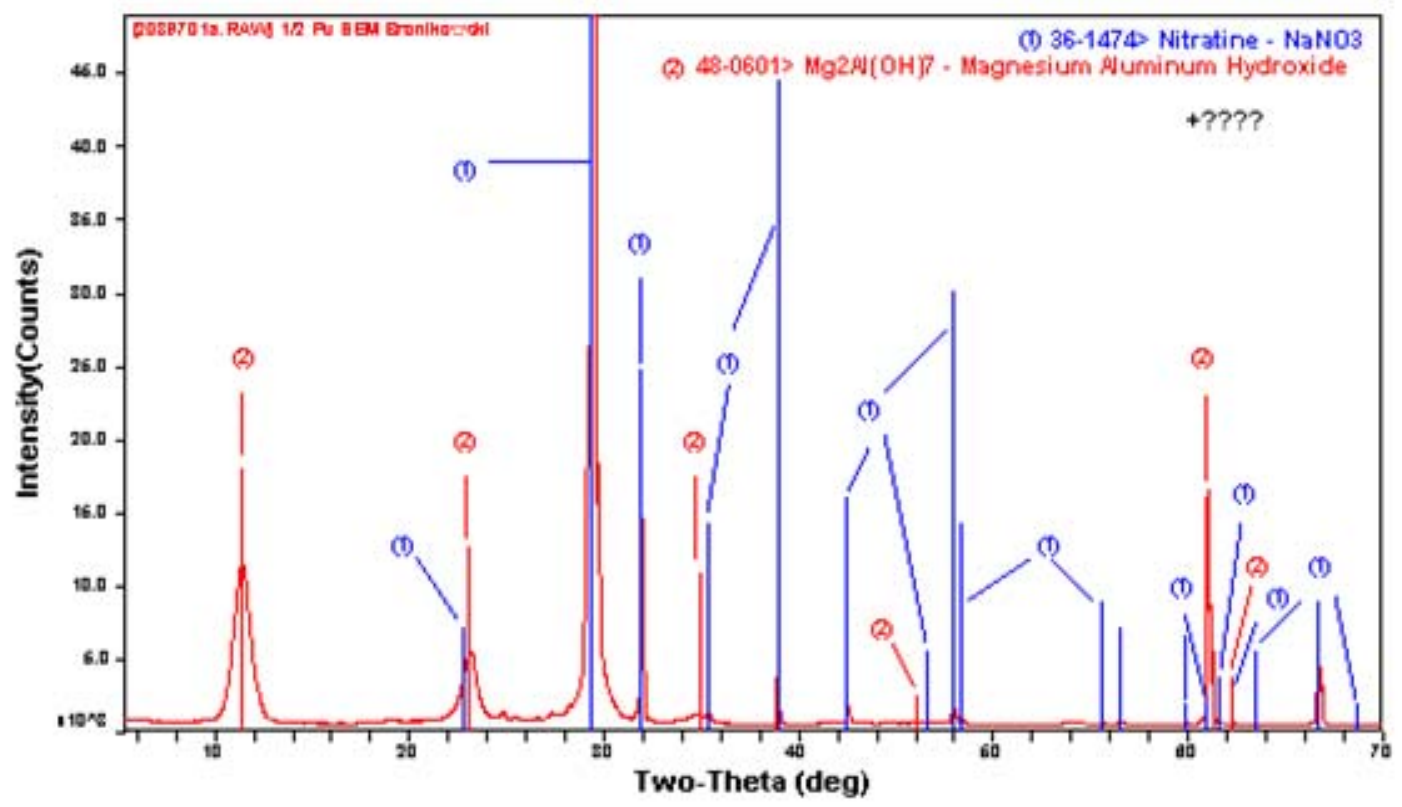

$\mathrm{U} / \mathrm{Pu} / \mathrm{Gd}$ Surrogate $-\mathrm{pH} 4.5$

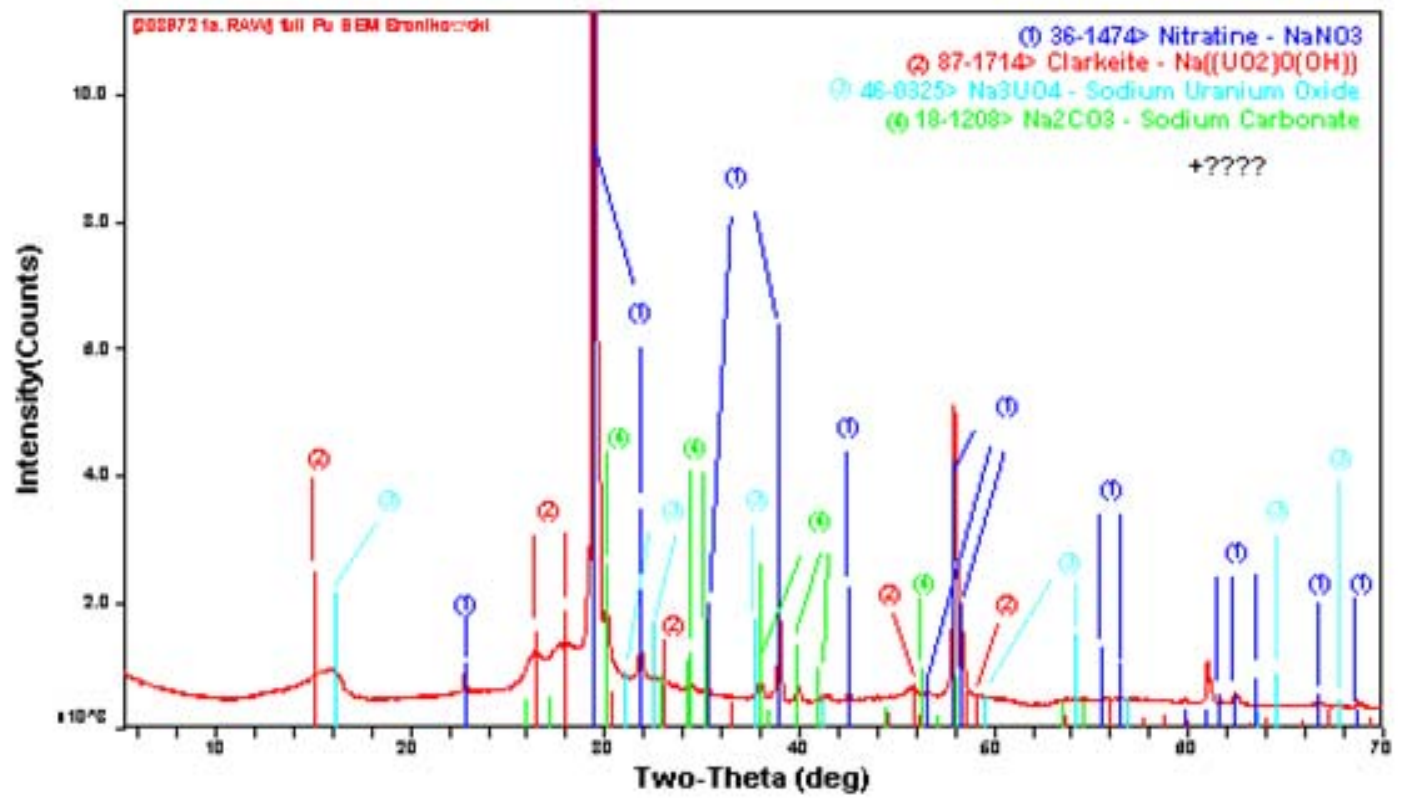

$\mathrm{U} / \mathrm{Pu} / \mathrm{Gd}$ Surrogate - 1.2M Excess $\mathrm{OH}^{-}$ 


\section{This page was intentionally left blank.}


Figure 10 Continued

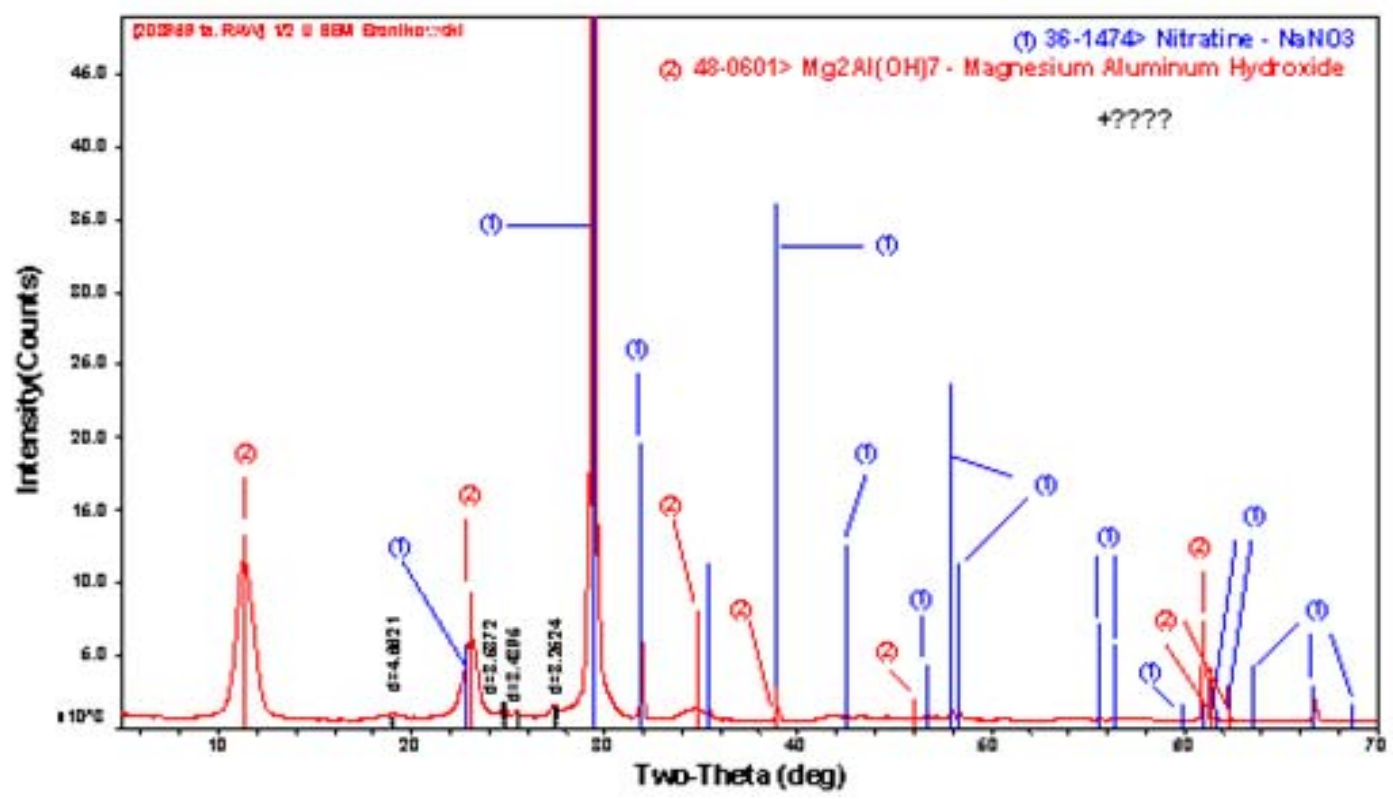

U/Gd Surrogate - pH 4.5

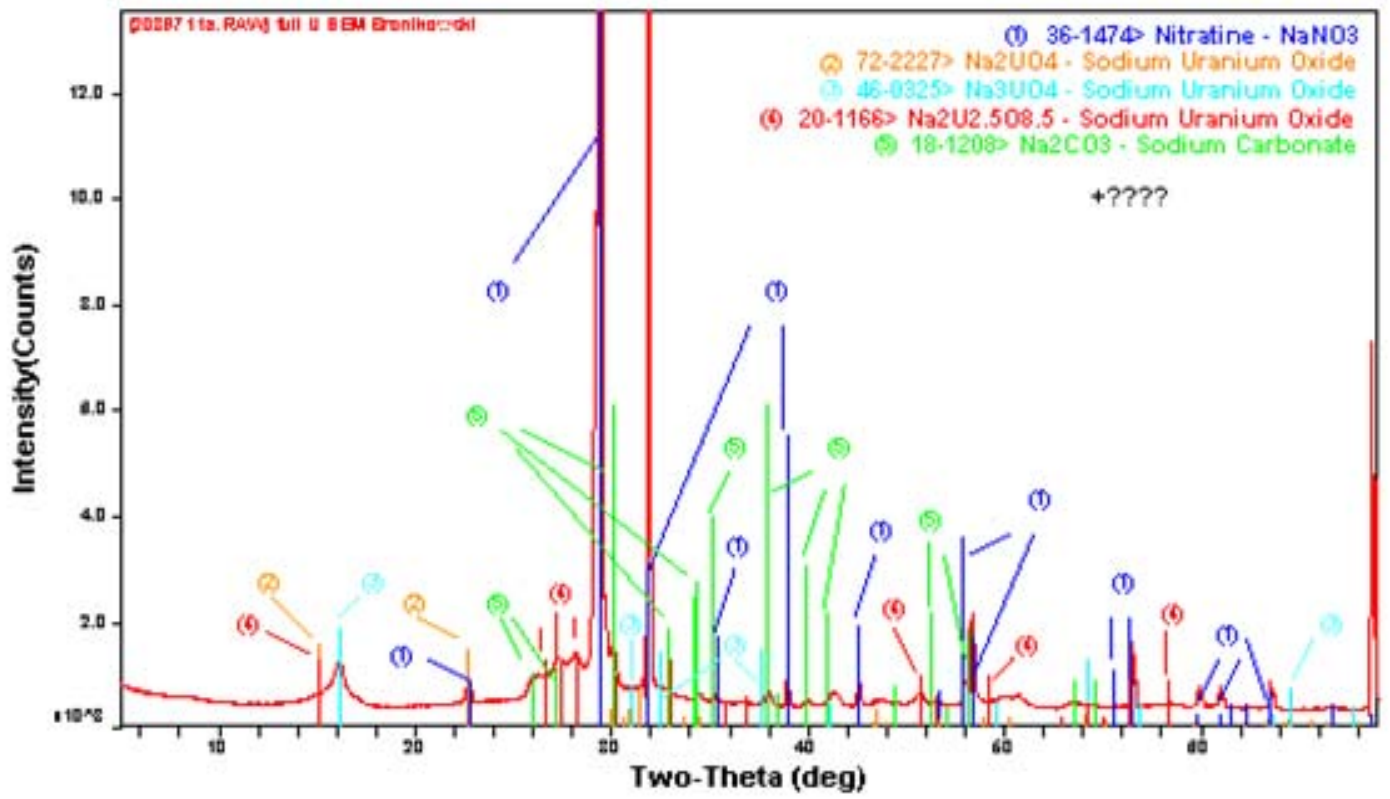

U/Gd Surrogate - 1.2M Excess $\mathrm{OH}^{-}$ 


\section{This page was intentionally left blank.}


Figure 11 Settling Rate of Neutralized Solutions

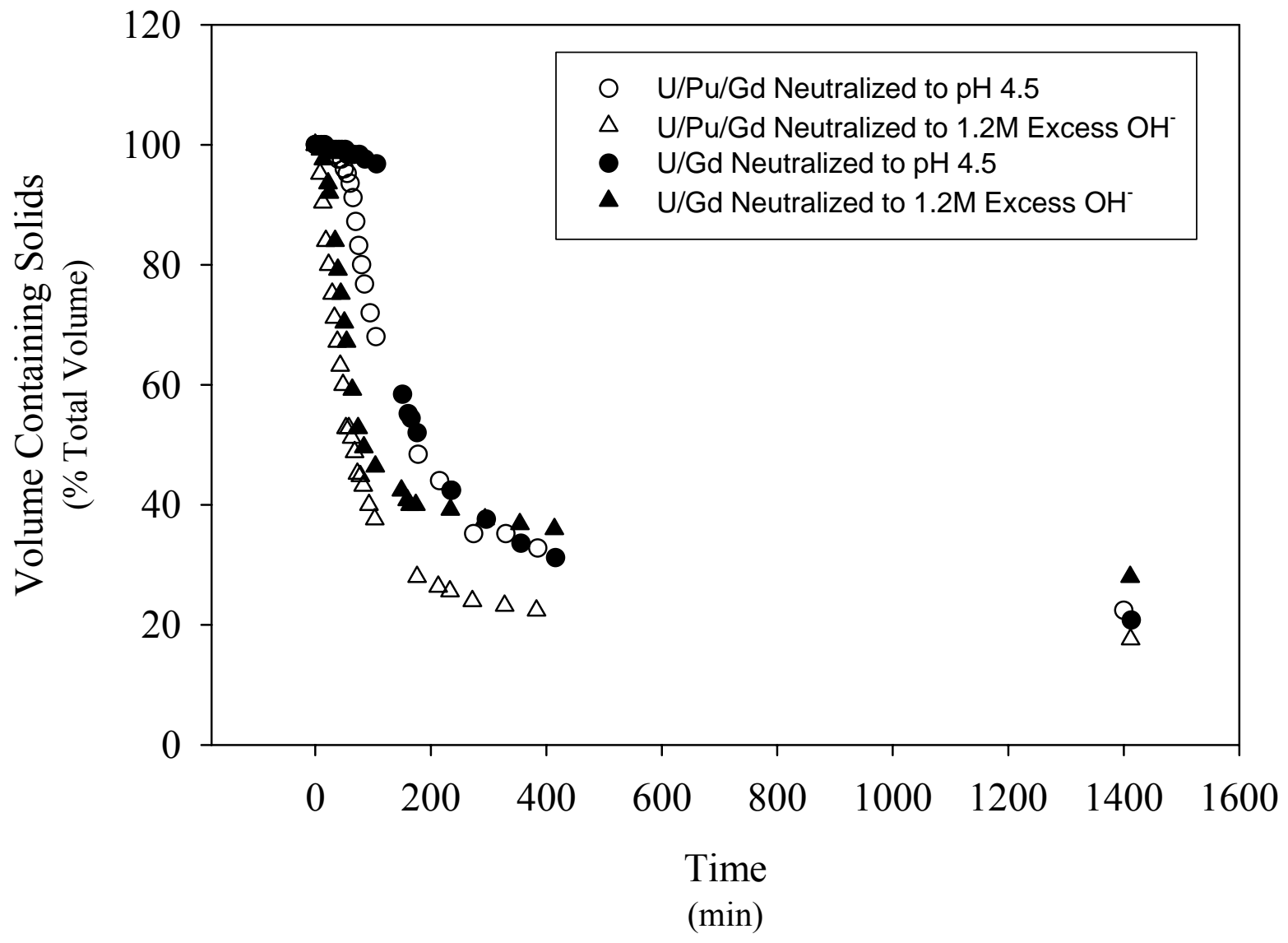




\section{This page was intentionally left blank.}


Figure 12 Particle Size Distribution of Precipitated Solids

$$
\square U-P u-G d(1.2 \mathrm{M}) \text { 口U-Pu-Gd (pH 4.5) }
$$

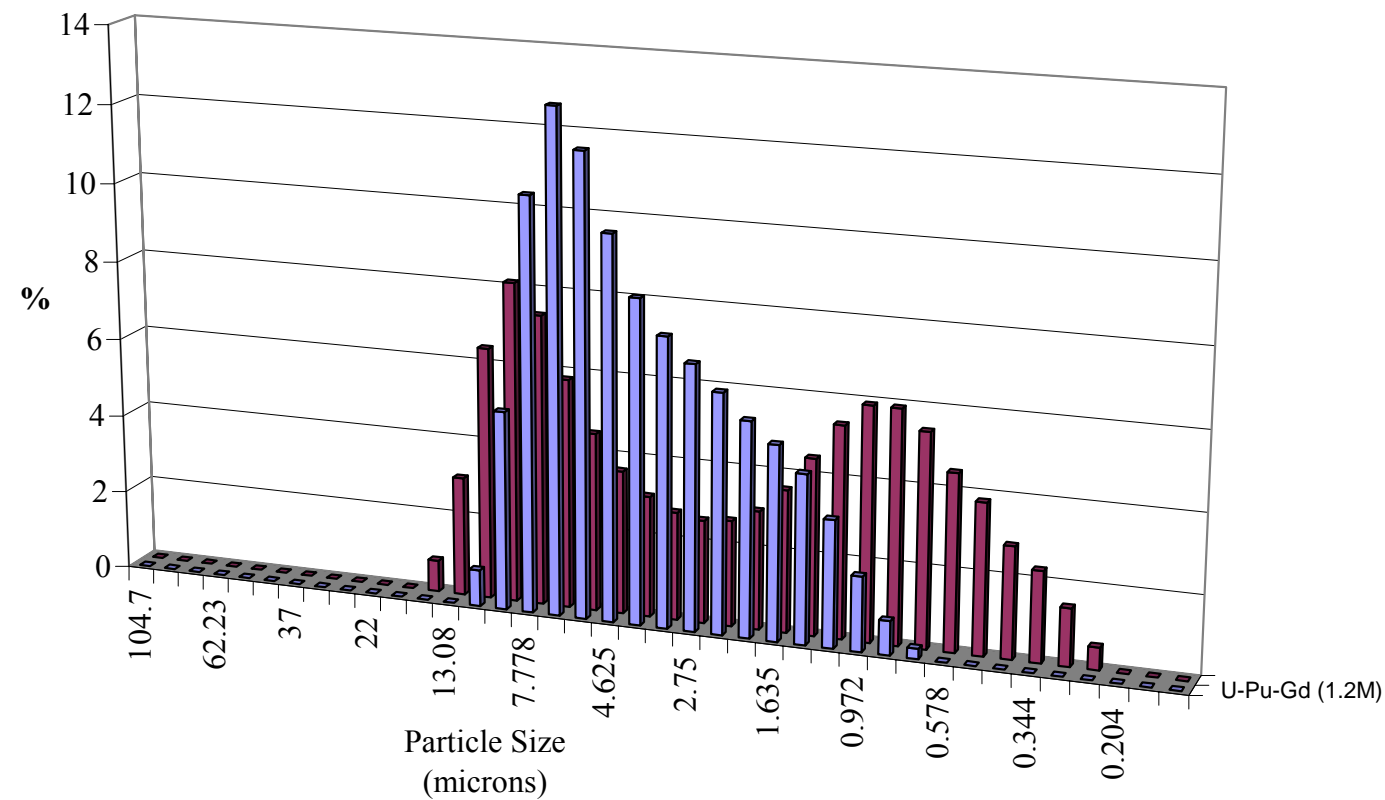

$\square U-P u-G d(1.2 M) \square U-G d(1.2 M)$

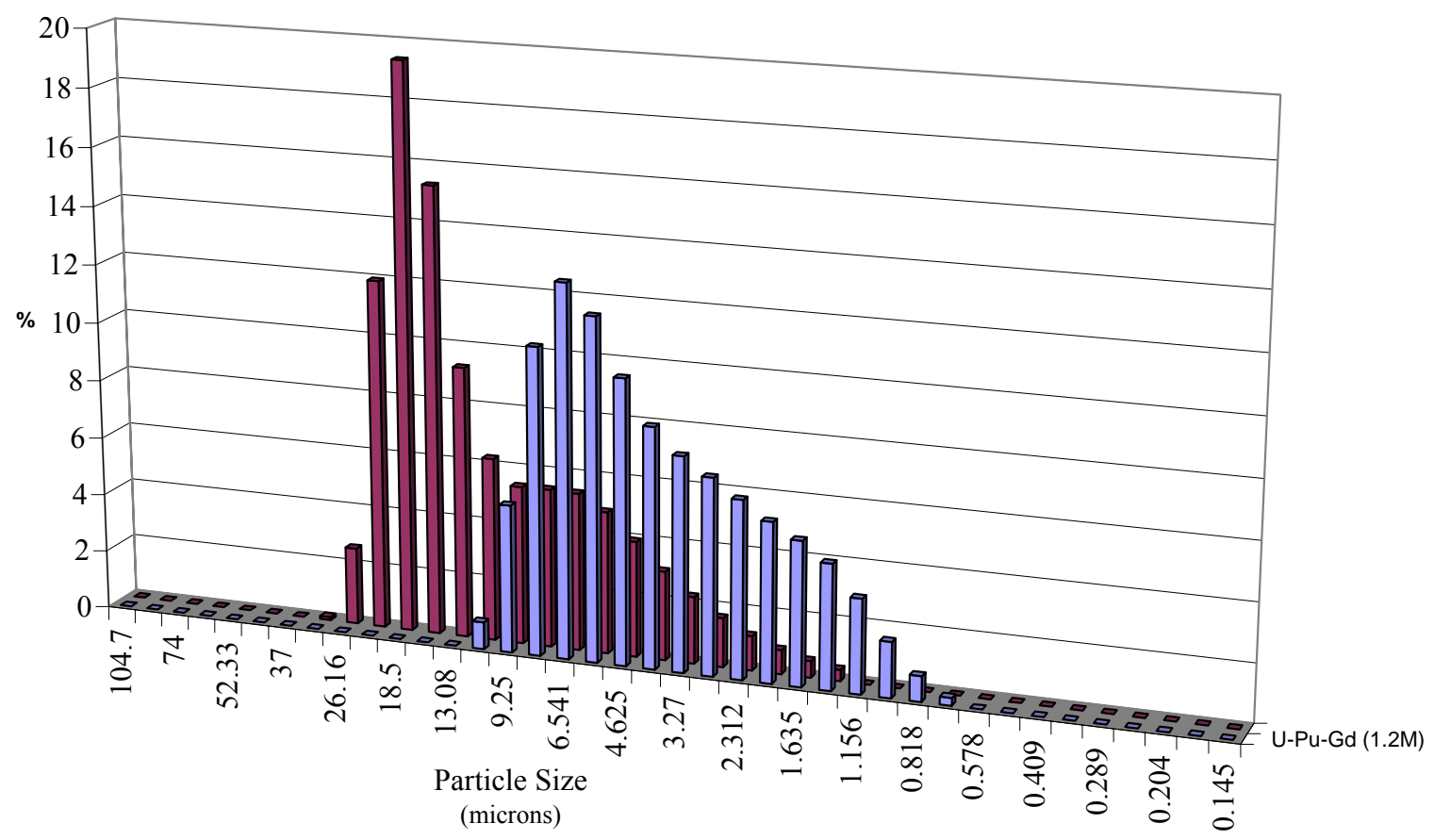




\section{This page was intentionally left blank.}


Figure 13 Percent of Precipitated Solids of Increasing Size
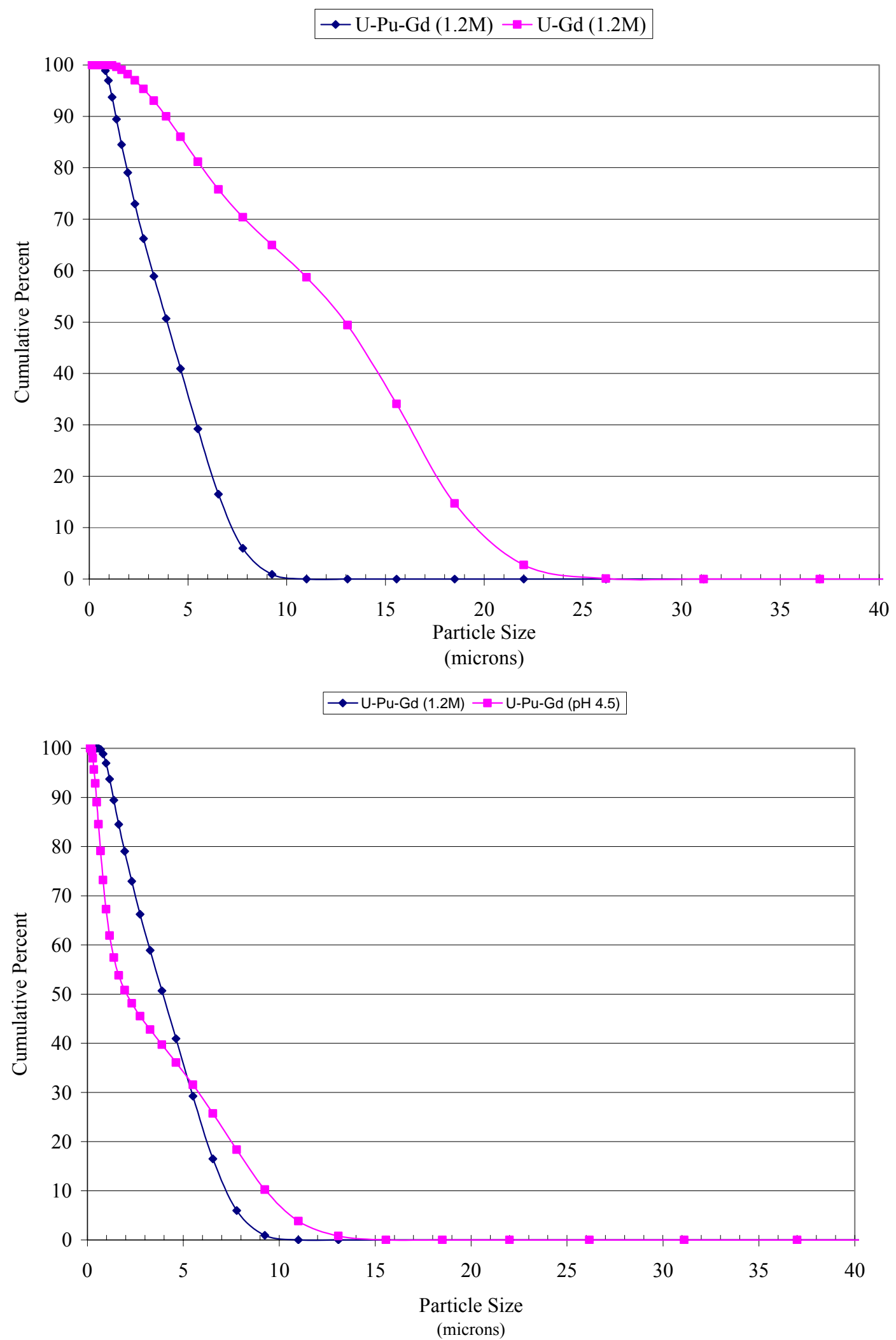


\section{This page was intentionally left blank.}


Figure 14 Thermogravimetric Analyses of Precipitate Solids

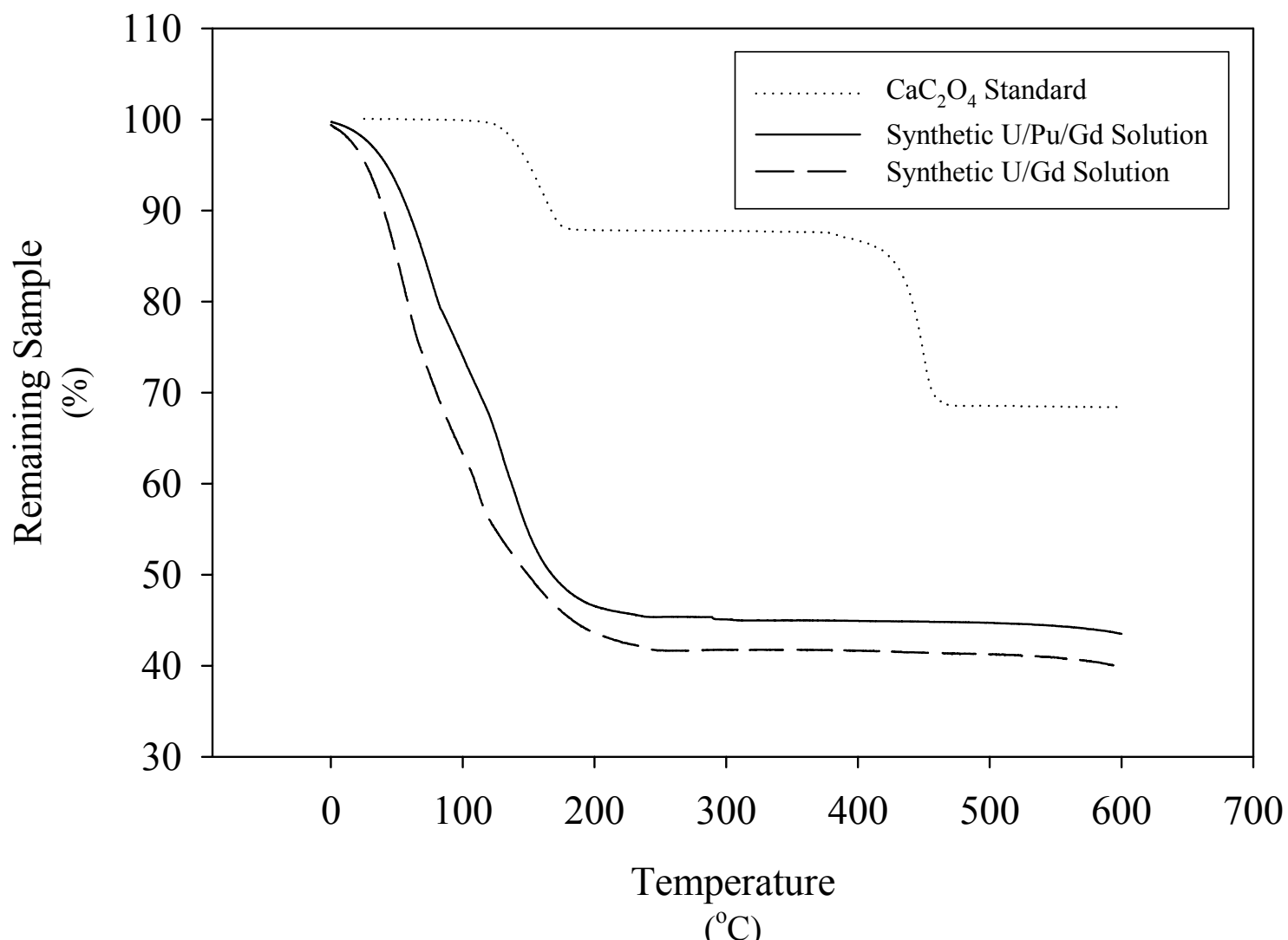

\begin{tabular}{cccc}
\hline \hline $\begin{array}{c}\text { Neutralized } \\
\text { Solution }\end{array}$ & $\begin{array}{c}\text { Initial } \\
\text { Solid Mass } \\
(\mathrm{mg})\end{array}$ & $\begin{array}{c}\text { Solid Mass } \\
\text { at } 250^{\circ} \mathrm{C} \\
(\%)\end{array}$ & $\begin{array}{c}\text { Water } \\
\text { Lost } \\
(\mathrm{mmoles})\end{array}$ \\
\hline $\mathrm{U} / \mathrm{Pu} / \mathrm{Gd}, \mathrm{pH} \mathrm{4.5}$ & 29.51 & 48.47 & 0.845 \\
$\mathrm{U} / \mathrm{Pu} / \mathrm{Gd}, 1.2 \mathrm{M} \mathrm{OH}^{-}$ & 27.53 & 45.35 & 0.836 \\
$\mathrm{U} / \mathrm{Gd}, \mathrm{pH} \mathrm{4.5}$ & 28.80 & 53.95 & 0.737 \\
$\mathrm{U} / \mathrm{Gd}, 1.2 \mathrm{M} \mathrm{OH}^{-}$ & 17.86 & 41.69 & 0.579 \\
\hline
\end{tabular}




\section{This page was intentionally left blank.}


Figure 15 Effect of $\mathrm{H}$ on the Safe Gd:Pu Ratio [1]

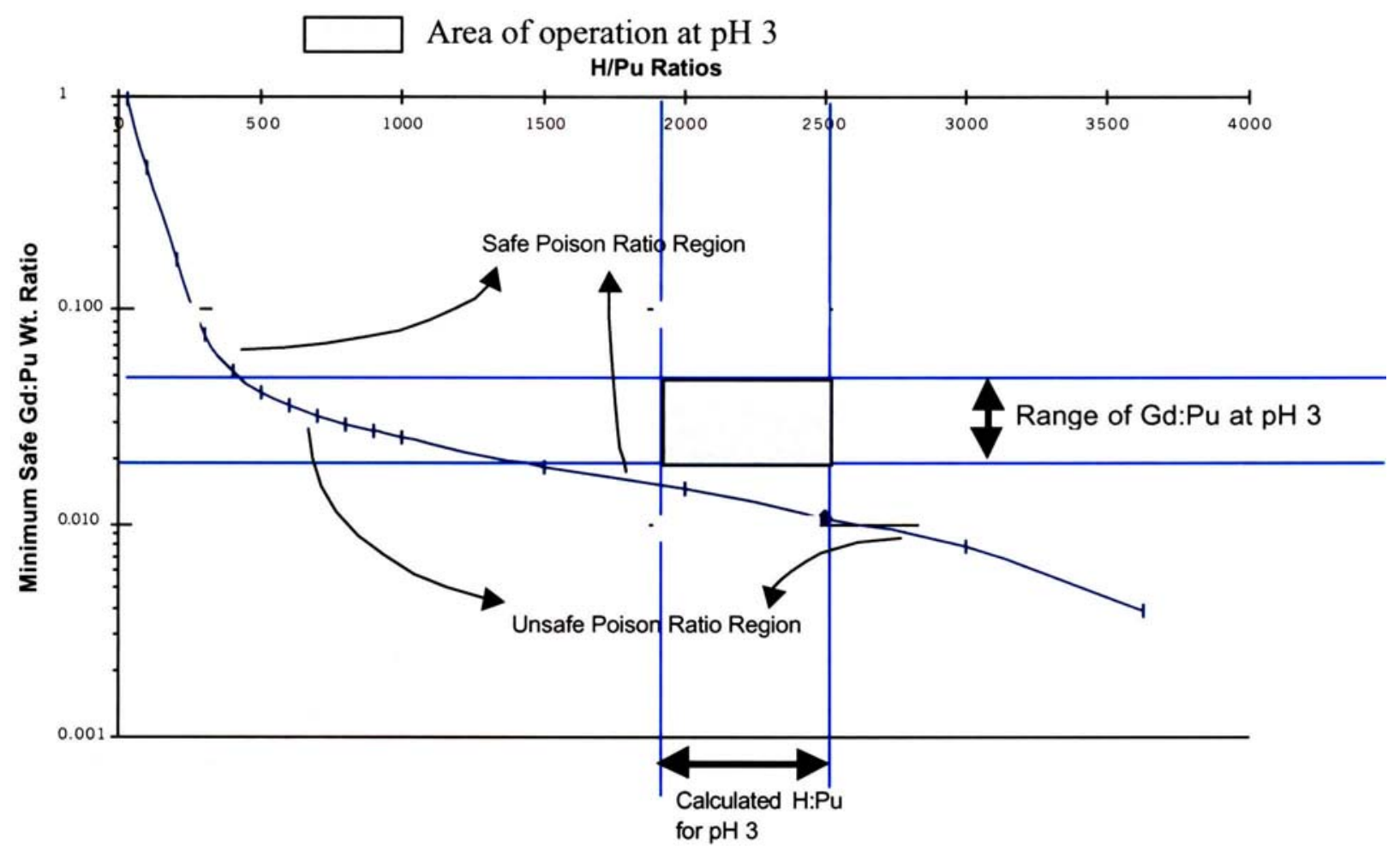




\section{This page was intentionally left blank.}




\section{Appendix A Procedure to Measure Water Content of Settled Solids}

The water content of the settled solids produced during each neutralization was measured using the following procedure.

1. Measure the mass of the an empty $25 \mathrm{~mL}$ graduated cylinder.

2. While stirring, transfer $25 \mathrm{~mL}$ of the supernate and solids to the graduated cylinder and measure the mass.

3. Allow the solids to settle for at least 24 hours.

4. Measure the mass of two $100 \mathrm{~mL}$ beakers.

5. Record the volume of supernate above the solids.

6. Transfer a majority of the supernate to one of the $100 \mathrm{~mL}$ beaker leaving $1-2 \mathrm{~mL}$ of supernate above the solids to ensure no solids are transferred to the beaker.

7. Measure the mass of the beaker and supernate removed from the graduated cylinder.

8. Record the volume of supernate left above the solids.

9. Measure the mass of the graduated cylinder and contents.

10. Pour the remaining supernate and solids into the second $100 \mathrm{~mL}$ beaker.

11. Rinse any remaining solids from the graduated cylinder into the second beaker using two $4 \mathrm{~mL}$ aliquots of deionized water.

12. Allow the solids to dry at ambient temperature.

13. Measure the mass of the beaker and dried solids.

The water associated with the settled solids is then calculated by difference using the mass and volume measurements obtained from the procedure above. 


\section{This page was intentionally left blank.}




\section{Appendix B Sample Calculations for Gd Ratios and Extent of Precipitation}

The $\mathrm{Pu}$ analyses for the synthetic $\mathrm{U} / \mathrm{Pu} / \mathrm{Gd}$ solution and the solids and supernate generated from the neutralizations are given in Table B.1. A specific activity of $1.598 \times 10^{8} \mathrm{dpm} / \mathrm{mg}$ was used to calculate the ${ }^{239+240} \mathrm{Pu}$ concentration. This specific activity is based on $94 \%{ }^{239} \mathrm{Pu}$ and $6 \%$ ${ }^{240} \mathrm{Pu}$.

Table B.1: Pu Analyses

\begin{tabular}{lcc}
\hline \hline \multicolumn{1}{c}{ Sample } & $\begin{array}{c}{ }^{239+240} \mathrm{Pu} \\
(\mathrm{dpm} / \mathrm{mL})\end{array}$ & $\begin{array}{c}{ }^{239+240} \mathrm{Pu} \\
(\mathrm{mg} / \mathrm{mL})\end{array}$ \\
\hline Synthetic U/Pu/Gd Solution & $1.14 \times 10^{8}$ & $7.13 \times 10^{-1}$ \\
Supernate, $\mathrm{pH} 4.5$ & $6.67 \times 10^{6}$ & $4.17 \times 10^{-2}$ \\
Solids, $\mathrm{pH} 4.5$ & $9.53 \times 10^{7}$ & $5.96 \times 10^{-1}$ \\
Supernate, $1.2 \mathrm{M} \mathrm{OH}^{-}$ & $2.89 \times 10^{5}$ & $1.81 \times 10^{-3}$ \\
Solids, $1.2 \mathrm{M} \mathrm{OH}^{-}$ & $9.71 \times 10^{7}$ & $6.08 \times 10^{-1}$ \\
\hline
\end{tabular}

The ICP-ES analyses for the synthetic $\mathrm{U} / \mathrm{Pu} / \mathrm{Gd}$ and $\mathrm{U} / \mathrm{Gd}$ solutions and the solids and supernate generated from the neutralizations are given in Table B.2. All sample dilutions have been taken into account.

Table B.2: ICP-ES Analyses for Al, Gd, and U

\begin{tabular}{|c|c|c|c|}
\hline Sample & $\begin{array}{c}\mathrm{Al}^{1} \\
(\mathrm{mg} / \mathrm{L}) \\
\end{array}$ & $\begin{array}{c}\mathrm{Gd} \\
(\mathrm{mg} / \mathrm{L})\end{array}$ & $\underset{\substack{\mathrm{U} / \mathrm{L}) \\
(\mathrm{U})}}{ }$ \\
\hline \multicolumn{4}{|l|}{$\mathrm{U} / \mathrm{Pu} / \mathrm{Gd}$} \\
\hline Synthetic Solution & $228(68.4)$ & 1730 & 3060 \\
\hline Supernate, $\mathrm{pH} 4.5$ & $124(8.68)$ & 1250 & 159 \\
\hline Solids, $\mathrm{pH} 4.5$ & $74.5(66.5)$ & 86.4 & 2810 \\
\hline Supernate, $1.2 \mathrm{M} \mathrm{OH}^{-}$ & $117(117)$ & 1.23 & 22.8 \\
\hline Solids, $1.2 \mathrm{M} \mathrm{OH}^{-}$ & $157(-3.5)$ & 1740 & 2960 \\
\hline \multicolumn{4}{|l|}{$\mathrm{U} / \mathrm{Gd}$} \\
\hline Synthetic Solution & $52.8(1.2)$ & 5710 & 5160 \\
\hline Supernate, $\mathrm{pH} 4.5$ & $402(12.7)$ & 4220 & 416 \\
\hline Solids, pH 4.5 & $16.3(-1.51)$ & 193 & 5110 \\
\hline Supernate, $1.2 \mathrm{M} \mathrm{OH}^{-}$ & $97.2(96.6)$ & 5.99 & 25.9 \\
\hline Solids, $1.2 \mathrm{M} \mathrm{OH}^{-}$ & $494(-13.4)$ & 5500 & 5230 \\
\hline
\end{tabular}

(1) Data corrected for Gd interference using 50:4.613 Gd:Al interference counts.

\section{$\underline{\text { Representative Calculations for the Results in Table } 3}$}

To determine the U:Gd ratio, the ICP-ES results for $\mathrm{U}$ were divided by those for Gd. For example, the ratio in the solids generated by the partial neutralization ( $\mathrm{pH} 4.5)$ of the $\mathrm{U} / \mathrm{Pu} / \mathrm{Gd}$ solution is calculated below. 
$2810 \mathrm{mg} / \mathrm{L} \mathrm{U}$ in solids from ICP-ES

$86.4 \mathrm{mg} / \mathrm{L} \mathrm{Gd}$ in solids from ICP-ES

$U: G d$ Ratio $=\frac{2810 \frac{\mathrm{mg}}{\mathrm{L}}}{86.4 \frac{\mathrm{mg}}{\mathrm{L}}}=32.5$

The $\mathrm{Pu}$ :Gd ratio was determined by dividing the measured $\mathrm{Pu}$ concentration by the ICP-ES results for Gd. For example, the ratio in the solids generated by the partial neutralization ( $\mathrm{pH} 4.5$ ) of the $\mathrm{U} / \mathrm{Pu} / \mathrm{Gd}$ solution is calculated below.

$0.0417 \mathrm{mg} / \mathrm{mL} \mathrm{Pu}$ in the supernate from TTA extraction/APHA $1250 \mathrm{mg} / \mathrm{L} \mathrm{Gd}$ in the supernate from ICP-ES

$P u: G d$ Ratio $=\frac{0.0417 \frac{\mathrm{mg}}{\mathrm{mL}} \times \frac{1000 \mathrm{~mL}}{\mathrm{~L}}}{1250 \frac{\mathrm{mg}}{\mathrm{L}}}=3.34 \times 10^{-2}$

The Fissile:Gd ratio was determined by assuming $33 \%$ of the U by ICP-ES was ${ }^{235} \mathrm{U}$. The mass of the fissile $\mathrm{U}$ was added to the $\mathrm{Pu}$ amount from TTA extraction/APHA and divided by the amount of Gd. For example, the ratio in the solids generated by the partial neutralization ( $\mathrm{pH} 4.5$ ) of the $\mathrm{U} / \mathrm{Pu} / \mathrm{Gd}$ solution is calculated below.

$0.596 \mathrm{mg} / \mathrm{mL} \mathrm{Pu}$ in solids from TTA extraction/APHA $2810 \mathrm{mg} / \mathrm{L} \mathrm{U}$ in solids from ICP-ES

$86.4 \mathrm{mg} / \mathrm{L} \mathrm{Gd}$ in solids from ICP-ES

$$
\begin{aligned}
& \frac{2810 \mathrm{mg} U_{\text {Total }}}{L} \times \frac{0.33 \mathrm{mg}{ }^{235} \mathrm{U}}{m g U_{\text {Total }}}=\frac{927 \mathrm{mg}{ }^{235} \mathrm{U}}{L} \\
& \text { Fissile : Gd Ratio }=\frac{\frac{0.596 \mathrm{mg} \mathrm{Pu}}{\mathrm{mL}} \times \frac{1000 \mathrm{~mL}}{L}+\frac{927 \mathrm{mg}{ }^{235} \mathrm{U}}{L}}{\frac{86.4 \mathrm{mg} \mathrm{Gd}}{L}}=17.6
\end{aligned}
$$

$\underline{\text { Representative Calculation for the Results in Table } 4}$

The extent of precipitation of $\mathrm{Gd}, \mathrm{U}, \mathrm{Pu}$, and $\mathrm{Al}$ in the solids from each neutralization are shown in Table 4. The method used to calculate these values is illustrated for the precipitation of Gd in the solids generated by the partial neutralization $(\mathrm{pH} 4.5)$ of the $\mathrm{U} / \mathrm{Pu} / \mathrm{Gd}$ solution. 
The concentrations of $\mathrm{Gd}$ in the dissolved solids and supernate (from Table B.2) are given below.

$86.4 \mathrm{mg} / \mathrm{L} \mathrm{Gd}$ in dissolved solids

$1250 \mathrm{mg} / \mathrm{L} \mathrm{Gd}$ in supernate

Since $1.5 \mathrm{~mL}$ of the precipitate slurry was transferred to the centrifuge vial, the amount of Gd in the supernate is calculated in the following manner.

$\frac{1250 \mathrm{mg} \mathrm{Gd}}{L} \times 0.0015 \mathrm{~L}=1.875 \mathrm{mg}$

To determine the mass of $\mathrm{Gd}$ in the precipitate, the concentration of the dissolved solids was multiplied by the volume of $\mathrm{HNO}_{3}$ (i.e. $0.001 \mathrm{~L}$ ) used to dissolve the solids.

$\frac{86.4 \mathrm{mg} \mathrm{Gd}}{L} \times 0.001 \mathrm{~L}=0.0864 \mathrm{mg}$

The extent of precipitation (\%) is then calculated from the ratio of Gd in the solids to the amount of $\mathrm{Gd}$ in the solids and supernate.

$\frac{0.0864 m g G d}{0.0864 m g G d+1.875 m g G d} \times 100 \%=4.4 \%$ 


\section{This page was intentionally left blank.}




\section{Appendix C Sample Calculations for $\mathrm{H}: \mathrm{Pu}, \mathrm{H}: \mathrm{U}$, and $\mathrm{H}: F i s s i l e$ Ratios Using Data from Thermogravimetric Analyses}

\section{$\underline{\mathrm{U} / \mathrm{Pu} / \mathrm{Gd} \text { Solution }}$}

Following the neutralization of the $\mathrm{U} / \mathrm{Pu} / \mathrm{Gd}$ solution to $1.2 \mathrm{M}$ excess $\mathrm{OH}^{-}$with $50 \mathrm{wt} \% \mathrm{NaOH}$, a $1.5 \mathrm{~mL}$ aliquot of the well mixed precipitate slurry was centrifuged at $5000 \mathrm{~g}$ for 5 minutes. The supernate was removed and the solids dissolved in $1 \mathrm{~mL}$ of $8 \mathrm{M} \mathrm{HNO}_{3}$. The resulting solution was analyzed for $\mathrm{U}, \mathrm{Pu}, \mathrm{Gd}$, and Al. Analytical results for the solution are given in Table B.1 and B.2.

Two successive $1.5 \mathrm{~mL}$ aliquots of the well mixed precipitate slurry were also centrifuged and the supernate removed. A $27.59 \mathrm{mg}$ sample of the resulting solids was heated at $10^{\circ} \mathrm{C} / \mathrm{min}$ to $600^{\circ} \mathrm{C}$ using a TGA. The mass of the sample at $250^{\circ} \mathrm{C}$ when all waters of hydration are removed was $45.35 \%$ of the initial mass. Using the data in Tables B. 1 and B.2 and the thermogravimetric analysis, the $\mathrm{H}$ ratios are calculated in the following manner.

The compounds present in the solids were assumed to be $\mathrm{Na}_{2} \mathrm{U}_{2} \mathrm{O}_{7}$, plutonium (IV) hydroxide $\left(\mathrm{Pu}(\mathrm{OH})_{4}\right)$, and gadolinium hydroxide $\left(\mathrm{Gd}(\mathrm{OH})_{3}\right)$. Since $\mathrm{Al}$ is amphoteric, the small amount present in the analyzed solution was assumed to be soluble in the interstitial liquid associated with the solids.

Using a basis of $1 \mathrm{~L}$ of solution, the total mmoles of solids are calculated from the concentration data in Tables B.1 and B.2.

$$
\begin{aligned}
& \frac{2960 \mathrm{mg} \mathrm{U}}{\mathrm{L}} \times 1 \mathrm{~L} \times \frac{1 \mathrm{mmole}}{238 \mathrm{mg}} \times \frac{1{\mathrm{mmole} \mathrm{Na}_{2} \mathrm{U}_{2} \mathrm{O}_{7}}_{2 \mathrm{mmole} \mathrm{U}}}{2 \mathrm{~mm}}=6.219 \text { mmole } \mathrm{Na}_{2} \mathrm{U}_{2} \mathrm{O}_{7} \\
& \frac{6.08 \times 10^{-1} \mathrm{mg} \mathrm{Pu}}{\mathrm{mL}} \times 1 \mathrm{~L} \times \frac{1000 \mathrm{~mL}}{\mathrm{~L}} \times \frac{1 \mathrm{mmole}}{239 \mathrm{mg}} \times \frac{1 \mathrm{mmole} \mathrm{Pu}(\mathrm{OH})_{4}}{\text { mmole } \mathrm{Pu}}=2.544 \text { mmole Pu }(\mathrm{OH})_{4} \\
& \frac{1740 \mathrm{mg} \mathrm{Gd}}{L} \times 1 \mathrm{~L} \times \frac{1 \mathrm{mmole}}{157.25 \mathrm{mg}} \times \frac{1 \mathrm{mmole} G d(\mathrm{OH})_{3}}{\text { mmole } \mathrm{Gd}}=11.07 \mathrm{mmole} \mathrm{Gd}(\mathrm{OH})_{3}
\end{aligned}
$$

The total mmoles of solids are 19.83 .

Mole fractions for each of the compounds in the solids are calculated using the total number of mmoles.

$$
\begin{array}{ll}
\mathrm{Na}_{2} \mathrm{U}_{2} \mathrm{O}_{7} & \frac{6.219 \text { mmoles }}{19.83 \text { mmoles }}=0.3136 \\
\mathrm{Pu}(\mathrm{OH})_{4} & \frac{2.544 \text { mmoles }}{19.83 \text { mmoles }}=0.1283 \\
\mathrm{Gd}(\mathrm{OH})_{3} & \frac{11.07 \text { mmoles }}{19.83 \text { mmoles }}=0.5581
\end{array}
$$


The average molecular weight for the solids is calculated using the mole fractions and the molecular weight of each compound.

$(0.3136)\left(\frac{633.98 \mathrm{mg}}{\text { mmole }}\right)+(0.1283)\left(\frac{307.03 \mathrm{mg}}{\text { mmole }}\right)+(0.5581)\left(\frac{208.27 \mathrm{mg}}{\mathrm{mmole}}\right)=\frac{354.44 \mathrm{mg}}{\text { mmole }}$

The mass of dry solids (at $250^{\circ} \mathrm{C}$ ) is $27.53 \mathrm{mg} \times 0.4535=12.48 \mathrm{mg}$.

The water content of the solids is $27.53 \mathrm{mg}-12.48 \mathrm{mg}=15.05 \mathrm{mg}$.

The total mmoles of $\mathrm{H}$ are calculated from the water content of the solids.

$15.05 \mathrm{mg} \mathrm{H}_{2} \mathrm{O} \times \frac{1 \mathrm{mmole}}{18.02 \mathrm{mg}} \times \frac{2 \text { mmole } \mathrm{H}}{\text { mmole } \mathrm{H}_{2} \mathrm{O}}=1.670$ mmole $\mathrm{H}$

The mmoles of $\mathrm{U}$ and $\mathrm{Pu}$ are calculated using the mass of dry solids and the average molecular weight.

$12.48 \mathrm{mg}$ solids $\times \frac{1 \mathrm{mmole}}{354.44 \mathrm{mg}} \times \frac{0.3136 \mathrm{mmole} \mathrm{Na}_{2} \mathrm{U}_{2} \mathrm{O}_{7}}{\text { mmole solids }} \times \frac{2 \mathrm{mmoleU}}{{\text { mmole } \mathrm{Na}_{2} \mathrm{U}_{2} \mathrm{O}_{7}}_{m}}=2.208 \times 10^{-2} \mathrm{mmole} U$

$12.48 \mathrm{mg}$ solids $\times \frac{1 \mathrm{mmole}}{354.44 \mathrm{mg}} \times \frac{0.1283 \mathrm{mmole} \mathrm{Pu}(\mathrm{OH})_{4}}{\text { mmole solids }} \times \frac{1 \mathrm{mmole} \mathrm{Pu}}{\text { mmole } \mathrm{Pu}(\mathrm{OH})_{4}}=4.518 \times 10^{-3} \mathrm{mmole} \mathrm{Pu}$

The ratios of $\mathrm{H}$ to $\mathrm{U}, \mathrm{Pu}$, and Fissile are calculated below.

$\frac{H}{U}=\frac{1.670 \text { mmole } H}{2.208 \times 10^{-2} \text { mmole } U}=76$

$\frac{H}{P u}=\frac{1.670 \text { mmole } H}{4.518 \times 10^{-3} \text { mmole } \mathrm{Pu}}=370$

$\frac{H}{\text { Fissile }}=\frac{1.670 \text { mmole } H}{2.208 \times 10^{-2} \text { mmole } U \times \frac{0.33 \text { mmole }{ }^{235} \mathrm{U}}{\text { mmole } U}+4.518 \times 10^{-3} \text { mmole Pu}}=141$

\section{$\underline{\mathrm{U} / G d \text { Solution }}$}

The solids generated by the complete neutralization $\left(1.2 \mathrm{M}\right.$ excess $\left.\mathrm{OH}^{-}\right)$of the synthetic $\mathrm{U} / \mathrm{Gd}$ solution were analyzed in the same manner as the solids produced from the neutralization of the $\mathrm{U} / \mathrm{Pu} / \mathrm{Gd}$ solution. The analysis for the dissolved solids are given in Table B.2. 
The solids from two successive $1.5 \mathrm{~mL}$ aliquots of the well mixed precipitate slurry were also centrifuged and heated at $10^{\circ} \mathrm{C} / \mathrm{min}$ to $600^{\circ} \mathrm{C}$ using a TGA. The initial sample mass was $17.91 \mathrm{mg}$. The mass of the sample at $250^{\circ} \mathrm{C}$ when all waters of hydration are removed was $41.69 \%$ of the initial mass. The data in Table B.2 and the results from the thermogravimetric analysis are used to calculate the $\mathrm{H}: \mathrm{U}$ ratio following the same method demonstrated above.

Using a basis of $1 \mathrm{~L}$ of solution, the total mmoles of solids are calculated from the data in Table B.2.

$$
\begin{aligned}
& \frac{5230 \mathrm{mg} \mathrm{U}}{\mathrm{L}} \times 1 \mathrm{~L} \times \frac{1 \mathrm{mmole}}{238 \mathrm{mg}} \times \frac{1 \mathrm{mmole} \mathrm{Na}_{2} \mathrm{U}_{2} \mathrm{O}_{7}}{2 \mathrm{mmole} \mathrm{U}}=10.99 \text { mmole }^{\mathrm{Na}} \mathrm{U}_{2} \mathrm{O}_{7} \\
& \frac{8250 \mathrm{mg} \mathrm{Gd}}{L} \times 1 \mathrm{~L} \times \frac{1 \mathrm{mmole}}{157.25 \mathrm{mg}} \times \frac{1 \text { mmole } \mathrm{Gd}(\mathrm{OH})_{3}}{\text { mmole } \mathrm{Gd}}=52.46 \mathrm{mmole} \mathrm{Gd}(\mathrm{OH})_{3}
\end{aligned}
$$

The total mmoles of solids are 63.45 .

Mole fractions for each of the compounds in the solids are calculated using the total number of mmoles.

$\begin{array}{ll}\mathrm{Na}_{2} \mathrm{U}_{2} \mathrm{O}_{7} & \frac{10.99 \text { mmoles }}{63.45 \text { mmoles }}=0.1732 \\ \mathrm{Gd}(\mathrm{OH})_{3} & \frac{52.46 \text { mmoles }}{63.45 \text { mmoles }}=0.8268\end{array}$

The average molecular weight for the solids is calculated using the mole fractions and the molecular weight of each compound.

$(0.1732)\left(\frac{633.98 \mathrm{mg}}{\text { mmole }}\right)+(0.8268)\left(\frac{208.27 \mathrm{mg}}{\text { mmole }}\right)=\frac{282.00 \mathrm{mg}}{\text { mmole }}$

The mass of dry solids $\left(\right.$ at $250^{\circ} \mathrm{C}$ ) is $17.86 \mathrm{mg} \times 0.4169=7.45 \mathrm{mg}$.

The water content of the solids is $17.86 \mathrm{mg}-7.45 \mathrm{mg}=10.41 \mathrm{mg}$.

The total mmoles of $\mathrm{H}$ are calculated from the water content of the solids.

$10.41 \mathrm{mg} \mathrm{H}_{2} \mathrm{O} \times \frac{1 \mathrm{mmole}}{18.02 \mathrm{mg}} \times \frac{2 \mathrm{mmole} \mathrm{H}}{\text { mmole } \mathrm{H}_{2} \mathrm{O}}=1.155$ mmole $\mathrm{H}$

The mmoles of $U$ are calculated using the mass of dry solids and the average molecular weight.

$7.45 \mathrm{mg}$ solids $\times \frac{1 \mathrm{mmole}}{282.00 \mathrm{mg}} \times \frac{0.1732 \mathrm{mmole} \mathrm{Na}_{2} \mathrm{U}_{2} \mathrm{O}_{7}}{\text { mmole solids }} \times \frac{2 \mathrm{mmoleU}}{{\text { mmole } \mathrm{Na}_{2} \mathrm{U}_{2} \mathrm{O}_{7}}_{m}}=9.151 \times 10^{-3} \mathrm{mmole} U$ 
The ratio of $\mathrm{H}$ to $\mathrm{U}$ and Fissile is calculated below.

$\frac{H}{U}=\frac{1.155 \mathrm{mmoleH}}{9.151 \times 10^{-3} \mathrm{mmole} U}=126$

$\frac{H}{\text { Fissile }}=\frac{1.155 \mathrm{mmoleH}}{9.151 \times 10^{-3} \text { mmole } U \times \frac{0.33 \text { mmole }^{235} U}{\text { mmole } U}}=382$ 
WSRC-TR-2004-00053

Revision 0

\section{Appendix D Sample Calculations for H:Pu, H:U, and H:Fissile Ratios Using Data from Graduated Cylinder Experiments}

The mass and volume measurements recorded during the graduated cylinder tests are recorded in Tables D.1 and D.2. These data are used to calculate the H:U, H:Pu, and H:Fissile ratios for solids produced during the neutralization experiments after settling for nominally 1 day (24 hours).

Table D.1 Graduated Cylinder Mass and Volume Measurements

\begin{tabular}{|c|c|c|c|c|c|}
\hline $\begin{array}{c}\text { Neutralized } \\
\text { Solution }\end{array}$ & $\begin{array}{c}\text { Empty } \\
\text { Graduated } \\
\text { Cylinder } \\
\text { Mass } \\
\text { (g) }\end{array}$ & $\begin{array}{c}\text { Graduated } \\
\text { Cylinder }+ \\
\text { Precipitate } \\
\text { Slurry } \\
\text { Mass } \\
\text { (g) }\end{array}$ & $\begin{array}{c}\text { Volume } \\
\text { Precipitate } \\
\text { Slurry } \\
\\
(\mathrm{mL})\end{array}$ & $\begin{array}{c}\text { Volume } \\
\text { Settled } \\
\text { Solids } \\
\text { After } \\
1 \text { Day } \\
\text { (mL) }\end{array}$ & $\begin{array}{c}\text { Vol. Solids } \\
+ \text { Solution } \\
\text { Following } \\
\text { Supernate } \\
\text { Removal } \\
\text { (mL) }\end{array}$ \\
\hline $\begin{array}{c}\mathrm{U} / \mathrm{Pu} / \mathrm{Gd} \\
\mathrm{pH} 4.5\end{array}$ & 56.9750 & 88.5710 & 24.8 & 5.8 & 9.0 \\
\hline $\begin{array}{l}\mathrm{U} / \mathrm{Pu} / \mathrm{Gd}^{1.2 \mathrm{M} \mathrm{OH}^{-}}\end{array}$ & 56.8789 & 89.5713 & 25.0 & 4.6 & 7.4 \\
\hline $\begin{array}{c}\mathrm{U} / \mathrm{Gd}^{-} \\
1.2 \mathrm{M} \mathrm{OH}^{-}\end{array}$ & 56.7837 & 89.2302 & 25.0 & 7.8 & 10.0 \\
\hline
\end{tabular}

Table D.2 Beaker and Graduated Cylinder Mass Measurements

\begin{tabular}{|c|c|c|c|c|c|c|c|}
\hline $\begin{array}{c}\text { Neutralized } \\
\text { Solution }\end{array}$ & $\begin{array}{c}\text { Empty } \\
\text { Beaker } \\
\text { Mass } \\
\text { (supernate) } \\
\text { (g) }\end{array}$ & $\begin{array}{l}\text { Empty } \\
\text { Beaker } \\
\text { Mass } \\
\text { (solids) } \\
\text { (g) }\end{array}$ & $\begin{array}{c}\text { Beaker + } \\
\text { Supernate } \\
\text { Mass }\end{array}$ & $\begin{array}{c}\text { Graduated } \\
\text { Cylinder }+ \\
\text { Remaining } \\
\text { Solution } \\
\text { Mass } \\
\text { (g) }\end{array}$ & $\begin{array}{c}\text { Beaker }+ \\
\text { Solids }+ \\
\text { Water } \\
\text { Mass } \\
\text { (g) }\end{array}$ & $\begin{array}{c}\text { Beaker }+ \\
\text { Supernate } \\
\text { (dry) } \\
\text { Mass } \\
\text { (g) }\end{array}$ & $\begin{array}{c}\text { Beaker }+ \\
\text { Solids } \\
\text { (dry) } \\
\text { Mass } \\
\text { (g) }\end{array}$ \\
\hline $\begin{array}{c}\mathrm{U} / \mathrm{Pu} / \mathrm{Gd} \\
\mathrm{pH} 4.5\end{array}$ & 22.4172 & 22.3019 & 42.4738 & 68.4660 & 40.9045 & 30.3680 & 25.8051 \\
\hline $\begin{array}{l}\mathrm{U} / \mathrm{Pu} / \mathrm{Gd} \\
1.2 \mathrm{M} \mathrm{OH}^{-}\end{array}$ & 22.9744 & 22.3661 & 45.8135 & 66.7148 & 41.1212 & 32.1505 & 26.6495 \\
\hline $\begin{array}{c}\mathrm{U} / \mathrm{Gd}^{(1)} \\
1.2 \mathrm{M} \mathrm{OH}^{-}\end{array}$ & 23.3812 & 23.1600 & 42.6089 & 69.9522 & 43.3392 & $34.5797^{\mathrm{w}}$ & 28.6928 \\
\hline
\end{tabular}

(1) The solids are still wet containing $\sim 4 \mathrm{ml} \mathrm{H}_{2} \mathrm{O}$.

Sample calculations for the $\mathrm{H}: \mathrm{U}, \mathrm{H}: \mathrm{Pu}$, and $\mathrm{H}$ :Fissile ratios following one day of settling for solids precipitated during partial neutralization $(\mathrm{pH} 4.5)$ of the $\mathrm{U} / \mathrm{Pu} / \mathrm{Gd}$ solution are summarized below.

Initial Mass of Slurry $=($ Grad. Cylinder + Precip. Slurry Mass $)-($ Grad . Cylinder Mass $)$

Initial Mass of Slurry $=88.5710 \mathrm{~g}-56.9750 \mathrm{~g}=31.5960 \mathrm{~g}$ 
Slurry Density $=\frac{\text { Initial Mass of Slurry }}{\text { Volume Precipitate Slurry }}$

Slurry Density $=\frac{31.5960 \mathrm{~g}}{24.8 \mathrm{~mL}}=1.274 \frac{\mathrm{g}}{\mathrm{mL}}$

$\underline{\text { Preliminary Calculation for Supernate Water }}$

Vol. Super. to Beaker $=($ Vol. Precip. Slurry $)-($ Vol. Solids + Sol. Following Super. Removal $)$

Vol. Super. to Beaker $=24.8 \mathrm{~mL}-9.0 \mathrm{~mL}=15.8 \mathrm{~mL}$

Mass Super. to Beaker $=($ Grad. Cyl. + Precip. Slurry Mass $)-($ Grad. Cyl.+ Remain. Sol. Mass $)$

Mass Super.to Beaker $=88.5710 \mathrm{~g}-68.4660 \mathrm{~g}=20.1050 \mathrm{~g}$

Density of Supernate $=\frac{\text { Mass Super.to Beaker }}{\text { Vol.Super.to Beaker }}$

Density of Supernate $=\frac{20.1050 \mathrm{~g}}{15.8 \mathrm{~mL}}=1.2725 \frac{\mathrm{g}}{\mathrm{mL}}$

Mass $\mathrm{H}_{2} \mathrm{O}$ in Super.to Beaker $=($ Beaker + Super. Mass $)-($ Beaker + Super. Dry Mass $)$

Mass $\mathrm{H}_{2} \mathrm{O}$ in Super. to Beaker $=42.4738 \mathrm{~g}-30.3680 \mathrm{~g}=12.1058 \mathrm{~g}$

$\frac{\text { Mass } \mathrm{H}_{2} \mathrm{O}}{\text { Volume Supernate }}=\frac{\text { Mass } \mathrm{H}_{2} \mathrm{O} \text { in Super.to Beaker }}{\text { Vol. Super.to Beaker }}$

$\frac{\text { Mass } \mathrm{H}_{2} \mathrm{O}}{\text { Volume Supernate }}=\frac{12.1058 \mathrm{~g}}{15.8 \mathrm{~mL}}=0.7662 \frac{\mathrm{g}}{\mathrm{mL}}$

Preliminary Calculations for Solids Water

Mass of Precip. Slurry Left in Grad. Cyl. $=($ Grad. Cyl. + Remain. Sol. Mass $)-($ Grad. Cyl. Mass $)$

Mass of Precip. Slurry Left in Grad. Cyl. $=68.4660 \mathrm{~g}-56.9750 \mathrm{~g}=11.4910 \mathrm{~g}$

Mass Precip. Slurry $+\mathrm{H}_{2} \mathrm{O}$ in Beaker $=\left(\right.$ Beaker + Solids $+\mathrm{H}_{2} \mathrm{O}$ Mass $)-\left(\right.$ Empty Beaker Mass $\left.{ }_{\text {solids }}\right)$

Mass Precip. Slurry $+\mathrm{H}_{2} \mathrm{O}$ in Beaker $=40.9045 \mathrm{~g}-22.3019 \mathrm{~g}=18.6026 \mathrm{~g}$

Note: Approximately $8 \mathrm{~mL}$ of water were added to the graduated cylinder to rise all of the solids into the beaker. As a check on the measurement procedure, the mass of water is calculated by difference.

Mass Rinse $\mathrm{H}_{2} \mathrm{O}=$ (Mass Precip. Surry $+\mathrm{H}_{2} \mathrm{O}$ in Beaker)

-(Mass Precip. Surry Left in Grad. Cyl.)

Mass Rinse $\mathrm{H}_{2} \mathrm{O}=18.6026 \mathrm{~g}-11.4910 \mathrm{~g}=7.1116 \mathrm{~g}$ 
Assuming a density of $1 \mathrm{~g} / \mathrm{mL}$, the calculated mass indicates that $7-8 \mathrm{~mL}$ of water were used to rinse the solids from the graduated cylinder.

$\underline{\text { Water in Supernate Above Solids }}$

Mass of Super. Left in Grad. Cyc. $=[($ Vol. Solids + Sol. Following Super. Removal $)$

-(Vol. Settled Solids After 1 Day $)] \times[$ Density of Super.]

Mass of Super. Left in Grad.Cyc. $=[9.0 \mathrm{~mL}-5.8 \mathrm{~mL}] \times\left[\frac{1.2725 \mathrm{~g}}{\mathrm{~mL}}\right]=4.0720 \mathrm{~g}$

Mass of Super. $\mathrm{H}_{2} \mathrm{O}$ Left in Grad. Cyl. $=[($ Vol. Solids + Sol. Following Super. Removal $)$

$-($ Vol. Settled Solids After 1 Day $)] \times\left[\frac{\text { Mass } \mathrm{H}_{2} \mathrm{O}}{\text { Vol.Super. }}\right]$

Mass of Super. $\mathrm{H}_{2} \mathrm{O}$ Left in Grad. Cyl. $=[9.0 \mathrm{~mL}-5.8 \mathrm{~mL}] \times\left[\frac{0.7662 \mathrm{~g}}{\mathrm{~mL}}\right]=2.4518 \mathrm{~g}$

$\underline{\text { Water in Settled Solids }}$

Mass of Dry Solids in Beaker $=($ Beaker + Solids Dry Mass $)-($ Empty Beaker Mass Solids $)$

Mass of Dry Solids in Beaker $=25.8051 \mathrm{~g}-22.3019 \mathrm{~g}=3.5032 \mathrm{~g}$

Mass $\mathrm{H}_{2} \mathrm{O}$ Evap. from Beaker $=$ (Mass Precip. Slurry $+\mathrm{H}_{2} \mathrm{O}$ in Beaker $)$

-(Mass Dry Solids in Beaker)

Mass $\mathrm{H}_{2} \mathrm{O}$ Evap. from Beaker $=18.6026 \mathrm{~g}-3.5032 \mathrm{~g}=15.0094 \mathrm{~g}$

Mass $\mathrm{H}_{2} \mathrm{O}$ in Solids $=\left(\right.$ Mass $\mathrm{H}_{2} \mathrm{O}$ Evaporated from Beaker $)-\left(\right.$ Mass Rinse $\left.\mathrm{H}_{2} \mathrm{O}\right)$ -(Mass Super. $\mathrm{H}_{2} \mathrm{O}$ Left in Grad. Cyl.)

Mass $\mathrm{H}_{2} \mathrm{O}$ in Solids $=15.0994 \mathrm{~g}-7.1116 \mathrm{~g}-2.4518 \mathrm{~g}=5.5360 \mathrm{~g}$

Moles of $\mathrm{H}$ in Settled Solids

$5.5360 \mathrm{~g} \mathrm{H}_{2} \mathrm{O} \times \frac{1 \text { mole } \mathrm{H}_{2} \mathrm{O}}{18.02 \mathrm{~g} \mathrm{H}_{2} \mathrm{O}} \times \frac{2 \text { mole } \mathrm{H}}{\text { mole } \mathrm{H}_{2} \mathrm{O}}=0.6144$ mole $\mathrm{H}_{2} \mathrm{O}$ 
$\underline{\text { Moles } \mathrm{Pu} \text { and } \mathrm{U} \text { in Solution }}$

If the total $\mathrm{Pu}$ in solution precipitates,

Mass $\mathrm{Pu}=24.8 \mathrm{~mL} \times \frac{1 \mathrm{~L}}{1000 \mathrm{~mL}} \times \frac{0.71 \mathrm{gPu}}{\mathrm{L}} \times \frac{50.00 \mathrm{~mL}}{50.00 \mathrm{~mL}+18.14 \mathrm{~mL}}=0.0129 \mathrm{~g}$

however, only $90.5 \%$ (see Table 4) precipitates.

Mass Pu in Solids $=0.0129 \mathrm{~g} \times 0.905=0.0117 \mathrm{~g}$

$0.0117 \mathrm{~g} P u \times \frac{1 \text { mole } \mathrm{Pu}}{239 \mathrm{gPu}}=4.90 \times 10^{-5}$ mole $\mathrm{Pu}$

If the total $\mathrm{U}$ in solution precipitates,

Mass $U=24.8 \mathrm{~mL} \times \frac{1 \mathrm{~L}}{1000 \mathrm{~mL}} \times \frac{3.06 \mathrm{~g} U}{L} \times \frac{50.00 \mathrm{~mL}}{50.00 \mathrm{~mL}+18.14 \mathrm{~mL}}=0.0557 \mathrm{~g}$

however, only $92.2 \%$ (see Table 4) precipitates.

Mass $U$ in Solids $=0.0557 \mathrm{~g} \times 0.922=0.0514 \mathrm{~g}$

$0.0514 \mathrm{~g} U \times \frac{1 \mathrm{~mole} U}{238 \mathrm{~g} U}=2.16 \times 10^{-4}$ mole $U$

$\underline{\text { Total Fissile Moles }}$

$4.90 \times 10^{-5}$ mole $\mathrm{Pu}+2.16 \times 10^{-4}$ mole $U \times \frac{0.33 \text { mole }{ }^{235} \mathrm{U}}{\text { mole } U}=1.20 \times 10^{-4} \mathrm{~mole}\left(\mathrm{Pu}+{ }^{235} \mathrm{U}\right)$

$\underline{\text { H Ratios }}$

$\frac{H}{\mathrm{Pu}}=\frac{0.6144 \text { mole } \mathrm{H}}{4.90 \times 10^{-5} \text { mole } \mathrm{Pu}}=12539(12500)$

$\frac{H}{U}=\frac{0.6144 \text { mole } H}{2.16 \times 10^{-4} \text { mole } U}=2844(2800)$

$\frac{H}{\text { Fissile }}=\frac{0.6144 \text { mole } H}{1.20 \times 10^{-4} \text { mole }\left({ }^{235} \mathrm{U}+\mathrm{Pu}\right)}=5120(5100)$ 